University of Louisville

ThinkIR: The University of Louisville's Institutional Repository

Electronic Theses and Dissertations

$12-2020$

\title{
Job satisfaction for individuals with disabilities: youth one year out.
}

Katherine Michelle Cooper PhD

University of Louisville

Follow this and additional works at: https://ir.library.louisville.edu/etd

Part of the Secondary Education Commons, and the Special Education and Teaching Commons

\section{Recommended Citation}

Cooper, Katherine Michelle PhD, "Job satisfaction for individuals with disabilities: youth one year out." (2020). Electronic Theses and Dissertations. Paper 3572.

https://doi.org/10.18297/etd/3572

This Doctoral Dissertation is brought to you for free and open access by ThinkIR: The University of Louisville's Institutional Repository. It has been accepted for inclusion in Electronic Theses and Dissertations by an authorized administrator of ThinkIR: The University of Louisville's Institutional Repository. This title appears here courtesy of the author, who has retained all other copyrights. For more information, please contact thinkir@louisville.edu. 


\title{
JOB SATISFACTION FOR INDIVIDUALS WITH DISABILITIES: YOUTH ONE YEAR OUT
}

\author{
By \\ Katherine Michelle Cooper \\ B.A., Indiana University Southeast, 2002 \\ M.Ed., University of Louisville, 2007

\begin{abstract}
Dissertation
Submitted to the Faculty of the

College of Education and Human Development

in Partial Fulfillment of the Requirements for the Degree of
\end{abstract}

Doctor of Philosophy in Curriculum and Instruction

Department of Special Education

University of Louisville

Louisville, Kentucky

December 2020 
Copyright 2020 by Katherine Michelle Cooper

All Rights Reserved 

JOB SATISFACTION FOR INDIVIDUALS WITH DISABILITIES: YOUTH ONE YEAR OUT

\author{
By
}

Katherine Michelle Cooper

B.A., Indiana University Southeast, 2002

M.Ed., University of Louisville, 2007

Dissertation Approved on

September 11, 2020

By the following Dissertation Committee

Debra K. Bauder

Thomas J. Simmons

Jason C Immekus

Jeremy Todd Whitney

Samantha Walte 


\section{DEDICATION}

This dissertation is dedicated to my three favorite men, who have helped me through this process, my father Leon Ritter, my son Evan Cooper, and my husband Chad Cooper.

I also dedicate this to my mother, Sharon Ritter, and all my friends and family who have supported me during this process.

And

Dr. Debra Bauder

She has been my advisor, champion, and friend. She has always encouraged me to finish. "ABD is not a terminal degree." 


\section{ACKNOWLEDGEMENTS}

I would like to thank my advisor, Dr. Debra Bauder, for her guidance and support. I would also like to thank my other committee members, Dr. Jason Immekus, Dr. Thomas Simmons, Dr. Samantha Walte, and Dr. Todd Whitney, for their comments, edits, and support during my dissertation process. I would like to express my thanks to my husband, Chad, for his understanding and patience during this whole process from beginning to end. I would a like to thank my parents, Leon and Sharon Ritter, they have always supported me in everything I've wanted to do. I also want to thank my friends, and my co-workers, who've always been there to listen, and my Uncle Jayme who says this is way bigger than a master's degree. Most importantly, I would like to thank my son Evan, he has been my number one fan, supporting me, encouraging me, and telling me "oh, you're going to finish this." Thank you for letting me be your mom, and a doctoral student. 


\begin{abstract}
JOB SATISFACTION FOR INDIVIDUALS WITH DISABILITIES: YOUTH ONE
\end{abstract} YEAR OUT

\author{
Katherine Michelle Cooper
}

September 11, 2020

Even though there have been decades of research, practice, and legislative efforts in the field of secondary transition, it is believed that students with disabilities are still less likely to enroll in postsecondary education or training, secure competitive employment, and live independently than their nondisabled peers. One of the reasons for this might be the lack of understanding students' perceptions of employment opportunities.

Much of the early vocational legislation focused on the needs of adult workers injured during a war or in civil employment. The last iteration of the Rehabilitation Act in the 1990s described disabilities, even the most significant disabilities, as part of the human experience and focused on the rights of individuals with disabilities (IWD) to be contributing members of society (Flexer et al., 2013; Johnson, 2012). The Education for All Handicapped Children Act of 1975, later renamed the Individuals with Disabilities Education Act (IDEA) in 1990, paved the way for students with disabilities to access a free and appropriate public education. IDEA went further in 2002 to include language and compliance indicators around the need for postsecondary transition planning, and 
reporting outcomes. IDEA required all students with disabilities in $8^{\text {th }}$ grade or over the age of 14 to have Individual Education Programs (IEP) that address transition outcomes, including a multi-year course of study that helps the student in achieving their postsecondary goals.

Based on the literature regarding what constitutes a successful postsecondary transition for IWD there is a paucity of evidence regarding students' beliefs about what constitutes successful transitions. Based on this lack of information, more research is needed to explore the relationship between high school transitions and postsecondary outcomes on individuals with intellectual disabilities. The purpose of this study was to identify the relationship between disability category, manner of exiting high school, and employment type on job satisfaction for students with intellectual disabilities. Specifically, this study focused on students with intellectual disabilities, including individuals with autism, mild mental disability, and functional mental disability. The Youth One Year Out Survey data, from the Commonwealth of Kentucky, was analyzed using a linear multiple regression model to examine the relationships between disability category, manner of exiting high school, and employment status, on job satisfaction for IDW. The findings of this study reveal that there are no differences in job satisfaction based on disability category or type of high school exit, one year after exiting high school. However, IWD that are involved in competitive employment do report higher rates of job satisfaction. 


\section{TABLE OF CONTENTS}

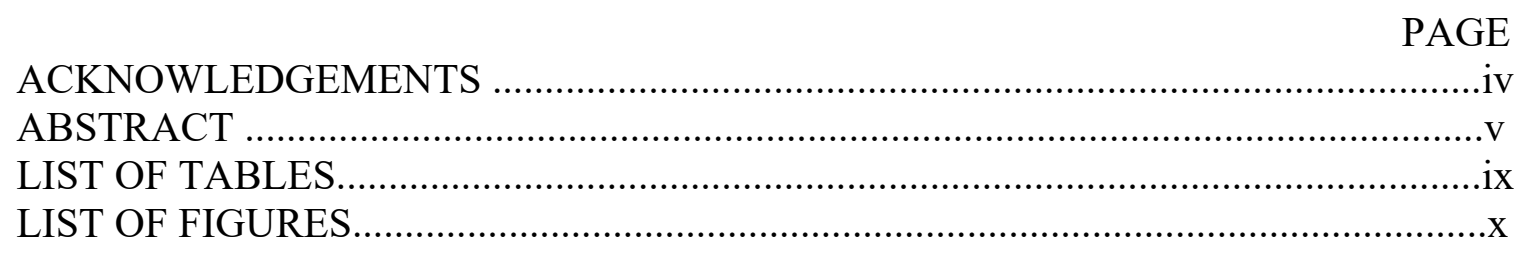

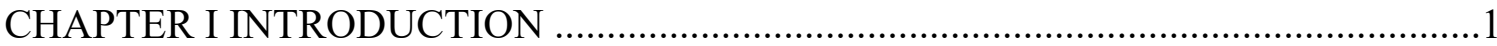

Statement of the Problem ...............................................................................

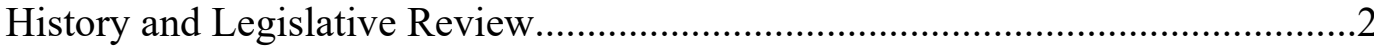

Individuals with Disabilities Transitioning from the School Setting..................... 3

Job Satisfaction and Quality of Life for Individuals with Disabilities...................5

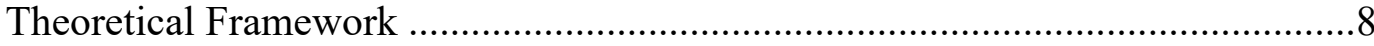

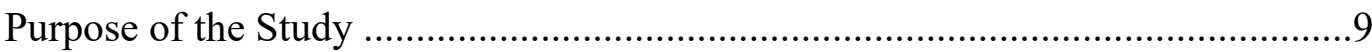

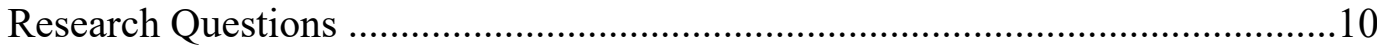

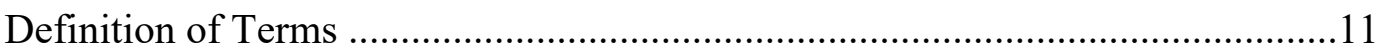

CHAPTER II REVIEW OF THE LITERATURE ...................................................13

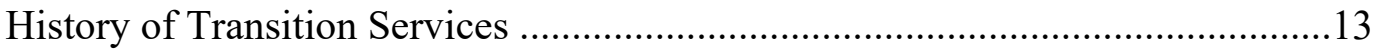

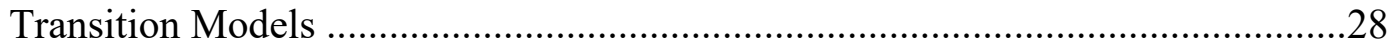

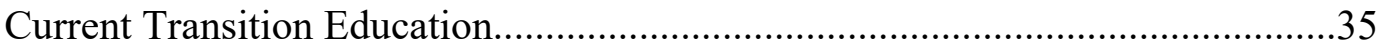

Transitions for Students with Intellectual Disabilities ....................................44

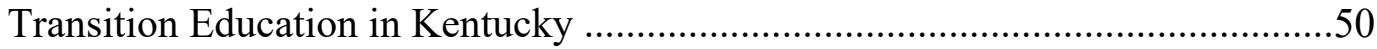

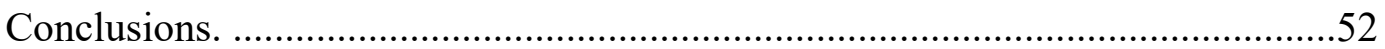

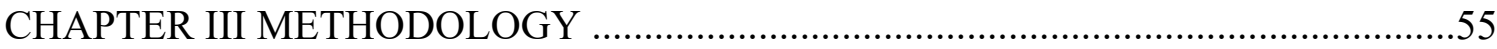


Kentucky Youth One Year Out Survey ...........................................................55

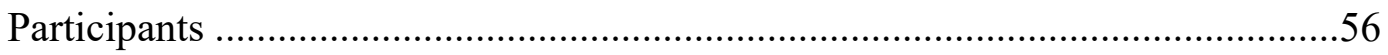

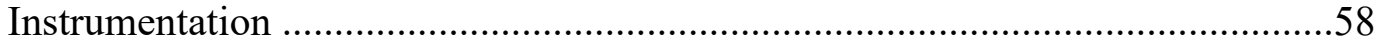

Procedures .........................................................................................6

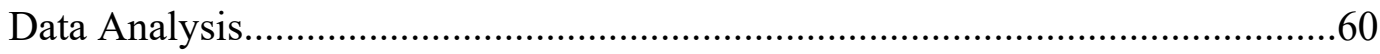

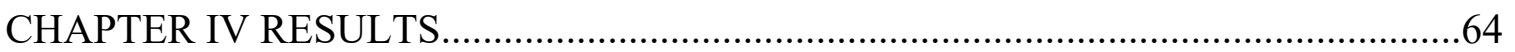

Overview of Research Components..............................................................64

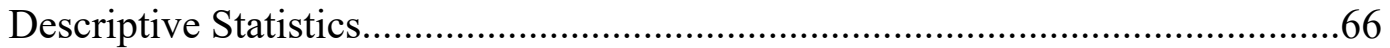

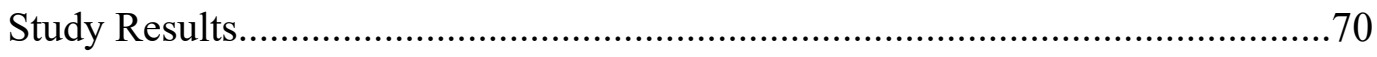

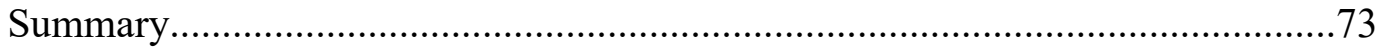

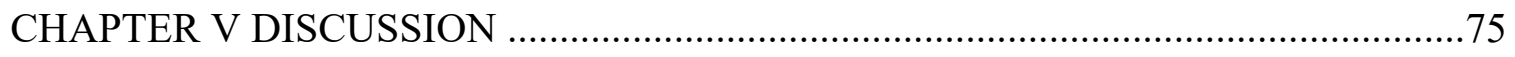

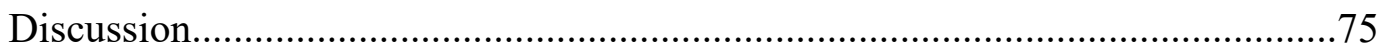

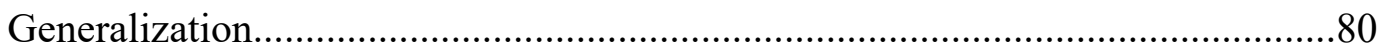

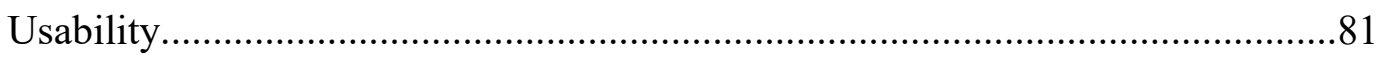

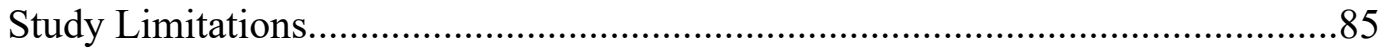

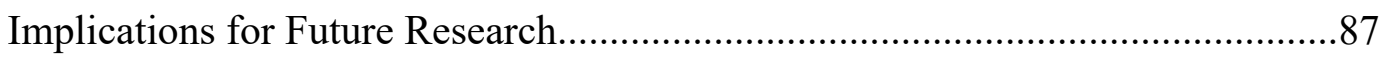

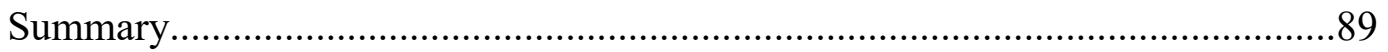

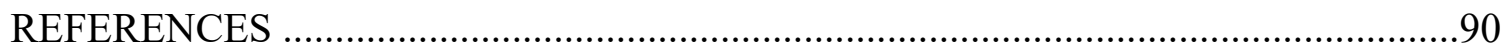

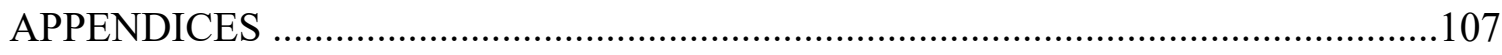

Appendix A: Youth One Year Out Survey Protocol..........................................108

Appendix B: IRB Study Application......................................................... 114

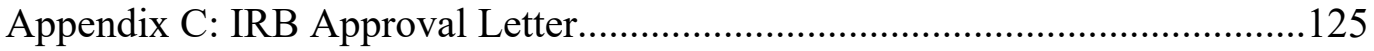

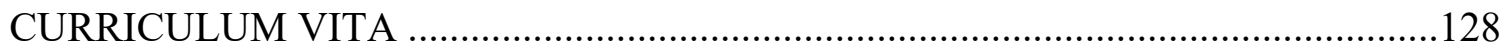




\section{LIST OF TABLES}

TABLE

PAGE

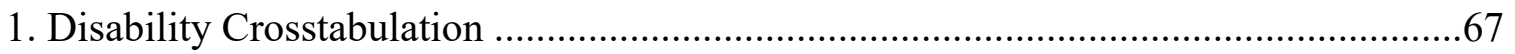

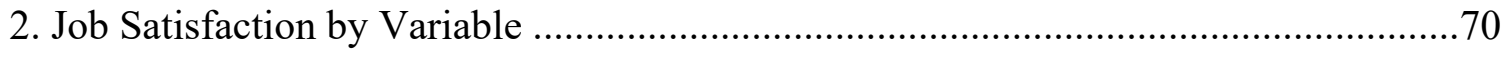

3. Linear Regression Job Satisfaction for IWD ........................................................ 72 


\section{LIST OF FIGURES}

\section{FIGURES}

PAGE

1. OSERS Transition Model …....................................................................................

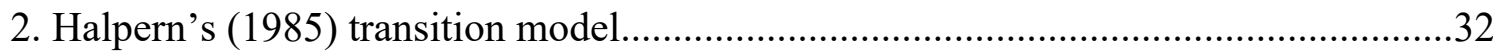

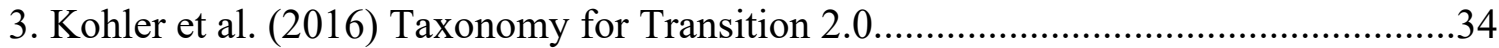




\section{CHAPTER I: INTRODUCTION}

This the purpose of this chapter is to describe the need for research on job satisfaction for individuals with disabilities. Specifically, this review will discuss the need to examine job satisfaction for individuals with intellectual disabilities.

\section{Statement of the Problem}

\section{History and Legislative Review}

Starting after World War I and throughout the 20th and 21st Centuries, the United States has refined legislation and educational practices for Individuals with Disabilities (IWD). Much of the early legislation focused on the needs of adult workers injured during a war or in civil employment. However, subsequent legislation focused on all IWD; specifically, the Vocational Rehabilitation Amendment (VRA; P.L. 83-565) and Vocational Rehabilitation Act (P.L. 88-120). These legislative acts paved the way for many of the services available to American workers today. The last iteration of the Rehabilitation Act in the 1990s described disabilities, even the most significant disabilities, as part of the human experience and focused on the rights of IWD to be contributing members of society (Flexer et al., 2013; Johnson, 2012; Turnbull \& Turnbull, 1990). As lawmakers continued to refine vocational training legislation for adults with disabilities, consideration of how to provide transition services for students with disabilities was also developed. 
The Education for All Handicapped Children Act (1975), later renamed the Individuals with Disabilities Education Act (IDEA; 1990), paved the way for students with disabilities to access a free and appropriate public education (FAPE). The focus of IDEA is to provide educational services to school-age students with disabilities, including the transition starting in the eighth grade or age 14, whichever comes first. IDEA requires that students age 16 and above have a description of transition needs and services on their Individual Education Program (IEP). The transition section of the IEP includes a statement of transition services, activities that help students achieve their postsecondary goals, and a statement of agencies responsible for providing services (Flexer et al., 2013; Johnson, 2012; Johnson \& Sharpe, 2000; Test et al., 2006). Other legislation, such as the Americans with Disabilities Act (ADA), enacted in 1990 and still in law today, guarantees the civil rights of all IWD in public and private sectors (Test et al., 2006). As the legislative acts described above started to shed light on the needs of IWD, a model of transition services was needed. Notably, Will's Bridges Model provided a framework for transitioning between high school and postsecondary settings. Will's model focused on employment and suggested activities designed to promote the transition from high school to a post-school setting (Flexer et al., 2013; Test et al., 2006; Will, 1983). Halper's Community Adjustment model went a step further and included an additional focus on residential and interpersonal domains (Flexer et al., 2013; Halpern, 1985). Finally, Kohler and Field's Transition-Education Model emphasized areas necessary for positive transition outcomes, most notably interagency collaboration (Kohler \& Field, 2003).

\section{IWD Transitioning from the School Setting}


As students with disabilities transition from school to a job setting, the way they can access their accommodations and modifications changes. IDEA includes 20 compliance indicators that require states to report data to the federal government on how they are providing free and appropriate education (FAPE) to students with disabilities (IDEA, 2004). IDEA Indicator 13 requires schools to report how they address the students' postsecondary transition needs in their IEP. The IEP must include postsecondary goals and a statement of services needed for students to achieve their goals. (Flexer et al., 2013; IDEA, 2004). IEPs should include goals that address training, education, employment, and independent living skills. However, many of these goals are not aligned with college and career readiness (Lombardi et al., 2017) and do not address students' work skills when they leave high school. Additionally, many students are passive participants in their IEP development and do not always play a role in developing their goals (Wilson et al., 2009). Finally, teachers may lack the knowledge of the postsecondary placements and the actual outcomes for their students to write realistic goals (Murray \& Doren, 2013).

Whether students are transitioning into a college, a technical training program, or going straight into the workforce, they face some of the same difficulties. One of the primary considerations for IWD when leaving high school is that they lose the protections they had under IDEA and must follow the Americans with Disabilities Act (ADA) guidelines. ADA requires IWD to have access to accommodations and modifications needed to be successful in the college or work environment; but unlike IDEA, IWD must disclose their disability, provide evidence of eligibility, and inform their college or workplace of their needs (Shaw, 2009; Asselin, 2014; White et al., 2017; 
Van Hees et al., 2018). Additionally, IWD must request accommodations as they need them in college and the workplace (Dutta et al., 2009; Shaw, 2009; White et al., 2017).

\section{College and Training Programs}

IDEA provides students with specially designed instruction, including accommodations and modifications to access the learning curriculum. Simultaneously, although IWD are eligible to receive their accommodations in postsecondary education; they are not automatic. The IWD must advocate for their needs in postsecondary settings (Asselin, 2014; Shaw, 2009; Van Hees et al., 2018; White et al., 2017), which requires specific direct instruction in the high school setting. This will include teaching students to disclose their disability and ask for accommodations from each professor. Students are also learning a new environment, managing a schedule, daily living skills, and other interpersonal skills that take self-advocacy. These challenges are not only present for students who attend college, but also for students going directly into the workforce.

\section{Employment}

Many IWD opt to go directly into the workforce after exiting high school. In addition to IDEA, the Workforce Innovation and Opportunity Act (WIOA; Public Law 113-128) seeks to provide equal opportunities for IWD to prepare them for a job [20 USC 1416(a)(3)(B)]. WIOA includes funding for Pre-Employment Transition Services (Pre-ETS), that provide job exploration and training to IWD ages 14-21. Even with these services, IWD earn less money per hour and are two times less likely to be employed than their nondisabled peers. (Murray \& Doren, 2013; Oertle \& O'Leary 2017; United States Department of Labor, 2018). As IWD age, the gaps in employment numbers between them and their nondisabled peers increase (Oertle \& O'Leary, 2017). These 
studies show the importance of proper postsecondary transition planning in high school so that IWD are leaving with the skills to obtain and maintain employment.

IWD need to participate in higher education and the workforce; however, the challenges described above impact the overall numbers of IWD. Data from the National Longitudinal Transition Study-2 (NLTS2) indicate that only around 38\% of all IWD that enter higher education leave with a two or four-year degree (Sanford et al., 2011). Furthermore, data from the Bureau of Labor Statistics (2019) show that 19.1\% of IWD have jobs than $66.3 \%$ of individuals without disabilities. A large percentage of IWD are not engaged in work or higher education after leaving high school. Additionally, these challenges lead to IDW leaving their college or technical training program, or losing their jobs during or after leaving high school (Sanford et al., 2011).

\section{Job Satisfaction and Quality of Life for Individuals with Disabilities}

Although there is research into what constitutes a successful postsecondary transition for individuals with disabilities (IWD), there is little research into what the students themselves regard as successful transitions. Indicator 14 data collected by individual states provide the information required for compliance but often does not include how students feel about their transition outcomes. Furthermore, for individuals with intellectual disabilities, much of the research focuses on competitive versus sheltered employment (Miglior et al., 2007). However, we know there are many benefits to engagement for IWD (Blustein, 2008). For example, survival skills, social connection, and self-determination/well-being (Blustein, 2008). Having employment increases one's self-esteem, self-worth, friendships, and increased physical and mental health (Cimera et al., 2014). Workers with disabilities suffer greater social isolation, stigma, and financial 
burdens than nondisabled workers, making employment even more crucial (Blustein, 2008). Despite the low numbers of IWD engaged in competitive employment, research shows many benefits to having a job. A common theme among research for college and career readiness is the need for self-advocacy and self-determination. While there is much research into job satisfaction and Quality of Live (QOL) for nondisabled workers, there is a need to expand research on this topic for IWD (Morningstar et al., 2015; Shogren \& Shaw, 2016; Verdugo, 2008; Wehmeyer et al., 2003). There is even a more significant need when considering job satisfaction for individuals with intellectual disabilities (Hofmans et al., 2012).

Much of the research in this area examines the differences in job satisfaction between sheltered and competitive employment. However, there are fewer opportunities for IWD to obtain sheltered employment as these facilities continue to close across the United States (Miglior et al., 2007). Much of the research around postsecondary transitions show that individuals with intellectual disabilities have less successful outcomes than other IWD (Sandford et al., 2007). An investigation is needed to explore the correlation between high school transitions and postsecondary outcomes on individuals with intellectual disabilities.

There are many benefits for IWD having a job (Blustein, 2008; Cimera et al., 2014). Having and keeping a job fulfills three basic human needs: survival, social connection, and self-determination/well-being (Bluestein, 2008). IWD that have obtained and retained jobs have an increased sense of self-esteem, self-worth, friendships, and increased physical and mental health (Cimera et al., 2014). Employment for IWD is particularly beneficial, as they tend to suffer greater social isolation, stigma, and financial 
burdens than nondisabled workers (Blustein, 2008). There is a growing recognition of the need to consider the quality of life (QOL) for IWD, and research in QOL for IWD has made an impact on research, practices, and policy decisions (Biggs \& Carter, 2016; Claes et al., 2010; Schalock et al., 2008a). However, many studies focus on postsecondary placements for transition-age youth but do not consider QOL for these individuals (Biggs \& Carter, 2016). While collecting data on where postsecondary transitions occur is an essential part of recording student transitions, successful transition programs should consider their QOL and job satisfaction.

According to studies, job satisfaction contributes to productivity and longevity for nondisabled workers. Factors such as job tenure, age, and pay, play an essential role in job satisfaction for nondisabled workers (Riza et al., 2018). However, research done for IWD in job satisfaction focuses on competitive versus non-competitive/sheltered employment. Sheltered employment is considered a job-training service; therefore, the wages, working conditions, and benefits may vary significantly. Integrated competitive employment occurs in the community with nondisabled peers and follows the general labor market (Miglior et al., 2007). To provide good transition services, providers must ask how do IWD obtain employment after high school, and how do we assess their job satisfaction?

IDEA Indicator 14 requires local school districts to gather and report data on the post-school outcomes for individuals with disabilities (IWD). Three general ways that IWDs transition out of high school include earning a high school diploma, earning an alternative diploma, or aging/dropping out. Within this data set used for this study, a successful postsecondary outcome for IWD is qualified as enrollment in postsecondary 
education and competitive/integrated employment (i.e., earning at least minimum wage; Metzel et al., 2007). According to Kentucky's Post School Outcomes Center (2020), $43.3 \%$ of all IWD within the Commonwealth had competitive employment one year after exiting high school, with either a high school or alternative high school diploma. However, $30.2 \%$ of IWDs are neither enrolled in postsecondary education, including vocational/training programs or had full- or part-time employment.

Furthermore, considering the extent to which employment is characterized as a successful postsecondary outcome is job interest, a determinant of individuals' careerrelated decisions (e.g., Akkerman et al., 2014) and quality of life (Sirgy et al., 2001). Indicator 14 surveys in each state may ask students questions about their job interest, benefits, pay, and ability to advance (KYSPO, 2020). There is a current literature gap on job interest among IWD who have transitioned from high school to a postsecondary placement in a job setting. Consequently, there is a need to investigate the relationships between what is categorized as a successful transition and actual outcomes for students. This research is further discussed in Chapter 2.

\section{Theoretical Framework}

Blustein (2008) created a conceptual framework that outlined the benefits of work/employment as a part of overall psychological health. He suggested that having and maintaining employment has been an essential part of one's overall mental health and well-being throughout history. Likewise, IWD benefit from having and maintaining employment. In fact, according to Blustein (2008), work may be particularly beneficial for IWD because they suffer greater social isolation, stigma, and financial burdens. In order to prepare IWD for transitions into adult life, there is a need for appropriate 
postsecondary transition planning. This planning includes writing strong postsecondary goals, providing IWD the opportunity to be active participants in transition planning, and teaching self-advocacy skills to students in high school. Advocacy allows IWD to not only obtain employment after leaving high school but helps them to determine what they need in order to maintain employment and advocate their needs in order to have a more satisfactory job experience.

\section{Purpose of the Study}

This study aimed to identify the relationship between disability category, manner of exiting high school, and employment type on job satisfaction for individuals with intellectual disabilities. Studying the employment outcomes of IWD would help better prepare service providers to provide effective postsecondary transition services for exiting high school students. This study focused on IWD in Kentucky, which exited high school in 2018, using the Youth One Year Out Data (YOYO). Specifically, this study focuses on students with intellectual disabilities, including individuals with autism, mild mental disability (MMD), and functional mental disability (FMD). Students with Other Health Impairment (OHI) were used as a comparison group. The YOYO data were analyzed using a linear multiple regression model to examine the relationships between disability category, manner of exiting high school, and employment status on job satisfaction for IWD. It was felt that multiple linear regression is an appropriate analysis when the goal of the research is to assess the extent of a relationship between a dichotomous or interval/ratio predictor variable on an interval/ratio criterion variable. The sample studied represents the population of IWD one year after exiting high school in the Commonwealth of Kentucky. The methodology is further discussed in Chapter 3. 


\section{Research Questions}

The following research questions were posed to understand better the relationship between disability and job satisfaction for students transitioning from high school to the workforce. Specifically, by analyzing Kentucky’s Youth One Year Out survey for differences among disability categories, type of high school exit, and employment type. Each of the factors investigated was identified in the literature review as having an impact on an IWD overall job satisfaction.

Research Question 1: Are there different levels of job satisfaction based on disability category (OHI, Autism, MMD, and FMD) among IWDs, controlling for job interest?

Research Question 2: Are there different levels of job satisfaction based on type of high school exit (regular diploma, alternate diploma, age out, or drop out) among IWDs, controlling for job interest?

Research Question 3: Are there different levels of job satisfaction based on employment status (competitive, non-competitive employment) among IWDs, when controlling for job interest?

\section{Significance of the Study}

Based on empirical evidence, students with disabilities are less likely to exit secondary school with a traditional diploma (Stetser \& Stillwell, 2014; USDOE, 2016); have higher dropout rates (Kena et al., 2016; Stetser \& Stillwell, 2014; USDOE, 2016); and more likely to be unemployed (Bureau of Labor Statistics, 2016; Newman et al., 2010) than students without disabilities. This study aimed to research postsecondary transitions for IWD in Kentucky, one year after exiting high school. It is essential because it can provide insight into programming that helps students prepare to transition 
into adult life. According to publically available data from KYPSO (2020), roughly 30\% of all IWD, and 70\% with intellectual disabilities are completely unengaged in postsecondary education or employment after leaving high school. This research can help teachers, administrators, and policymakers create programs that better meet the needs of this student population.

\section{Definition of Terms}

Competitive Employment. Employment in which the individual makes at least minimum wage and is working non-disabled peers (Metzel, et. al., 2007). Individuals with Disabilities (IWD). A person who has a physical or mental impairment that substantially limits one or more major life activities, a person who has a history or record of such an impairment, or a person who is perceived by others as having such an impairment (IDEA, 2004; Kentucky Administrative Regulations, 2008).

IDEA Indicator 1. The percent of youth aged 16 and above with an IEP that includes coordinated, measurable annual IEP goals and transition services that will reasonably enable the student to meet the postsecondary goals (IDEA, 2004).

IDEA Indicator 14. The percent of youth who are no longer in secondary school, had IEPs in effect at the time they left school, and were: (a) Enrolled in higher education within one year of leaving high school; (b) Enrolled in higher education or competitively employed within one year of leaving high school, or (c) Enrolled in higher education, competitively employed, enrolled in other education or training, or in some other type of employment within one year of leaving high school (IDEA, 2004).

Pre-Employment Transition Services. Transition employment services that include; job exploration and counseling, work-based learning experience, counseling on opportunities 
for enrollment in comprehensive transition or postsecondary education programs, workplace readiness training to develop social skills and independent living, an introduction to self-advocacy, (WIOA, 2014).

Postsecondary Transitions. A transition from the high school setting into the adult world. Specifically, into a college or training program or into the workforce (IDEA, 2004; Kentucky Administrative Regulations, 2008; WIOA, 2014).

Sheltered Employment. A training program in which workers with disabilities receive vocational training. Wages earned are generally below minimum wage and based on piece work (Metzel, et. al., 2007).

Students with Disabilities (IWD). A student who has a physical or mental impairment that substantially limits one or more major life activities, specifically those related to the school setting (IDEA, 2004; Kentucky Administrative Regulations, 2008).

Transition. When a student leaves the K-12 setting (either by graduating or exiting high school without a diploma) and enters into the adult world (IDEA, 2004; Kentucky Administrative Regulations, 2008; WIOA, 2014). 


\section{CHAPTER II: REVIEW OF LITERATURE}

The purpose of this section is to provide a review of the pertinent literature related to this study. Four major areas are addressed: (a) historical context, (b) legislation; (c) transitional models; (d) transition for individuals with disabilities; and (e) transition in Kentucky.

\section{History of Transition Services}

The entry into the world of work is a prominent hallmark of postschool success in the United States for all students (Carter et al., 2012). However, students with disabilities (IWD) often leave high school without the skills, experiences, and supports that lead to meaningful employment for various reasons (Carter et al., 2012). Additionally, individuals with severe disabilities have varying degrees of success in accomplishing employment status (Shaw, 2009). Ensuring that all individuals can gain and obtain employment is beneficial to both the IWD and the community (Blustein, 2008). To enter the employment market, transition services mandated through various legislative initiatives have been paramount. For example, early legislative acts led the way for IWD throughout the 20th Century and today.

\section{Legislation}

The first legislative acts to help IWDs were the Smith-Hughes Act (P.L. 64-347) in 1917 and the Smith-Sears Act (P.L. 65-178) in 1918. These acts, passed just after World War I, provided support for employment and rehabilitation for injured veterans returning from the war. Services were extended to civil service citizens with disabilities 
in 1920 by the Smith-Hughes Act (P.L. 66-236). These benefits only met the needs of that small, specific group of people (Destafano \& Snauwaert, 1989; Flexer et al., 2013). However, in 1943, the Braden-LaFollette Act (P.L. 77-113) extended the same benefits to non-government workers. These services (e.g., examinations, surgery, prosthetic) were, in theory, expanded to include individuals with intellectual disabilities (ID) and mental illness to help them become employed. The following section is a review of legislation in the employment, training, and education sectors, as well as other key legislation that impacts IWD. Subsequent sections will explore how models for transition and current transition practices impact outcomes for IWD, specifically in the area of job satisfaction.

Employment and Training Legislation. According to the United States Bureau of Labor Statistics (2019), 19.1\% of IWD are engaged in either full or part-time employment. This means that there are significant gaps between disabled and nondisabled workers (Alsaman \& Lee, 2017; Cimera et al., 2014; Murray \& Doren, 2014; Oertle \& O'Leary, 2017). Furthermore, we know having and maintaining employment provides self-esteem, social connections, and increases one's overall well-being (Bluestein, 2008; Cimera et al., 2014). For these reasons, as well as a need in the workforce, the United States government has sought to create and refine legislation that protects the rights of disabled workers.

In 1954, the Vocational Rehabilitation Amendment (VRA; P.L. 83-565) provided seed money to create work-study, sheltered workshops, and job placement services for IWD across the United States. Eventually, the VRA distributed federal funds using a graduated matching process for employment services to the states starting at $50 \%$; rising to $60 \%$; and finally reaching $75 \%$ in 1965 . Much of these funds were distributed to 
community agencies as a fee for service and/or matching funds. The recipients of these funds were charitable and parent-formed organizations that focused on employment outcomes for IWD. These funds continued to be appropriated through the 1960s (Flexer et al., 2013; Johnson, 2012; Turnbull \& Turnbull, 1990).

Vocational Rehabilitation Act. In the 1960s, John F. Kennedy's President's Panel on Mental Retardation and the Vocational Rehabilitation Act of 1963 (P.L. 88-210) focused on providing support to children with disabilities in state-operated schools, community hospitals, and local school districts. This Act laid the foundation to meet the needs of all IWD. This legislation included setting aside $10 \%$ of vocational education funding for education services for students with disabilities. Additionally, P.L. 88-210 provided for the development of vocational programs for disadvantaged populations (Flexer et al., 2013; Johnson, 2012; Test et al., 2006).

The Mental Retardation and Facilities and Construction Act (MRFCA) of 1963 (P.L. 88-164) was established to prioritize services for individuals with intellectual disabilities. The MRFCA defined significant life activities for IWD and helped create systems for services and supports to meet those needs. One example is the provision of a framework for service delivery. It also established a funding source for state and local agencies to create community-based instruction. (Flexer et al., 2013; Johnson, 2012). This legislation led to the development of work-study programs. As vocational rehabilitation (VR) became a federal/state partnership, more priority was placed on the rehabilitation services for IWD. As a collaboration between public schools and local and state agencies, work-study programs emerged, serving thousands of students (Flexer et al., 2013; Johnson, 2012). 
Throughout the 1970s, special education law, including transition, became more refined. The Developmental Disabilities Services and Facilities Construction Act of 1970 (PL 91-517) was enacted to provide comprehensive services for individuals with intellectual disabilities, cerebral palsy, epilepsy, and other complex neurological conditions (Flexer et al., 2013; Johnson, 2012. Further funding to the states was provided through the Vocational Rehabilitation Act of 1973 (P.L. 114-95). The VRA funding helped IWD to access services to prepare for funding, at age 16. Additionally, Section 504 of the VRA linked with civil rights legislation to prohibit discrimination based on disability, specifically for agencies receiving public funding (Flexer et al., 2013; Johnson, 2012; Test et al., 2006).

Outcome-based planning and interagency collaboration for IWD (Murray \& Doren, 2013) were the main focus of the Rehabilitation Act of 1973. Youth and adults transitioning into an employment setting were provided with comprehensive and coordinated vocational assistance, regardless of the severity of their disability. Moreover, it made it illegal to discriminate against a citizen-based on disability. The Act was amended in 1978 to create independent living programs and again in 1986 to establish supported employment (Flexer et al., 2013). Supported employment is integrated, paid, employment in real-work settings, with support from rehabilitation services (Flexer et al., 2013).

The Job Training and Partnership Act (JTPA) of 1982 provided significant funding for job training and placement programs for youth with disabilities. This was especially important as occupational skills training was provided to any unemployed youth or adult that was not able to contribute to the economy through work. 
The Amendment to the Rehabilitation Act in 1992 specifically addresses the need for respect, inclusion, and support for customers of vocational rehabilitation (VR). The amendment described disability, including significant disabilities, as part of the human experience. Further, having a disability no way diminishes the rights of individuals to live independently, enjoy self-determination, make choices, contribute to society, and pursue meaningful careers. The amendment noted that families and natural support played an essential role in the success of VR programs. Furthermore, it clarified that services for IWD should include personal assistance, transition, and supported employment services (Flexer et al., 2013; Test et al., 2006). Finally, in 1998, the Rehabilitation Act was amended to establish links between state VR programs and the Workforce Innovation Act to require access to electronic and information technology provided by the federal government (Flexer et al., 2013; Johnson, 2012).

Education Legislation. While employment and training legislation provided a roadmap for workers with disabilities in the United States, education legislation has insured that students with disabilities receive educational benefits equal to that of their non-disabled peers (Flexer et al., 2013; Johnson, 2012; Test et al., 2006). Even early iterations of educational legislation included statements about transition services for students with disabilities as they moved into postsecondary placements. The Individuals with Disabilities Education Act (IDEA) establishes guidelines for providing systematic transition services for IWD and requires documentation on how, when, and by whom the services are provided (IDEA, 2004).

Education for All Handicapped Children Acts. In 1975, the Education for All Handicapped Children Act (EHA; P.L. 94-142) ensured all students receive a Free and 
Appropriate Education (FAPE) regardless of disability. FAPE included all children between the ages of 3-21 and encompassed access to vocational education, career planning, industrial arts, consumer, and homemaking programs. EHA also required that Individual Education Programs (IEP) include at least one career education goal (Flexer et al., 2013; Johnson, 2012; Test et al., 2006; Wei, Wagner, Hudson, Yu \& Javits, 2016).

The Vocational Education Amendment (VEA), enacted in 1976, further strengthened the $10 \%$ set aside for IWD. To be consistent with EHA, VEA required programs to be integrated and conducted in the student's least restrictive environment (LRE). VEA also included plans for vocational education as part of the student's IEP (Flexer et al., 2013; Johnson, 2012). The VRA, VEA, and EHA of 1976 formed the core legal mandates that support IWD in the areas of career development and vocational training from the mid-1970s and into the 1980s (Johnson, 2012). In addition to these, the Career Education Implementation Incentive Act of 1977 temporarily increased the emphasis for special educators to develop a functional and life skills curriculum to link to academic and vocational education. While this Act ended in 1983, it was a precursor to the School to Work Opportunities Act of 1994 (Flexer et al., 2013; Johnson, 2012).

Amendments to section 626 of the EHA (1986) further defined transition services for students with disabilities. Specifically, the amendment added a purpose to stimulate the improvement of vocational and life skills for IWD to prepare them for the transition into adult life. The amendment goes on to expand discretionary grant monies for research in the areas of school dropouts for IWD, the development of special education curriculum, and instructional techniques that will help with transitions into adult life. Furthermore, the amendment provided money for physical education and therapeutic 
recreation programs specifically designed to increase the potential of youth with disabilities to access community participation. In a measure for supporting families, the amendment stated that parents and IWD should be involved in the planning, development, and implementation of their services. This law also defined supported employment as paid employment in an integrated real-work situation for at least 20 hours per week. Finally, the amendment required interagency cooperation between rehabilitation services and other adult agencies that provide long-term, ongoing support for individuals with severe disabilities (Flexer et al., 2013; Johnson, 2012)

Individuals with Disabilities Education Act (IDEA). When the EHA was reauthorized in 1990, it was renamed the Individuals with Disabilities Act (IDEA; P.L. 101-476). With the passing of IDEA came several changes intended to help state and local agencies address the transition needs of IWD and their families. IDEA strengthened the definition for transition and required for all students ages 16 and older, services on the Individualized Education Program (IEP) must include transition services. Therefore, the transition section of the IEP must include; (a) a statement of the needed transition services, (b) a coordinated set of activities that will help students achieve their postsecondary goals, and (c) a statement of the agency responsible for providing these services (Flexer, et.al, 2013; Johnson, 2012; Johnson \& Sharpe, 2000; Test et al., 2006).

Four major transition service requirements were added when IDEA was amended in 1992. These requirements included (a) parent notification, (b) student and agency participation in the meeting, (c) transition content in the IEP, and (d) documentation of the agency responsible (IDEA, 2004; Johnson, 2012). This emphasis on postsecondary planning strengthened the implementation of transition services for IWD. 
IDEA continued to intensify the focus on transition planning. Amendments made in 1997 further required that IEPs include a statement of transition services. Students must also have a multi-year course of study that puts the student on a path to achieve postsecondary goals starting in 8 th grade or by age 14 , whichever comes first. It also required that IWD gain more access to the general education curriculum (Flexer et al., 2013; Johnson, 2012; Wilson et al, 2009). President George W. Bush signed the last authorization of IDEA in 2004 which became effective in 2006 (Johnson, 2012). Some of the notable changes to IDEA 2004 included guidance that transition services should be results-oriented and attending higher education should be a consideration for IWD. Additional emphasis was placed on functional programming for IWD and is considered as part of their postsecondary transition planning. According to the new amendment, transition goals must be developed based on student preferences and strengths, and the IEP team must consider instruction, related services, community experiences, employment, postsecondary adult living, daily living skills, and functional vocational evaluations. IDEA provided clarification that FAPE does not explicitly apply to students ages three to five and 18 to 21 . However, IDEA did stipulate that individual state's laws could extend services for students ages 18-21 to provide special education services addressed in a student's IEP. However, it should be noted that once a child has graduated with a high school diploma, they are no longer qualified for services under FAPE.

IDEA 2004 also stipulated that once a student reaches the age of 16, they must be notified and invited to their IEP meeting; parents must be notified and informed that transition services will be discussed in the meeting, and any agency responsible for paying for services on the IEP must also be invited to the meeting. IDEA made clear that 
the transition period is viewed as a shared responsibility among and between schools and community service agencies. Moreover, students should receive a summary of their performance related to their postsecondary goals. Finally, IDEA specified that research and professional development are developed around creating comprehensive transition services for IWD (Flexer et al., 2013; Johnson, 2012; Test et al., 2006).

No Child Left Behind Act. In 2002, the No Child Left Behind Act (NCLB; P. L.107-110) intended to close the gap between typical students and students that are classified as low economic status, English language learners, minority students, and IWD. The four principles of NCLB were to: (a) improve accountability, (b) expand flexibility and local control, (c) expand options for parents, and (d) emphasize proven teaching methods. NCLB also mandated that all students in grades three through eight are tested every year, and schools receive a report card annually based on the results of those tests. Report card data includes data from IWD. NCLB made certain that all students, including those with disabilities, have access to the general education curriculum and receive a free and appropriate public education (Test et al., 2006; Johnson, 2012).

Every Student Succeeds Act. Signed into law in 2015, Every Student Succeeds Act (ESSA; P.L. 114-95) replaced and renamed NCLB. ESSA helped shift educational priority back to the states, which was a contrast from NCLB that put emphasis on federal oversight. This act emphasized that all students, regardless of disability, should be college and career ready. Furthermore, the focus is placed on the need for students to complete college or training programs (Malin, et al., 2017).

Carl D. Perkins. The Carl D. Perkins Vocational Education Act of 1984 (P.L. 98524) emphasized the need for quality vocational education programs that were developed 
through the $10 \%$ funds set aside for IWD. This legislation viewed vocational education as critical to preparing students from high school to a work environment and further emphasized the need to provide services in the least restrictive environment (Flexer et al., 2013; Johnson, 2012; LRE; Test et al., 2006).

The Carl D. Perkins Career and Technical Education Improvement Act was initially enacted in 1984, reauthorized in 1994 and 1998, and again in 2006. Carl D. Perkins provided funding so that IWD has access and full participation in vocational education. States receiving Perkins funds must use this funding to develop and carry out vocation activities and programs that eliminate gender bias, stereotyping, and discrimination. The most recent revisions to the Carl D. Perkins Act require that Career and Technical Education (CTE) preparation programs be in a separate funding stream. It further required that a student's program of study is linked to academic and technical content across secondary and postsecondary education. The Act also emphasized the importance of developing rigorous academic standards and accountability measures for academic and technical programs (Johnson, 2012: Flexer et al., 2013).

Educate America Act (1994). The Educate America Act (P.L. 103-227) provided resources to states and communities to ensure that all students reach their full potential. The framework identified academic standards that measured student progress and set a goal that they would be in place by 2001 . The framework stated that all students should be ready to start school prepared to learn. High school graduation rates would increase to at least $90 \%$ and that students in grades 4,8 , and 12 would demonstrate competency in English, math, and science. The Act sought to ensure that every adult in America would be literate and that the US would lead the world in math and science. Language in the Act 
also focused on providing schools that were free from drugs and violence. Finally, teachers would have access to programs to improve their professional development to gain the skills necessary to prepare American students for the next century (Test et al., 2006).

School-to-Work Opportunities Act. In 1994, the School-to-Work Opportunities Act (P.L. 103-239), called on states to plan and implement transition systems that would help youth with transitions to post-school environments. This Act enabled all children to acquire the skills necessary to make a transition from school to work or postsecondary education. It required expansion of ways in which youth could be integrated through work-based learning and focused on preparation for all youth that leads to college and career opportunities. It also linked professional and academic learning to strengthen the transition between secondary and postsecondary education (Flexer et al., 2013; Norman \& Bourexis, 1995; Test et al., 2006).

Higher Education Opportunity Act. Designed to strengthen colleges and universities in assisting IWD, the Higher Education Opportunity Act was passed in 2004 and reauthorized in 2019. This policy included funding and a model program for increasing access to instructional materials. The policy also made provisions for providing higher education programs for students with intellectual disabilities, which included federal technical assistance to support the state and local programs. Further, students with intellectual disabilities and veterans with disabilities can now access federal financial aid to pay for college. Finally, the policy allowed funding to create programs to train teachers and other personnel working with IWD (Johnson, 2012). 
Workforce Innovation and Opportunity Act. First passed in 1998 and amended in 2014, the Workforce Innovation and Opportunity Act (WIOA; P.L. 113-128) emphasized improving the services and outcomes for transition-aged youth between the ages of 14 to 24 years. IDEA Indicator 14 requires all state and local school districts to gather and report data on the postsecondary transitions for IWDs. School districts must record the number of students that had IEP upon the high school department (e.g., dropout, degree attainment). Moreover, the legislation mandates it is the responsibility of school districts to report the number of IWDs enrolled in postsecondary education, competitively employed, or involved in a type of training program one year after high school (20 USC $1416(\mathrm{a})(3)(\mathrm{B}))$

The WIOA, the Department of Labor, and the Department of Education Office of Special Education and Rehabilitation Services (OSERS), 2015; Office of Special Education and Rehabilitation Services (OSEP), 2015; Public Law 1130118; U.S. Government Accountability Office, 2015) require that each state allocate $15 \%$ of federal grant funding to Pre-Employment Transition Services (Pre-ETS) for IWD. Passed in July of 2014, WIOA established new initiatives for VR that target IWD ages 14-21. Pre-ETS focuses on improving vocational outcomes for students eligible or potentially eligible for VR services. Title IV of this bill designated $15 \%$ of all VR state's federal funding for PreETS. There are five Pre-ETS, including (a) job exploration, (b) work-based learning, (c) workplace readiness, (d) postsecondary counseling, and (e) self-advocacy. Additionally, there are four requirements for states, including, identifying the target population, required services, authorized activities, and coordination of responsibilities (Carlson et al, 2019; WIOA, 2014). 
Workforce Investment Act. Comprehensive job training systems that consolidated federally funded programs and allowed access for IWD was provided through the Workforce Investment Act (WIA; 1998). WIA specified provisions that supported the participation of IWD (Flexer et al., 2013; Johnson, 2012). In order to be eligible for WIA, students must be ages 14-21, low income, and have barriers that prevent them from accessing employment (WIA, 1998). These barriers include; skill deficiencies, drop out, homelessness, runaway, foster, teen pregnancy/parenthood, be offenders, or require assistance to complete their education (Test et al., 2006). The implementation of WIA worked well in some local areas, but overall, there had been a downward trend in the provision of employment services, particularly in the number of job seekers being referred to training programs (Barnow \& King, 2003). WIA was reauthorized in 2014 as the Workforce Innovation and Opportunity Act (WIOA) (P.L. 113-128).

Other Legislation. Other legislation not related to vocational or education have also given IWD rights within the community. Many of these acts are seen part of the civil rights movement for people with disabilities. These acts ensure that all IWD are able to access their community and have funding to live if they are unable to work.

Americans with Disabilities Act (ADA). The Americans with Disabilities Act (ADA) of 1990 guaranteed civil rights to people with disabilities by prohibiting employment, public services, transportation, public accommodation, and telecommunication discrimination against anyone with physical or mental disabilities. An amendment in 2008 further clarified and broadened the definition of "disability" and expanded the list of "life activities" covered by the law to include caring for oneself, performing tasks, and work. The message of ADA was that IWD are treated with respect, 
inclusion, and support (Flexer et al., 2013; Johnson, 2012; Test et al., 2006). Though

ADA specifies that an employer cannot discriminate against an employee due to a disability, it also says that it should not cause undue hardship to the employer (Test et al., 2006). The Americans with Disabilities Act (ADA) protects individuals with disabilities by requiring employers to make "reasonable accommodations" to allow them to perform jobs that they're qualified for (disABLEDperson, 2020), It is important to note that the Center for Disease Control (CDC) has recently indicated that one in four adults in the United States is living with a disability (disABLEDperson, 2020). This equates to a large portion of the workforce may need some sort of accommodations to allow for gainful employment. However, ADA language says that employers must make reasonable accommodations, but an individual still must be qualified for the job, and able to perform essential functions of that job. Essential functions include what the employer considers essential, the job description, the amount of time allocated for the function, negative effects of not requiring the employee to perform the function, and finally the workers experience, and that of other employees in the same job. Finally, not all employers are required to adhere to ADA. Federal law only requires employers with more than 15 workers to comply with ADA (ADA, 1990)

Technology-Related Assistance to Individuals with Disabilities Act. The Technology-Related Assistance to Individuals with Disabilities Act of 1988 (P.L. 100407) assisted states in developing technology programs to support IWD and their families. Funding through this act provided the development of statewide, consumerresponsive information and training programs designed to meet the assistive technology (AT) needs of individuals with disabilities of all ages. In Kentucky, the Office of 
Vocational Rehabilitation coordinates all activities through this initiative through the Kentucky Assistive Technology Service (KATS) Network. It should also be noted that technology use for IWD, including the consideration of AT as part of the planning process for students with disabilities, was enacted through IDEA in 1997 (Alper \& Raharinirina, 2006). This law has been reauthorized under the Assistive Technology (AT) Act of 2004.

Social Security and Medicaid provisions. The Social Security Act provided Supplemental Security Income (SSI) monthly benefits based on family household income to individuals with long term disabilities (lasting longer than 12 months). Those receiving SSI are typically eligible for Medicaid benefits as well (Flexer et al., 2013; Johnson, 2012). The Ticket to Work and Work Improvement Act of 1999 allowed IWD the ability to join the workforce without fear of losing their Medicare or Medicaid coverage. IWD had two options for this: 1) a buy-in option that allowed people to buy into Medicaid if their disability was not so severe that they could not work yet; or 2) the opportunity to extend Medicare coverage for an additional four and half years for people who recently returned to work (Test et al., 2006; Johnson, 2012).

Developmental Disabilities Assistance and Bill of Rights Act. The Developmental Disabilities Assistance and Bill of Rights Act (DD Act; P.L. 106-402) of 2000 focused on advocacy both for IWD and their families. The DD Act promotes research in service delivery for IWD. Moreover, the DD Act provides funding for ongoing support for IWD. The Administration for Community Living (ACL) oversees programming authorized by the DD Act, including State Councils on Developmental 
Disabilities, State Protection and Advocacy Systems, and University Centers for Excellence in Developmental Disabilities, Research, and services (ACL, 2017).

\section{Legislative Summary}

These notable legislative acts are what created vocational and education services for IWD in the United States. Each legislation reviewed- most notably the VRA, VEA, IDEA, and ADA- paved the way for transition services for IWD exiting high school (Flexer et al., 2013). Many of these legislative acts are still in existence today, in some form, and continue to impact the rights of IWD. Whether in the area of employment and training, education, or equity and access, each contributes to current services provided to IWD today.

\section{Transition Models}

As the United States passed and amended legislation that would provide transition services for students and adults with disabilities, transition models began to emerge with recommendations for how to structure curriculum and programming (Flexer et al., 2013; Test et al., 2006;). The various models considered education, vocational training, transition to employment, and their impact on postsecondary transitions for IWD. While each model has a component that addresses employment, other models prioritized social and emotional training as well as daily living skills (Flexer et al., 2013). This section outlines each of the transition models used to help support transition for IWD.

\section{Bridges Model}

One early model, Will's Bridges Model, is still referenced today. Madeline Will was a parent and advocate for IWD who later became the Assistant Secretary of the Office of Special Education and Rehabilitative Services (OSERS) within the Department 
of Education. In her 1983 article, Will discussed that according to the most recent census, between 50 and $80 \%$ of IWD reported that they did not have a job. She went on to say that IWD that did not have jobs turned to community services that had long waiting lists (Will, 1983). According to the US Department of Labor (1979), at the time, adults with disabilities were entering publicly supported vocational work programs, and as a result, were then subject to low wages, a slow movement towards employment, and were not in job settings with nondisabled peers. Will identified transition as an "important part of normal life" (Will, 1983, p. 2). She went on to discuss how the transition from high school to a community and work setting required a lot of decisions, including career, daily living, and social life. Will described three assumptions about transition programming. The first assumption was that public and private schools provide a range of transition services to IWD are organized. The second assumption was that all IWD were able to access these transition programs upon leaving high school. The final hypothesis was that sustained employment is an essential outcome for any individual leaving the school setting (Will, 1983).

Will developed a model that focused on "bridges" between school and postsecondary environments (Will, 1983; see Figure 1). Will's conceptual framework included three major components of the transition process from high school to employment, (a) transition with special services (e.g., postsecondary education), (b) transition with time-limited services (e.g., vocational rehabilitation), and (c) transition with ongoing services (e.g., supported employment; Flexer et al., 2013). The model focused on employment and addressed coordination secondary/postsecondary activities designed to promote movement to postschool settings. Finally, Will outlined a five-part 
model for transition services. This model sought to improve the transition foundation provided in the secondary school, through research, by developing cooperative programs with vocational education. Next, educators must collaborate with community colleges and vocation/technical schools to offer age-appropriate content for youth with disabilities. Additionally, there was a need for improvement of time-limited services through collaboration with special education, vocational rehabilitation, and vocational education. IWD need ongoing support to shift from day programs to work activities. Finally, there was a need to improve employment opportunities for IWD. While Will Bridge's Model was influential, the primary focus was on employment for IWD (Test et al., 2006; Flexer et al., 2013).

Figure 1

OSERS Transition Model

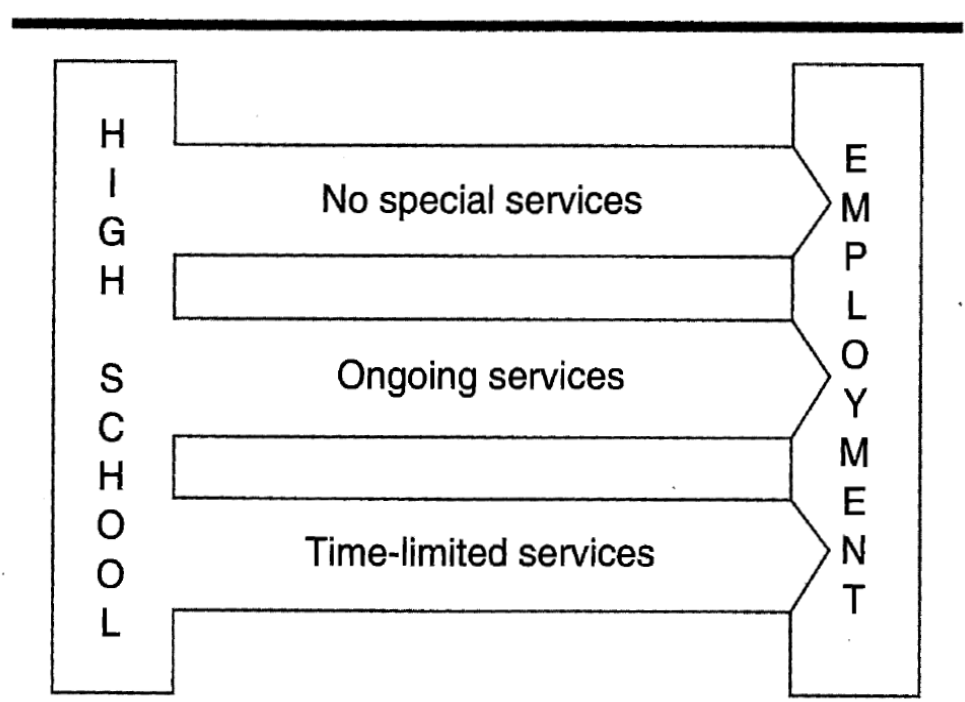

Note. From OSERS programming for the transition of youth with disabilities: Bridges from school to working life, by M. Will 1984, U.S. Office of Education Community Adjustment Model 
Halpern's Community Adjustment Model (1985) challenged Will's primary focus on employment. Halpern's model included residential and interpersonal domains as part of transition planning (See Figure 2). While Halpern agreed with the emphasis on employment in the Will Bridges model, he felt that there were individual independent living and social skills that could not be taught within the context of a job. He gave the example that an IWD that had difficulty with paying bills and maintaining his apartment would need specific strategies for daily living that could not be taught on a job site (Halpern, 1985). The Halpern Model included three pillars for community adjustment: (a) employment, (b) residential environments, and (c) social and interpersonal networks (Halpern, 1985; Flexer et al., 2013). Halpern also studied why transition education was so difficult. Even after many years of funding, IWD still were not achieving high rates of success. Halpern surveyed teachers and parents to see what they perceived as barriers to transition instruction. Teachers identified lack of curriculum, need for more preparation time, need for training, and a need for more staff as barriers contributing to providing high-quality transition instruction (Halpern, 1985). Unfortunately, teachers still voice these concerns today (Oertle \& O'Leary, 2016).

In 1993, in response to federal legislation, Halpern added quality of life as another part of his model. In the 1990s, the Federal legislation around transition services adjusted the definition to include services beyond just employment for IWD. The new language brought in education, vocational training, and community living skills. Halpern argued that, while there was still a focus around employment, lawmakers recognized the needs of IWD beyond employment. He continued to make the case that the quality of life plays a vital role in the services we provide for IWD. He makes the point that the literature, plus 
his research, shows that employment alone is not adequate; job satisfaction needs to be a consideration (Halpern, 1993).

In a study published in 2009, Halpern et al., further explored his model examining how employment, residential environments, social and interpersonal networks, and quality of life or satisfaction cluster together empirically and independently of each other. The researchers found that each of the dimensions were highly correlated with one another. They argued that success in one dimension could be predictive of success in another. Further, that having employment did not necessarily translate into better social outcomes. Finally, the researchers found that it was important that services providers focus interventions aimed specifically at the outcome they wished to impact (Halpern et al., 2009).

Figure 2

Halpern's Transition Model.

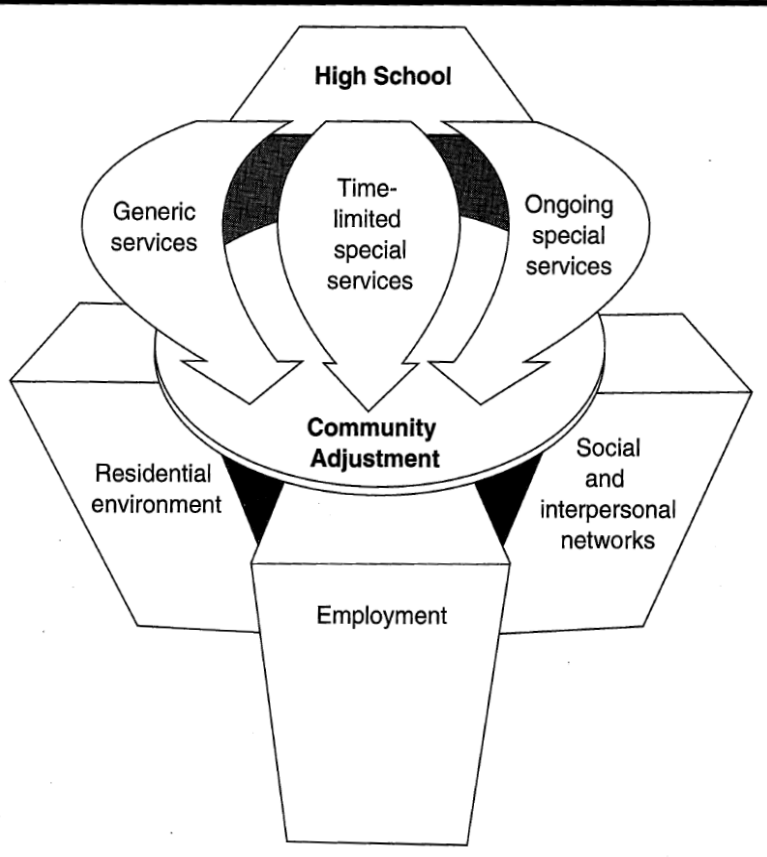


Note. From Transition: A look at the foundations by A. S. Halpern, Exceptional Children, 51(6), 1985, p. 481. Copyright (1985) by the Council for Exceptional Children, Reprinted with permission.

\section{Transition-Education Model}

Kohler and Field's (2003) Transition-Education model also sought to expand on the Will's Bridge Model by including education as part of postsecondary transitions for IWD. The Transition-Education model emphasized five categories necessary for positive transition outcomes: (a) student-focused planning, (b) student development, (c) interagency collaboration, (d) family involvement, and (e) program structure, and attributes (Kohler \& Field, 2003; Flexer et al., 2013). Student-focused planning emphasized the importance of making educational decisions that are centered around the student's interests and strengths. Student development practices help a student develop life employment and occupational skills through school and worked based learning experiences. Student development activities start to teach self-advocacy and selfdetermination skills. Collaborative service delivery outlines an interagency agreement with school personnel, community businesses, and IWD to create a mutually beneficial relationship. Kohler and Field go on to explain that family involvement improves outcomes for all students but have specific benefits for IWD. Finally, program structures refer to the features of a transition-focused education program that lead to effective and efficient services. These programs include community-based instruction, cultural and ethnic sensitivity, articulate missions and values, qualified staff members, and sufficient allocation of resources (Kohler \& Field, 2003). Kohler et al. (2016), updated Kohler and Fields original transition model and renamed it Taxonomy for Transition Programming 
2.0 (see Figure 3). This update applied new literature in the area of transition for IWD to the existing model and includes resources for practitioners and families.

\section{Figure 3}

Taxonomy for Transition Programming 2.0

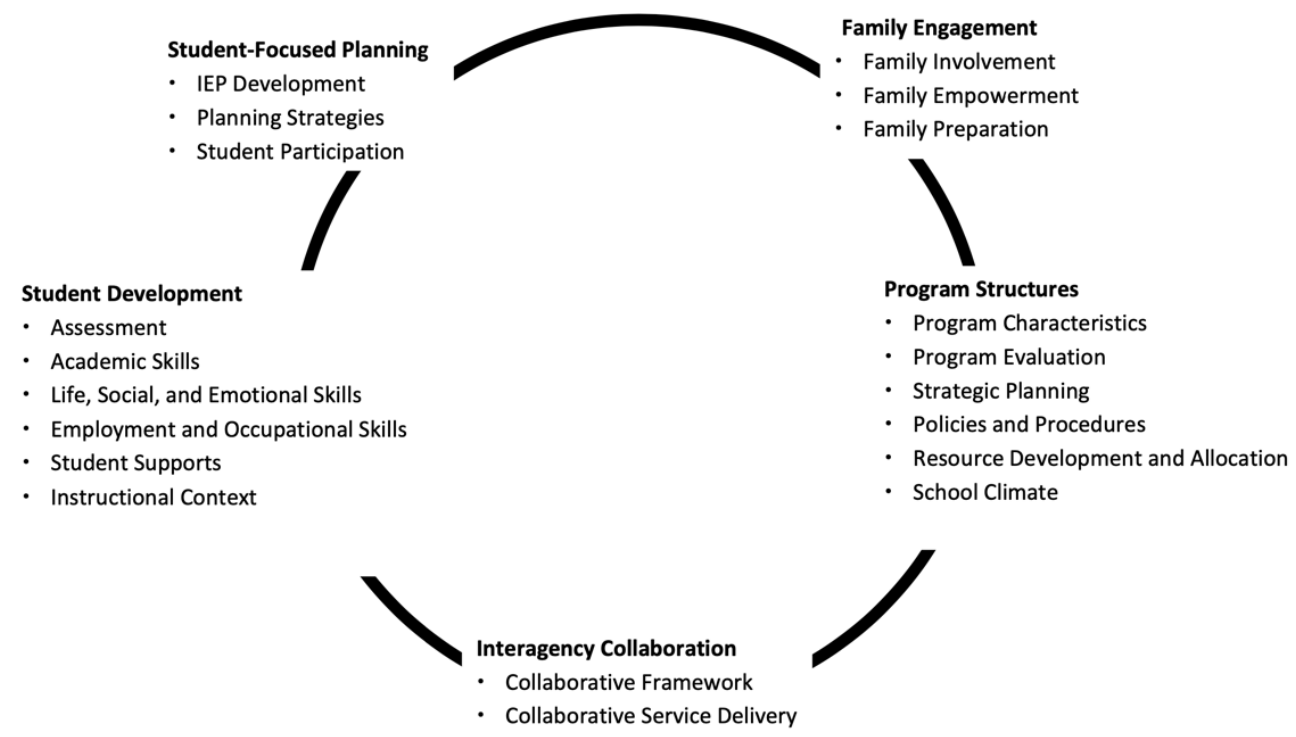

Note. From Kohler, P. D., Gothberg, J. E., Fowler, C., \& Coyle, J. (2016). Taxonomy for transition programming 2.0: A model for planning, organizing, and evaluating transition education, services, and programs (p. 3). Support for the development of this document was provided in part by the National Technical Assistance Center on Transition (NTACT), funded by Cooperative Agreement Number H326E140004 with the U.S. Department of Education, Office of Special Education and Rehabilitative Servers (OSERS). Products and resources are public domain. Authorization to reproduce in whole or in part is granted. 


\section{Current Transition Education}

A focus outlined in some of the transition models is to improve educational experiences related to transition for IWD while they are still in high school. When IWD transition from high school to postsecondary placements there are many considerations. There are questions to be answered such as: how will the student exit, with a high school diploma, an alternative high school diploma (AHSD), drop out or age out (Thurlow et al., 1995) and what do all students need in order to be prepared for life after high school? Many states have adopted College and Career Readiness (CCR) as a way to examine the needs of students, and better prepare them for transitions while they are in high school (Lombardi et al., 2017). In order for a student to meet the guidelines of college and career readiness, they must complete a curriculum based on the core academic standards. Career readiness requires them to also have technical knowledge about employability, vocational training, as well as understanding of their own strengths and weaknesses in these areas (Career Readiness Partner Council, 2013; Cease-Cook et al, 2015). For IWD this includes having a process for transition outlined in their IEP and a plan to engage the student in a variety of opportunities that help them make decisions about their future (Cease-Cook et al., 2015).

\section{Transition Education Curriculum and Frameworks}

There are many frameworks, curriculums, and unit plans designed to meet the transition needs of all students. Furthermore, there is a body of research that analyzes postsecondary outcomes for IWD. Oertle and O'Leary (2017) reviewed research into what leads to better outcomes for IWD in the workplace. Their review found that students who have participated in integrated settings by involvement in the general education 
classes and earned a high school diploma with career development activities were better prepared for the workplace. Furthermore, school to work programs, completion of Career Technical Education (CTE) courses, and engagement in paid work experiences were also associated with successful workplace outcomes (Oertle \& O'Leary, 2017). Likewise, Doren et al. (2013) specified three critical features of postsecondary planning as (a) youth-centered individualized employment services, (b) collaboration among professionals, and (c) connection to caring professions, such as vocational rehabilitation workers, as paramount to job success for IWD. Several studies indicated access to the general education curriculum as a critical component of CCR (Morningstar et al., 2017; McConnell, Martin \& Hennessey, 2015; Oertle \& O'Leary, 2017).

Students that spend time in the general education classroom have the opportunity to learn the core content knowledge, but also the social skills they need to work with a variety of people that they will encounter in the workplace. Equally important are actual work experiences for IWD in the community (Gold et al., 2013; Lindstrom et al., 2011; Oertle \& O'Leary, 2017). Providing these experiences in high school not only set the student up for a successful transition, but also help students focus on skill development needed to be successful in the workplace. These experiences also allow students to learn job skills, participate in career exploration, and make informed choices about the jobs they are seeking (Webb et al., 2014).

Preparing IWD for involvement in the workforce begins with proper postsecondary transition planning and education in high school (Lindstrom et al., 2011; Gold et al., 2013; Murray \& Doren, 2013; Web et al., 2014; McConnell et al., 2015; Oertle \& O'Leary, 2017). IDEA requires that a student's IEP addresses transition by 
setting postsecondary goals. While most plans are technically compliant, goals are not always aligned to college and career readiness (CCR). CCR standards for employment, postsecondary education and training, and independent living do not align with general education policy (Lombardi et al., 2017). Additionally, teachers may not have the opportunity to observe the long-term employment or postsecondary outcomes to better align with goals (Murray \& Doren, 2013).

\section{College and Technical Education}

An increased number of IWD are attending college (Shaw, 2009; White et al., 2017) in the United States, but it is not without challenges. While all students face specific problems when attending college, there are additional considerations taken into account for IWD. There is a loss of protection under IDEA in the delivery of services when students with disabilities transition from high school. Under ADA, college students can receive their accommodations; however, they must disclose their disability and inform the school of their needs. Disclosing one's disability takes a great deal of selfefficacy as students are also responsible for managing their class schedules, course loads, time management, daily living needs, and other interpersonal and social skills (Shaw, 2009; Asselin, 2014; White et al., 2017; Van Hees et al., 2018).

While IDEA mandates that IWD have goals that are related to postsecondary transition and schools provide services needed to meet those goals, many students' IEPs do not address goals for college readiness (Wilson et al., 2016; White et al., 2017; Van Hees et al., 2018). Therefore, IWD are behind peers in both postsecondary enrollment and completion rates (Oertle \& O'Leary, 2017). Much of the course work and training for high school IWD focus on vocational training rather than continuing education (Wilson et 
al., 2009; Van Hees et al., 2018). Additionally, IWD do not have instruction on how to fully engage in their IEP meetings and help with goal setting (Wilson et al., 2009). Because of this, IWD entering college for the first-time face experiences for which they are not prepared. IWD have to learn the unique environment of a college campus, different classroom and educational expectations, and the need to advocate for accommodations previously provided to them during high school.

The lack of emphasis on college goals could be due to considerations made for students with intellectual disabilities (ID). While some students with ID attend college, most attend higher education for adult learning experiences or service-learning (Grigal et al., 2012; Carter et al., 2012). However, these considerations should not limit other IWD and their access to quality transition goals. Schools and teachers need to place high expectations on IWD (Shaw, 2009) and write postsecondary goals that will address the needs they have in college.

While ADA does require that IWD have access to the accommodations and modifications they need to be successful in the college environment; the student must disclose their disability, provide evidence of eligibility, and inform individual professors of their needs. Students must request their accommodations as they need them (Shaw, 2009; White et al., 2017; Dutta et al., 2009). Self-advocacy can be hard for IWD, which means many are not receiving what they need to access and fully participate in the college classroom (White et al., 2007; Dutta et al., 2009; Asselin, 2014; Van Hees et al., 2018). IWD attending college are facing fragmented services due to uncoordinated mechanisms for eligibility determination, information sharing, and communication (Dutta 
et al., 2009). Therefore, there is a strong need for IWD to be taught self-efficacy skills in the years before they transition out of high school.

\section{Vocational/Job Training}

Many IWD opt not to attend college and go directly into the workforce. Be that as it may, there are significant gaps between disabled and nondisabled workers in the workforce (Cimera et al., 2014; Murray \& Doren, 2014; Alsaman \& Lee, 2017; Oertle \& O'Leary, 2017). IWD are two times less likely to be employed (Oertle \& O'Leary 2017; United States Department of Labor, 2018) and are earning less money hourly than that of their nondisabled peers (Murray \& Doren, 2013). Not only are IWD less likely to gain employment after exiting high school, but the gaps between disabled and nondisabled workers also get higher as employees age (Oertle \& O'Leary, 2017). Other environmental factors, such as unemployment rates, demographic characteristics, and disability type, also play into employment rates for IWD (Alasman \& Lee, 2017). Despite these numbers, research shows there are many benefits to having a job for IWD (Bluestein, 2008; Cimera et al., 2014). Having and keeping a job fulfills three basic human needs: survival, social connection, and self-determination/well-being (Blustein, 2008). Also, IWD that have jobs have an increased sense of self-esteem, self-worth, friendships, as well as increased physical and mental health (Cimera et al., 2014). Employment is particularly beneficial to IWD as they tend to suffer greater social isolation, stigma, and financial burdens than that of nondisabled workers (Blustein, 2008).

Career planning and development, such as CTE coursework, career counseling, job shadowing, and internships, help prepare students for their future careers (Oertle \& O'Leary, 2017). Students cannot only be exposed to the tools they need to make 
successful transitions, but there are also other skills and personal attributes that IWD need to be successful. Morningstar et al. (2017), outlined a framework for CCR that uses both academic domains. Their framework included (a) academic engagement, (b) mindset, (c) learning process, (d) critical thinking, (e) interpersonal engagement, and (f) transition competency (Lombardi et al., 2017). Academic engagement includes those essential core content standards and subject areas such as math, reading, science, social studies, and science (Colton, 2010) and CTE courses. Included in academic engagement are the classroom behaviors that improve a student's ability to learn, such as attendance, participation, and productivity (Lombardi et al., 2017). Second, mindset refers to a sense of belonging, growth, ownership of learning, and perseverance, that students need when accessing the learning environment. These are enhanced when students feel a sense of community and connect to their school and feel supported when they are attempting to learn and grow (Morningstar, et al., 2017; Lombardi et al., 2017). Third, the learning process is broken into subsections, accessing the content and engagement in learning, including strategies and accommodations needed to access the content (Farrington et al., 2012). Fourth, critical thinking refers to cognitive strategies necessary for postsecondary education and academic success, including problem-solving, research, interpretation, communication, and precision/accuracy (Conely, 2010). Fifth, interpersonal engagement focuses on the interaction between adults but also includes empathy and other skills needed to understand others. It is important to note that they are not strictly academic skills (Morningstar, et al., 2017). Finally, transition competencies encompass skills suggested for employment and postsecondary education including early planning, career 
culture, college culture, and adult roles and responsibilities (Morningstar et al., 2017; Lombardi et al., 2017).

The Morningstar et al. (2017) framework suggests that there is a need for both academic and technical training, but also a strong need for students to learn self-efficacy skills. Other career development activities, such as person-centered planning, career assessments, and career planning, help teach students the self-determination they need to find jobs that they like (Webb et al., 2014). It is these soft skills-such as choice, selfadvocacy, persistence, and level of performance that lead to the self-efficacy skills that IDW need to be successful for either college or the workplace.

\section{Pre-Employment Transition Services}

Carlson et al. (2019), examined if and how 38 states' Pre-ETS policies addressed the guidelines under WIOA. The researchers visited each state's VR website and identified policies and procedures that address Pre-ETS, transition services, school-towork services, and youth services. Of the 38 states, 31 included Pre-ETS policies within their state policy and procedure manuals and seven states had separate Pre-ETS policies. While the researchers found a lot of variability between the states, they did find specific themes within the requirements. Each state identified participants as either students or youth with disabilities and addressed language around eligible and potentially eligible. State policies consistently addressed services including; purpose, skills/activities/services, group and individual services, location of services, and responsible personnel. Finally, they found that while most of the states were engaging in Pre-ETS activities with students, they still had funding left over, showing a need for more 
training to providers and educators to assist with the understanding of Pre-ETS services and what is available to IWD (Carlson et al., 2019).

\section{Self-Advocacy}

Whether students choose to go to college or trade school or go into the workforce after exiting high school, one key concern is their ability to advocate for themselves in these settings. High levels of self-efficacy in IWD can also be predictors of higher financial independence, employment, social relationships, independent living, and postsecondary education opportunities (Shogren \& Shaw, 2016). The literature around college and career readiness all points to self-efficacy as one of the most important skills a student needs to obtain. Student motivation and engagement are critical factors in one's ability to be successful in college or the workplace (Morningstar et al., 2015).

Self-determination refers to actions identified by the person's ability to act autonomously, self-regulate behaviors, the ability to initiate and respond to events in a psychologically empowered manner, and the person acting in a self-realizing manner (Wehmeyer et al., 2003). Not only are self-efficacy and social skills necessary for positive outcomes for students, but they are transferable to other settings (Murray \& Doren, 2013). Schalock, Bonham, and Verdugo (2008) discussed quality of life factors, such as emotional well-being, interpersonal relations, material well-being, personal development, physical well-being, self-determination, social inclusion and right, and how they impact self-efficacy. Self-efficacy is a strong indicator of a person's ability to advocate for themself (Shogren \& Shaw, 2016).

Job Satisfaction for Individuals with Disabilities 
There is a growing recognition of the need to consider the quality of life (QOL) for IWD. Research in QOL for IWD has made an impact on research, practices, and policy decisions (Biggs \& Carter, 2016; Claes et al., 2010; Schalock et al., 2007). A study conducted by Bonham et al., (2004) identified eight QOL indicators for IWD: social inclusion, personal development, self-determination, rights, interpersonal relations, emotional well-being, physical well-being, and material well-being. Although many studies focus on postsecondary placements for transition-age youth, QOL has not been examined for these individuals (Biggs \& Carter, 2016). Collecting data on where postsecondary transitions occur is an integral part of recording student transitions, but and individual's QOL and job satisfaction should also be a consideration in a successful transition.

Obtaining employment, in itself, does not necessarily make a transition successful; other factors lead to better outcomes for employees. Studies have shown that job satisfaction plays a role in productivity and longevity for non-disabled workers. Factors such as job tenure, age, and pay may also play a significant role in job satisfaction for non-disabled workers (Riza et al., 2018). Although data suggests that IWD can have difficulty obtaining and retaining employment after exiting high school, there is limited research into job satisfaction for this population (Hofmans et al., 2012). Much of the research on job satisfaction for IWD focuses on competitive versus noncompetitive/sheltered employment. Sheltered employment is a training program in a facility where most people have disabilities and are working on job skills with supervision. The wages, working conditions, and benefits may vary in sheltered employment since it is considered a job-training service. Integrated competitive 
employment takes place in the community with non-disabled peers and follows the guidelines of the general labor market (Miglior et al., 2007).

\section{Transition for Individuals with Intellectual Disabilities}

As discussed in the previous sections, there are areas of high need for any IWD that transitions from high school to a postsecondary placement, either in college or technical training or in a vocational or job setting. One issue that many IWD face when leaving the high school setting into a postsecondary placement is the change of protections under IDEA to ADA (Shaw, 2009; Asselin, 2014; White et al., 2017; Van Hees et al., 2018). There are many transition models and curriculum that help guide teachers, parents, and students through the transition process. However, we still see many IWD leaving high school unengaged in postsecondary activities (IES NCSER, 2019). Transitions become an even bigger struggle for individuals with intellectual disabilities earning an alternative high school diploma (AHSD; Simonsen \& Neubert, 2012). Only around $33 \%$ of individuals with intellectual disabilities enter postsecondary education, as compared to around $61-75 \%$ of all IWD that enter college. Likewise, only around $39 \%$ of individuals with intellectual disabilities are competitively employed five years after high school, compared to $57-67 \%$ of all IWD. Additionally, $83 \%$ of IWD that did not complete high school are in the lowest level income bracket (less than $\$ 25,000$ annual) as compared to $59 \%$ of IWD that did earn a high school diploma (Sandford et al., 2011). Many students with intellectual disabilities exit high school with an AHSD or classified as a non-completer (USDOE, 2020). These statistics show a need for further research on how individuals with intellectual disabilities transition from high school.

High School Transitions for Individuals with Intellectual Disabilities 
There are several ways that students exit high school. Students can exit with a standard high school diploma, an AHSD, drop out, or age out (Thurlow et al., 1995). According to IDEA (Section 300.160), states may choose to provide an AHSD for students with the most significant disabilities. For a student to qualify for an AHSD, they must have significant disabilities that prohibit them from participating in the general assessment, even with accommodations. Students earning an AHSD would also qualify to take an alternate assessment. The alternate assessment standards must be aligned with the general assessment and must measure the achievement of IWD against those of same-age peers (IDEA, 2004). The Every Student Succeeds Act (ESSA) of 2018 sets the standard allowing only $1 \%$ of all students can receive an AHSD. States that exceed this $1 \%$ rule must then apply for a waiver (ESSA, 2018). Most states offer an alternative high school diploma; however, some do not.

Students participating in an AHSD must meet specific guidelines based on the state in which they receive services. For example, according to Guidance for Admissions and Release Committees (ARC) on Participation Decisions for the Kentucky Alternate Assessment (2019), students must meet eligibility criteria in one or more disability categories under IDEA. Students earning an AHSD must have a significant cognitive and adaptive disability and require extensive individualized instruction across settings. Further, a student that participates in an alternate assessment must have a significant cognitive or adaptive disability that requires individualized instruction across multiple settings and prevents them from accessing grade-level content.

Johnson et al. (2009), studied outcomes associated with having an AHSD. States that chose not to have an AHSD have a higher number of IWD that graduate high school, 
but also an increased number of students that age out 21 years old or drop out of school. Alternatively, states that did offer an AHSD saw less IWD graduating with a standard diploma and more qualifying for an alternate assessment. On the other hand, the requirements for graduating with a standard diploma were much higher. Additionally, IWD had less access to the general education classroom. Further, IWD that received an AHSD have fewer options for postsecondary education as it is as rigorous as a standard diploma (Johnson et al., 2009).

An IEP team must consider exclusionary criteria when considering alternate assessments. These criteria are state specific, as this study specifically looks at Kentucky data, the example exclusionary criteria is from that state. Students must meet the eligibility criteria for at least one disability according to the IDEA, have a significant cognitive or adaptive disability preventing them from accessing grade-level content. Students must also require extensive modifications and adaptations to the general curriculum and need individualized instruction across multiple settings. Exclusionary criteria also state that a "disability cannot be the primary result of excessive absences, another underlying disability, social, cultural, or economic differences, limited English proficiency, poor performance on grade-level assessments, testing anxiety, classroom placement, or an administrators decision" (Kentucky Department of Education, 2019, p. 6). Alternate assessment participation should not determine a student's least restrictive environment (LRE). However, it does often impact the setting in which they receive their instruction. Based on a multi-site study across 15 states, Kleinert et al. (2015) found that among students with significant disabilities (e.g., intellectual disabilities, multiple disabilities) generally receive educationally serves in a separate classroom and/or school 
setting and have limited access to same-age peers. Receiving services in special class limits the students' abilities to interact with the same population that they would be encountering in a job setting, requiring more training. So, while earning an alternative diploma may be the best option for some students, it could limit jobs available to them or impact their job satisfaction.

\section{Postsecondary Education for Individuals with Intellectual Disabilities}

Over the last 40 years, programs for students with intellectual disabilities to attend college have emerged around the world (Raue \& Lewis, 2011; Grigal et al., 2012). Raue and Lewis (2011) report as many as $41 \%$ of institutions of higher learning enrolled students with ID. Under IDEA students can receive special education services until they are 22 years old. For some IWD this provides opportunities for dual enrollment in college courses while receiving their special education services from their high school (Hart et al., 2005; Grigal et al., 2012). These programs open up opportunities for students with ID to attend college courses while continuing to work on transition services such as community-based instruction (Grigal et al., 2012). However, there are programs for students with ID who are not enrolled in K-12 education. These programs, provided on a college campus, serve students with ID that are 18 years of age or older. While the programs are on the college campus, access to college courses varies based on the program (Hart et al., 2005; Grigal et al., 2012). Programs exist, a high degree of variability exists between them. Some students are involved in social activities, and audit or take courses for credit, others only participate in programming designed for IWD (Grigal et al., 2012). While these programs offer additional transition support for IWD, 
the primary focus, as for any college student, is to prepare them for competitive/integrated employment.

\section{Vocational/Job Training for Individuals with Intellectual Disabilities}

Individuals with ID generally have two options when entering the workforce. Individuals that participate in competitive/integrated employment work in the community, with non-disabled peers, and follow the guidelines of the general labor market. Sheltered employment, often viewed as a training program, takes place in a facility where most of the individuals have disabilities and are working on job skills with direct supervision. In sheltered employment wages, work conditions, and benefits may vary as this type of employment is considered a job-training service (Metzel, et. al, 2007). The National Longitudinal Transition Study 2 (NLTS2) data analyzed data from IWD five years post-graduation (IES NCSER, 2019). The NLTS2 data showed only $27.9 \%$ of students with severe IDs have paid work experiences. Additionally, according to Carter, Austin, and Trainor (2011) individuals without a diploma and lower self-care skills were less likely to be employed. With data showing low numbers of youth with ID are gaining competitive/integrated employment after exiting high school, there is a need to study further how to increase positive postsecondary outcomes for students with complex needs.

\section{Self-Advocacy for Individuals with Intellectual Disabilities}

Shogren and Shaw (2016) conducted a study that examined self-determination for students with intellectual disabilities. Their findings suggested the need to plan for the complexity of factors between self-determination and postsecondary outcomes. Schools must provide high expectations, create meaningful opportunities, and high levels of 
support to begin to teach self-determination to IWD. Shogren and Shaw (2016) also identified the need to teach and promote skills such as choice-making and self-advocacy that lead toward better postsecondary outcomes for IWD. While there are fewer studies that focus only on self-efficacy as a topic for postsecondary transitions for IWD, much of the research into college and career readiness indicates that self-efficacy is a skill needed for students to have successful outcomes.

\section{Job Satisfaction for Individuals with Intellectual Disabilities}

A study conducted in the Netherlands examined job satisfaction for employees with ID in both sheltered and competitive/integrated employment using photovoice (Akkerman et al., 2014). The participants took pictures to document their work experiences in both settings. The researchers instructed participants to take pictures of things that made them feel both good and not good about their jobs. The researchers conducted interviews with participants to explain the pictures. Many of the pictures showed social relationships at work, working conditions, and the nature of the work itself. These themes were similar in both sheltered and integrated employment. Also, Akkerman et al. (2014) reported that these themes are consistent with studies on job satisfaction for non-disabled workers.

While there are similar themes for job satisfaction for both sheltered and competitive/integrated employment, an individual's preference for employment must also be considered. Many IWD are placed in sheltered workshops as trainees to teach them job skills to use in the general labor market. However, many of these participants rarely transition out of these programs. Additionally, workers do not earn competitive wages 
and benefits. Furthermore, workshops do not allow IWD to work in an integrated setting with non-disabled peers (Miglior et al., 2007).

Miglior et al. (2007) studied preference for sheltered or competitive/integrated employment of individuals with ID, their families, and staff that work with them in sheltered or integrated employment. The data showed that $82 \%$ of individuals with ID thought integrated employment was preferable. Consistently, the majority, $75 \%$ of families felt their son/daughter had the skills to perform the tasks in competitive/integrated employment, and $78 \%$ of staff believed adults with ID could become employed outside of the workshop. These data show a strong preference by individuals with ID and their families for competitive/integrated employment.

\section{Transition Education in Kentucky}

Federal and state regulations require school districts to gather and report data on the post-school outcomes for IWD. As previously discussed, the Workforce Innovation and Opportunity Act (WIOA; Public Law 113-128) seeks to ensure equal opportunities for individuals with disabilities in the workforce (20 USC 1416(a)(3)(B)). IDEA Indicator 14 requires state and local school districts to collect and report information on students' transitions out of high school into postsecondary education (e.g., HS diploma), employment status. Data is also collected on other career and educational factors (e.g., job interest).

According to publicly available data from the Year One-Year Out (YOYO) survey conducted in the Commonwealth of Kentucky, approximately $30 \%$ of IWD are engaged in higher education or employment one year after exiting high school. For IWD that exited high school with an AHSD, the number of individuals which are unengaged in 
postsecondary placements, goes up to around $70 \%($ KYPSO, 2020). Currently, Kentucky has eight pathways to graduation that can be accessed by any student graduating with a high school diploma, and an AHSD for students with moderate to severe disabilities. Students participating in the Kentucky Alternate Assessment must be determined eligible by their IEP team after they consider assessment data, longitudinal IEP and classroom data, and based on their need for significant modification to the curriculum (KDE, 2019). All students, regardless of disability, must complete minimum graduation requirements in one of the eight pathways, and meet criteria on assessments in both eighth and tenth grades, to be considered transition ready (KDE, 2020).

Students completing an AHSD must also meet criteria on an alternative assessment or complete a course of study and make a benchmark on an assessment for career readiness to be considered transition ready (KDE, 2020). The Career Work Experience Certification (CWEC), developed specifically for students participating in the Kentucky Alternate Assessment and receiving an AHSD, provides a course of study to prepare students with intellectual disabilities for employment. The CWEC includes the Employability and Foundational Academic Standards-Alternate Assessment (EFAS-AA), addressed from kindergarten through post-high school. The EFAS-AA standards in high school are part of a course of study taken during high school and assessed using the Employability Skills Attainment Record (ESAR). Students also complete work-based learning hours in the community for each course if a student completes the course work, work-based learning hours, and achieving a benchmark on the ESAR they are considered transition ready in the area of employment (Kentucky Alternate Assessment Career Work Experience Certification Administration Guide, 2019). The first year for full 
implementation of the CWEC course of study was the 2018-2019 school year (KDE, 2020).

\section{Conclusion}

Many notable legislative acts helped form vocational and education services for IWD today. Early legislation such as the Vocational Rehabilitation Amendment, the Vocational Education Amendment, Education for All Handicap Children Act/Individuals with Disabilities Act, and the Americans with Disabilities Act paved the way for transition services for IWD exiting high school (Flexer et al., 2013). Transition models such as Will's Bridges Model, Halper's Community Adjustment Model, and Kohler's Transition Education Model and Taxonomy for Transition Programming 2.0, helped create frameworks for transition education for IWD (Will, 1983; Halpern, 1985; Halpern, 1993; Kohler \& Field, 2003; Kohler et al., 2016).

Currently, many states have adopted College and Career Readiness standards as a way to prepare high school students for postsecondary outcomes. For many students with disabilities, there is a need for further transition planning to help them make successful transitions (Cease-Cook et al., 2015). Current research shows that the more an IWD is exposed the general education curriculum, participates in school to work programs, and learns social skills in their LRE the better prepared they are for postsecondary outcomes (Lindstrom et al., 2011; Gold et al., 2013; Murray \& Doren, 2013; Web et al., 2014; McConnell et al., 2015; Oertle \& O'Leary, 2017; Lombardi et al., 2017).

As IWD leave the high school setting, where they received services under IDEA, they face new challenges in their postsecondary placement. One of these challenges is that unlike IDEA, accessing disability services under ADA requires more self-advocacy. 
Specifically, as IWD enter into college or the workplace they must disclose their disability, prove eligibility, and request accommodations. This can be an overwhelming task for a young person entering the workforce for the first time (Shaw, 2009; Asselin, 2014: White et al., 2017; Van Hees et al., 2018).

While many individuals with disabilities are in the workforce, there are still significant gaps in the number of disabled and nondisabled workers. Additionally, disabled workers typically work fewer hours for less pay (Cimera et al., 2014; Murray \& Doren, 2014; Alsaman \& Lee, 2017; Oertle \& O'Leary, 2017; United States Department of Labor, 2018). Despite the low numbers of IWD that are engaged in competitive/integrated employment, research shows that there are many benefits to having a job. IWD that have jobs tend to increase self-esteem, more friendships, and better mental and physical health (Bluestein, 2008; Cimera et al., 2014). As a response to this need, the WIOA requirements for providing Pre-ETS, along with other individual state initiatives, provide structure and funding for transition education (WIOA, 2014). However, many states still need to further develop Pre-ETS programming for students with disabilities to increase access to more students (Carlson et al., 2019).

A common theme among research for college and career readiness is the need for self-advocacy and self-determination. Many IWD lack the ability to advocate for themselves whether they are in a postsecondary education setting or in the workplace. This lack of self-advocacy can lead to difficult transitions and the potential for failure in the new setting (Wehmeyer et al., 2003; Verdugo, 2008; Morningstar et al., 2015; Shogren \& Shaw, 2016). While self-advocacy is a good skill for IWD in the school or 
work environment, strong skills in this area transfer to other settings which can impact their overall QOL (Murray \& Doren, 2013).

While there is a lot of research into job satisfaction and QOL for non-disabled workers, this is an area where more research is needed for IWD (Hofmans et al., 2012). There is an even bigger need when considering job satisfaction for individuals with intellectual disabilities. Much of the research in this area examines the differences in job satisfaction between sheltered and competitive/integrated employment, but there are fewer opportunities for IWD to obtain sheltered employment as these facilities close across the United States (Miglior et al., 2007). In fact, much of the research around postsecondary transitions show individuals with intellectual disabilities have less successful outcomes than other IWD (Sandford et al., 2007). Additional investigation is needed to explore the correlation between the impact of high school transitions and postsecondary outcomes on individuals with intellectual disabilities. 


\section{CHAPTER III: METHODOLOGY}

The purpose of this chapter is to describe the methods that were used in this study. The major areas addressed include survey description, sample, instrumentation, participants, procedures and data analysis.

\section{Kentucky Youth One Year Out Survey}

IDEA Indicator 14 requires that all state and local school districts gather and report data on postsecondary transitions for SWD. Federal and state, IDEA Indicator 14, legislation mandates that each school district report the number of SWD enrolled in postsecondary education, competitive/integrated employment, or a training program one year after high school (20 USC 1416(a)(3)(B)). Despite this legislation, to-date there is little research on how disability category and manner of exit affects an individual's ability to obtain employment (Honeycutt et al., 2017). Further, there is even less research around job satisfaction for SWD once they get employment (Akkerman et al., 2014). Within the Commonwealth of Kentucky, the Youth One Year Out (YOYO) survey is used to gather and assess this information regarding transition outcomes for students with disabilities one year after exiting high school. Data were collected on student outcomes, including but not limited to; enrollment in postsecondary education, employment, and job satisfaction. The YOYO survey was administered by local school district staff each spring with the aim of documenting postsecondary outcomes for students with disabilities. (Kentucky Post School Outcomes Center, 2019). This section will describe 
the study's methodology, including, participants and instrumentation. Further, outlined are the procedures and data analysis methods that were used to evaluate the differences in manner of exit, disability category, and employment status on job satisfaction for individuals with intellectual disabilities.

Research Question 1: Are there different levels of job satisfaction based on disability category (OHI, Autism, MMD, and FMD) among IWDs, controlling for job interest?

Research Question 2: Are there different levels of job satisfaction based on type of high school exit (regular diploma, alternate diploma, age out, or drop out) among IWDs, controlling for job interest?

Research Question 3: Are there different levels of job satisfaction based on employment status (competitive, non-competitive employment) among IWDs, when controlling for job interest?

\section{Participants}

Study data were collected from IWD in the Commonwealth of Kentucky who receive special education services, one year after exiting high school between April and June of 2019 for students $(N=2,481)$ who graduated at the end of 2018-2019 academic year. Specifically, eligibility required that students, between the ages of 18-22, who received services under an IEP when they exited high school, regardless of background demographics. Participation was not mandatory; however, an effort was made to contact each student. Parents or guardians could respond on behalf of their child if he/she is unable to complete the survey. Within the sample, $30.5 \%$ of the students identified themselves as female and $69.5 \%$ male. In addition, $81.5 \%$ of the respondents identified themselves as white, $12.2 \%$ as black or African American, 3.3\% as Hispanic or Latinx, 
$2.2 \%$ as two or more races, and less than $1 \%$ identified in each of the following categories, American Indian, Asian, and Native Hawaiian or Pacific Islander. Within this study, four disability categories were considered: OHI (23.1\%), autism (9.2\%), MMD (19.9\%), and FMD (6\%). The categories of autism, MMD, and FMD were selected based on the pervasive nature of their disability and number of students participating receiving an alternative high school diploma (KDE, 2008), whereas OHI served as the comparison group.

Kentucky has 14 disability categories in which a student can be eligible for receiving services under IDEA. According to Kentucky Administrative Regulations (2008), a student receiving services under the eligibility for other health impairment (OHI) has chronic or acute health problems that adversely affect the child's educational performance. A student with autism has a developmental disability that significantly affects their nonverbal communication and social skills and adversely affects their educational performance. A student with MMD is average performance on at least two standard deviations below tests of cognition, adaptive behavior, and academic performance. A student with FMD, defined as having a cognitive function in at least three standard deviations below the mean, adaptive behavior deficits at least three standard deviations below the mean and a severe deficit exists in overall academic performance (KDE, 2008).

When determining criteria for qualifying for special education services a standardized intelligence test is often part of the referral process, to attempt to obtain an IQ score. There are many commonly used standardized intelligence tests, such as the Wechsler Intelligence Scale for Children 5th Edition (WISC-V), Stanford-Binet 
Intelligence Scales-Fifth Edition (SB5), and the Woodcock-Johnson IV Tests of Cognitive Abilities (WJ IV COG). Test choice is often based on the needs of the individual student and the preference of the school psychologist administering the test and would not be an appropriate continuous measure for this data analysis (Sattler, 2018).

\section{Instrumentation}

The data analyzed for this study was gathered from the 2019 YOYO survey administered by the Kentucky Board of Education. The Kentucky Post Schools Outcome Center (KyPSO), started in 2005, as part of legislation from the US Department of Education, Office of Special Education Programs (OSEP). KyPSO collects post-school outcome data from students in Kentucky that have exited school with an IEP. In 2009 additional requirements to collect data on students enrolled in higher education and competitively employed were added to the Indicator 14 requirements. The YOYO survey was developed between 2005 and 2007 and was administered to students for the first time in the spring of 2007 (KyPSO Annual Report, 2004). For 2019 data collection, the survey was administered via telephone interviews to SWD or their parent/guardian between April and July 2018 by trained school district staff. A person administered the survey via a phone call; the surveyor either talked to the student or respective parent(s). The surveyor may make other attempts to contact students to request a phone call, such as email, social media, and in-person contact. Since the surveyors interview former students or their parents/guardians, school personnel had necessary demographic information such as name, gender, and ethnicity. Information on school, district, disability category, and manner of exiting high school was also available. Approximately $56 \%$ of students or their 
parents completed interviews. The information collected focuses on what secondary school systems can do to prepare SWD for the transition to higher education

\section{(www.kypso.org).}

The YOYO survey consisted of 35 selected (e.g., multiple-choice, yes/no) and open-ended (e.g., short answer) response questions and, on average, takes about 10 minutes to complete. Items asked about individuals' employment, postsecondary education, and involvement in training programs. Example questions included: "Who is being surveyed, and what is their relationship to the student?" "Where did the student live in the last year?" See Appendix A for the full survey. If the students are not engaged in either employment or postsecondary education, there was a question that asked how the student spends their time. Finally, there was a line of questioning around competitive employment and student's perceptions of their employment status. These questions included, "as far as you know, do you work with people with and without disabilities?"

"As far as you know, do you get similar pay as your coworkers doing the same job?" "As far as you know, do you get similar benefits as your coworkers doing the same job?" "As far as you know, do you get similar opportunities for advancement as your coworkers doing the same job?". The rating scale for this line of questioning was, $5=$ Definitely Yes, 4 = Yes, 3-No, 2-Definitely No and 1-I don't know. The question "How interesting is your job?" had a separate rating scale, 1-Very interesting, 2- Somewhat interesting, 3Medium-neither interesting or boring, 4-Not very interesting, 5- Not interesting at all. Additional information and details about the YOYO survey are available from the Kentucky Post School Outcomes website (www.kypso.org). 


\section{Procedures}

Data were obtained from the state contractor for the collection of the YOYO data at the Human Development Institute (HDI) at the University of Kentucky. As described, data was collected by the public-school system of the Commonwealth of Kentucky to report the post-school outcomes of SWDs under indicator 14 of IDEA (2004), to the United States Department of Education's Office of Special Education Program (OSEP). Contact was attempted for all students who had IEPs in place at the time of exit.

\section{Data Analysis}

Linear multiple regression (LMR) was used to examine the association of disability category, high school exit, and employment status on the job satisfaction of SWD (using the questions around competitive employment, and job satisfaction, one year after exiting high school. Linear regression is an appropriate analysis when the goal of the research is to assess the extent of a relationship between a set of predictor variables and a single, continuous dependent (criterion) variable. Linear regression is also used when interested in examining predictors of subsequent outcome. This study is seeing to predict what variables may be indicative of job satisfaction. This is a novel study in this field, seeking to identify key predictors of postsecondary outcomes. Specifically, within this study, job satisfaction is the dependent variable, measured as individuals' average score across five scale items. Each participant is asked to rate on a scale of one to five. Four of the questions use the rating: $5=$ Definitely Yes, $4=Y e s, 3-N o, 2-$ Definitely No and 1- I don't know. Meaning a higher score indicates higher job satisfaction. One question, "how interesting do you find your job", uses the scale 1-Very interesting, 2- 
Somewhat interesting, 3-Medium-neither interesting nor boring, 4-Not very interesting, 5- Not interesting at all. Meaning a lower score indicated a higher interest in their job. In total, four disability categories were included in the analysis: OHI, autism, MMD, and FMD. Type of high school exit included three predictors: Drop/age out, alternative diploma, and high school diploma. Drop and age out were combined, as only one percent of the population aged out; meaning they did not exit with a regular or alternative high school diploma. Employment status included two predictors: Competitive employment and non-competitive employment. Within the analysis, categorical variables were coded in which one of the groups served as the referent group to examine group differences on job satisfaction. For disability there were three different dummy coded variables, in each OHI served as the referent group and was coded 0. For type of high school exit, general diploma served as the referent group, and for employment, competitive employment was referent group and therefore coded 0 . The Cronbach's coefficient alpha was estimated and reported to measure internal consistency reliability.

To examine the research questions, a linear multiple regression was conducted to investigate whether or not disability category, manner of exiting high school, employment status, and gender predict job satisfaction. Multiple measures were used to assess the fit of the overall regression model. First, the overall $F$-statistic was used to assess whether the model as a whole explains variance in outcome of job satisfaction, with a p-value less than 0.05 used for hypothesis testing. $R$-squared was reported and used to determine how much variance in the dependent variable can be accounted for by the independent variable, which ranges from 0 to 1.00 . The $t$ - statistic was used to determine if the regression coefficient is statistically different from 0 , or no difference 
between the referent and the comparison groups. A value is greater than .80 (ranges from 0 to 1.00 ), with higher values indicates less error in scores. A dummy coding scheme was used for each IV with OHI coded 0 as the referent group. Additionally, dummy variables were created to compare other group's job satisfaction to the referent group. The unstandardized regression coefficient is used to judge whether job satisfaction scores differ statistically between the comparison groups (FMD, MMD, and autism) and the referent group (OHI) coded as 0 . The unstandardized regression coefficient value tells the difference between the mean of the referent group and each comparison group. For statistically significant models, for every one unit increase in the predictor, the dependent variable will increase or decrease by the number of unstandardized beta coefficients. Here, the regression coefficient for a dummy coded variable reports the average difference in job satisfaction between the compared groups. The assumptions of a linear regression — linearity and homoscedasticity_-was assessed. Linearity assumes a straightline relationship between the predictor variables and the criterion variable and homoscedasticity assumes that scores are normally distributed about the regression line. Residuals were checked for normality (using histogram of residuals), and homoscedasticity by creating a scatterplot with the residual on y-axis and each predictor on X-axis. Linearity and homoscedasticity were assessed by examination of a scatter plots of residuals (Statistics Solutions, 2013).

Independent variables were dummy coded nominally to formally examine the association of key indicators (e.g., disability category, employment status) on job satisfaction among IWD. For the disability category, OHI served as the comparison 
(referent) group, whereas drop/age out is the referent group for high school exit. All analyses were conducted using SPSS. 


\section{CHAPTER IV: RESULTS}

The purpose of this chapter is to provide the results and discuss the findings of the study. First is a brief overview of the research model and descriptive statistics. Then, each research question is posed followed by the data analysis.

\section{Overview of Research Components}

A multiple linear regression (MLR) model was used to examine the association of disability category, high school exit, and employment status with IWD's job satisfaction, when controlling for job interest, one year after exiting high school. Disability categories included autism, mild mental disability (MMD), functional mental disability (FMD), and other health impairment (OHI), with $\mathrm{OHI}$ being the control group. The categories of autism, MMD, and FMD were selected based on the pervasive nature of their disability and the number of students participating receiving an alternative high school diploma, whereas OHI served as the comparison group.

The following 4 inclusionary definitions were used in this study which determined the data sets used. Disability categories are defined in the following way; a student with autism has a developmental disability that significantly affects their nonverbal communication and social skills and adversely affects their educational performance. A student with MMD and FMD (also identified as an intellectual disability), defined as having a cognitive and adaptive function in at least two to three standard deviations below the mean, respectively. $\mathrm{OHI}$ is defined as having a medical 
condition that impacts the student's ability to access their education (KDE, 2008). High school exit criteria included drop/age out, alternative diploma, and regular high school diploma. Employment status was defined as competitive and non-competitive. Job interest (Item 13) was based on respondents' answers to a single item and operationalized as Interesting, Neutral, and Not Interesting.

The dependent variable, job satisfaction, was assessed by creating a composite using the average score across the four questions from the Youth One Year Out survey (Osborne, 2016). These questions included, "As far as you know, do you work with people with and without disabilities?" "As far as you know, do you get similar pay as your coworkers doing the same job?" "As far as you know, do you get similar benefits as your coworkers doing the same job?" and "As far as you know, do you get similar opportunities for advancement as your coworkers doing the same job?" The rating scale for this line of questioning was $5=$ Definitely Yes, $4=$ Yes, $3=$ No, $2=$ Definitely $N o$ and $1=I$ don't know.

For the purposes of this analysis, the "I don't know" responses were removed to create a data set that only included individuals that answered the question definitively $(n$ $=715$ ). For this study, Cronbach's coefficient alpha was .79 for the four questions used to determine job satisfaction, to determine scale reliability (Osbourne, 2016). Prior to hypothesis testing, each study variable's frequency distributions were examined to determine the representation of individuals across each level of study variables (see Descriptive Statistics).

The independent variables were dummy coded nominally to formally examine the association of key indicators (e.g., disability category, employment status) with job 
satisfaction among individuals with disabilities (IWD). Other Health Impairment (OHI) served as the comparison (referent) group for disability category, regular high school diploma was the referent group for high school exit, and competitive employment is the referent group for employment status.

\section{Descriptive Statistics}

As seen in Table 1, the count percentage represents what percentage of students within the entire dataset represent that number, while the percentage within disability represents the percentage of individuals within that disability category who responded with that answer. For example, for high school students with OHI represent $46.7 \%$ of all the students in the dataset that graduated with a regular high school diploma, however among students with $\mathrm{OHI}, 94.8 \%$ graduated with a regular high school diploma.

Table 1 provides information regarding the makeup of the sample with respect to the predictors in this study (i.e., high school exit, employment status, and job interest). IWD from each category that exited with a high school diploma are as follows, for students diagnosed with OHI 94.9\% earned a general high school diploma, for students diagnosed with autism, $73.7 \%$ received a earned high school diploma ; 88.9\% of students with MMD, earned a general high school diploma, and $8.7 \%$ of students with FMD, earned a general high school diploma.

In terms of competitive employment one year after high school exit, $74.9 \%$ of students with $\mathrm{OHI}, 50 \%$ of students with autism, $76 \%$ of students with MMD, and $41.4 \%$ of students with FMD, were engaged in competitive employment. Students identified with either competitive or non-competitive employment included; $65.5 \%$ of students with 
OHI, $77.7 \%$ of students with autism, $68.4 \%$ of students with MMD, and $45.3 \%$ of students with FMD reported that they found their job somewhat or very interesting.

Table 1

Exit * Disability Crosstabulation

Disability

OHI Autism MMD FMD Total

\begin{tabular}{|c|c|c|c|c|c|c|c|}
\hline \multirow{3}{*}{\multicolumn{2}{|c|}{ Regular }} & Count & 543 & 168 & 439 & 13 & 1163 \\
\hline & & $\%$ within Exit & $46.7 \%$ & $14.4 \%$ & $37.7 \%$ & $1.1 \%$ & $100 \%$ \\
\hline & & $\%$ within Disability & $94.8 \%$ & $73.7 \%$ & $88.9 \%$ & $8.7 \%$ & $80.5 \%$ \\
\hline & Alternative & Count & 2 & 51 & 31 & 119 & 203 \\
\hline & Diploma & $\%$ within Exit & $1.0 \%$ & $25.1 \%$ & $15.3 \%$ & $58.6 \%$ & $100 \%$ \\
\hline & & $\%$ within Disability & $0.3 \%$ & $22.4 \%$ & $6.3 \%$ & $79.3 \%$ & $14.0 \%$ \\
\hline & Drop Out/ Max & Count & 28 & 9 & 24 & 18 & 79 \\
\hline & Age & $\%$ within Exit & $35.4 \%$ & $11.4 \%$ & $30.4 \%$ & $22.8 \%$ & $100 \%$ \\
\hline & & $\%$ within Disability & $4.9 \%$ & $3.9 \%$ & $4.9 \%$ & $12.0 \%$ & $5.5 \%$ \\
\hline Exit & & Count & 573 & 228 & 494 & 150 & 1445 \\
\hline & & $\%$ within Exit & $39.7 \%$ & $15.8 \%$ & $34.2 \%$ & $10.4 \%$ & $100 \%$ \\
\hline & & $\%$ within Disability & $100 \%$ & $100 \%$ & $100 \%$ & $100 \%$ & $100 \%$ \\
\hline
\end{tabular}

Employment

$\begin{array}{llrrrrr}\text { Competitive } & \text { Count } & 295 & 40 & 203 & 12 & 550 \\ \text { Employment } & \text { \% within } & 53.6 \% & 7.3 \% & 36.9 \% & 2.2 \% & 100 \% \\ & \text { Employment } & & & & & \end{array}$


Table 1

Exit * Disability Crosstabulation

\begin{tabular}{|c|c|c|c|c|c|c|}
\hline & $\%$ within & $74.9 \%$ & $50.0 \%$ & $76 \%$ & $41.4 \%$ & $71.4 \%$ \\
\hline & Disability & & & & & \\
\hline Other & Count & 99 & 40 & 64 & 17 & 220 \\
\hline Employment & $\%$ within & $45 \%$ & $18.2 \%$ & $29.1 \%$ & $7.7 \%$ & $100 \%$ \\
\hline & Employment & & & & & \\
\hline & $\%$ within Disability & 25.1 & $50.0 \%$ & $24.0 \%$ & $58.6 \%$ & $28.6 \%$ \\
\hline & & $\%$ & & & & \\
\hline Employment Total & Count & 394 & 80 & 267 & 29 & 770 \\
\hline & $\%$ within & 51.2 & $10.4 \%$ & $34.7 \%$ & $3.8 \%$ & $100 \%$ \\
\hline & Employment & $\%$ & & & & \\
\hline & $\%$ within Disability & $100 \%$ & $100 \%$ & $100 \%$ & $100 \%$ & $100 \%$ \\
\hline Job Interest Not & Count & 8 & 1 & 8 & 0 & 17 \\
\hline interesting & $\%$ within Job & $47.1 \%$ & $5.9 \%$ & $47.1 \%$ & $0.0 \%$ & $100 \%$ \\
\hline at all & Interest & & & & & \\
\hline & $\%$ within Disability & $1.9 \%$ & $1.2 \%$ & $2.6 \%$ & $0.0 \%$ & $2.0 \%$ \\
\hline Not very & Count & 29 & 5 & 15 & 0 & 49 \\
\hline interesting & $\%$ within Job & 59.2 & $10.2 \%$ & $30.6 \%$ & $0.0 \%$ & $100 \%$ \\
\hline & Interest & $\%$ & & & & \\
\hline & Count & 112 & 13 & 73 & 10 & 208 \\
\hline
\end{tabular}


Table 1

Exit * Disability Crosstabulation

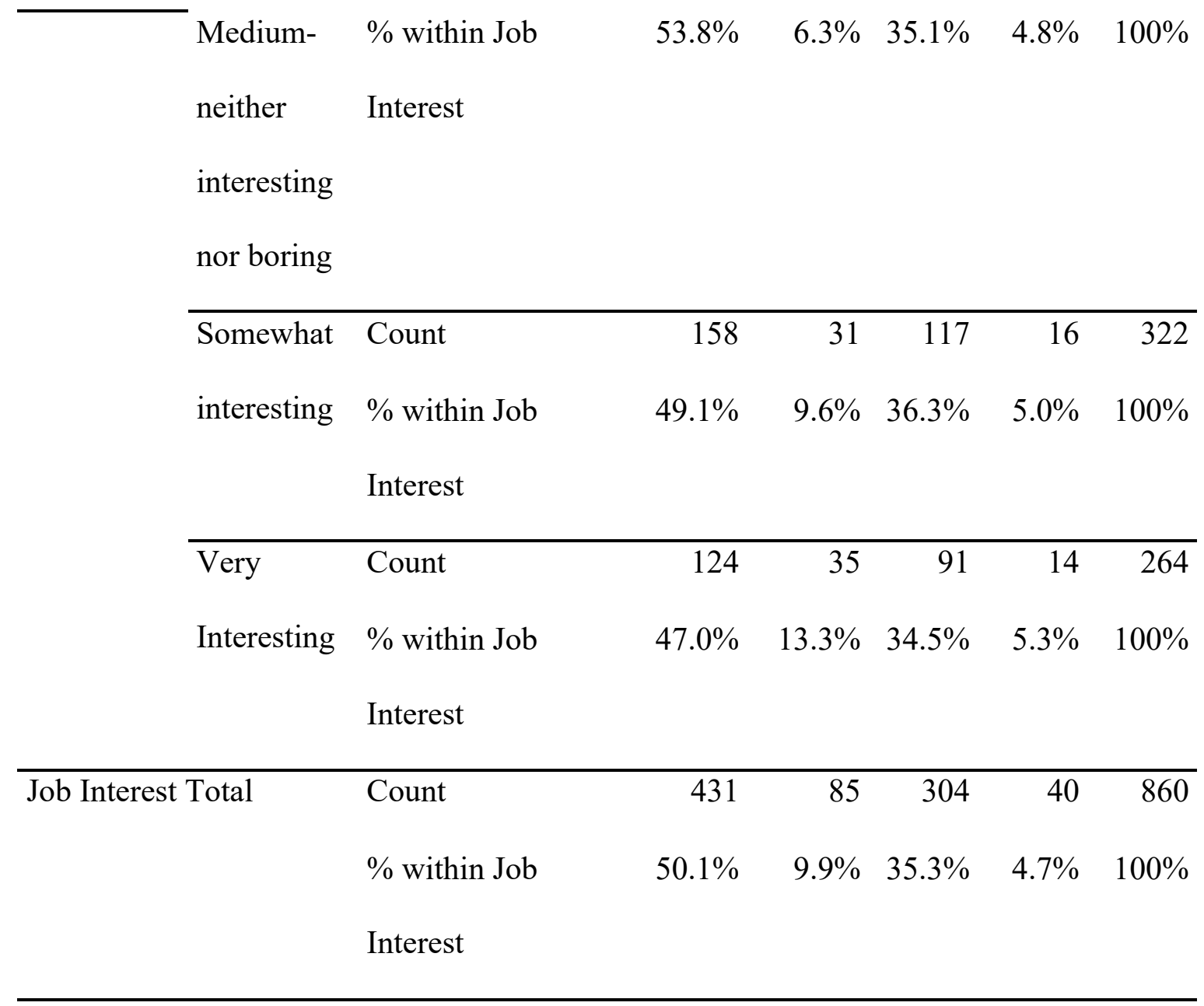

Finally, Table 2 shows descriptive statistics of job satisfaction score responses based on disability, type of high school exit, and employment type. Each variable has a mean score around 3.50. Based on the results of this table we can assume that individuals in non-competitive employment 3.21(.604) have lower job satisfaction scores on average than those in other categories. This could be due to the nature of non-competitive employment and the questions in this survey. Variables that include the highest levels of 
job satisfaction are individuals with $\mathrm{OHI} 3.67(.538)$ and individuals in competitive employment 3.63(.423).

Table 2

Job Satisfaction Rates by Variable

\begin{tabular}{|c|c|c|c|c|c|c|}
\hline \multirow[t]{2}{*}{ Category } & Variable & Mean & Std. & Minimum & Maximum & $\mathrm{N}$ \\
\hline & \multicolumn{6}{|c|}{ Deviation } \\
\hline \multirow[t]{4}{*}{ Disability } & $\mathrm{OHI}$ & 3.67 & .538 & 1 & 4 & 399 \\
\hline & Autism & 3.50 & .540 & 2 & 4 & 80 \\
\hline & MMD & 3.51 & .568 & 1 & 4 & 286 \\
\hline & FMD & 3.60 & .435 & 3 & 4 & 37 \\
\hline Type of High & Regular & 3.48 & .535 & 1 & 4 & 2103 \\
\hline \multirow[t]{4}{*}{ School Exit } & Diploma & & & & & \\
\hline & Alternative & 3.64 & .508 & 2 & 4 & 251 \\
\hline & Diploma & & & & & \\
\hline & Age/Drop Out & 3.38 & .648 & 1 & 4 & 127 \\
\hline \multirow[t]{4}{*}{ Employment } & Competitive & 3.63 & .432 & 3 & 4 & 1074 \\
\hline & Employment & & & & & \\
\hline & Other & 3.21 & .604 & 1 & 4 & 403 \\
\hline & Employment & & & & & \\
\hline
\end{tabular}

\section{Study Results}

The first research question was, "Are there different levels of job satisfaction based on disability categories (OHI, Autism, MMD, and FMD) among IWD, when 
controlling for job interest?" Using SPSS, the dummy coded disability categories were put into the first block of the regression analysis, with $\mathrm{OHI}$ being the referent group (see Table 3). The results this analysis (Table 3) shows four variable blocks. Block one, representing research question one, is not significant with $F(3,711)=.49, p=.69$ with an $R^{2}=.002$. Meaning there was no difference in job satisfaction based on disability category.

The second research question was to ascertain if job satisfaction differed based on the type of high school exit (i.e., regular diploma, alternate diploma, age out, or drop out) among IWDs, controlling for job interest. The type of high school exit was put into the second block of the linear regression model, with a general high school diploma as the referent group. Block two shows no significant difference in job satisfaction by on type high school exit with $F(2,709)=2.01, p=.123$ with an $R^{2}=.008$.

The third research question was, "Are there different levels of job satisfaction based on employment status (i.e., competitive and non-competitive employment) among IWDs, when controlling for job interest?" For this question, there was a statistically significant difference between job satisfaction for IWD in competitive versus noncompetitive employment $F(1,708)=113.04 p<.05$ with an $R^{2}=.145$. Meaning a person with competitive employment was $14.5 \%$ more likely to report higher job satisfaction than someone in non-competitive employment. Those with competitive employment report higher job satisfaction .395 or almost four points higher than those in noncompetitive employment. Lastly, block four included job interest resulted in a $R^{2}$ change of .02 which was statistically significant $F(1,707)=19.41 p<.05$ with an $R^{2}=.167$. This 
means that job interest explains $16.7 \%$ of the variance in job satisfaction. Additionally, for every one-point increase in job interest, there was a 0.078 increase in job satisfaction. Table 3

Linear Regression Job Satisfaction for IWD

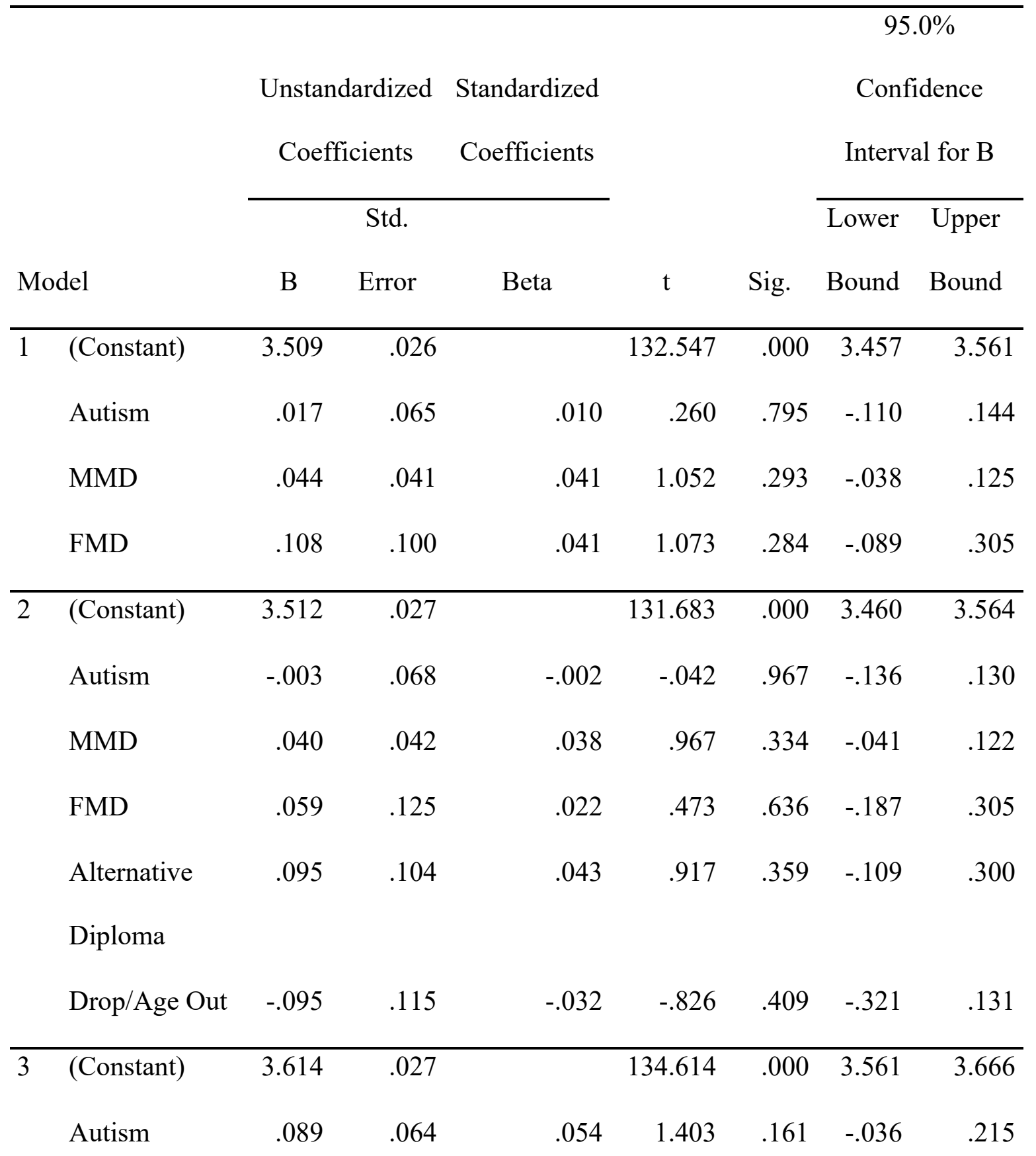


Table 3

Linear Regression Job Satisfaction for IWD

MMD

$.028 \quad .039$

$\begin{array}{llll}.027 & .727 & .467 & -.048\end{array}$

.104

FMD

.161

.117

.061

$\begin{array}{lll}1.368 & .172 & -.070\end{array}$

.391

Alternative

.138

.097

$\begin{array}{llll}.062 & 1.414 & .158 & -.053\end{array}$

.329

Diploma

Drop/Age Out

$.026 \quad .108$

$\begin{array}{llll}-.009 & -.245 & .806 & -.238\end{array}$

.185

Employment

$-.411 \quad .040$

$\begin{array}{lllll}-.367 & -10.176 & .000 & -.491 & -.332\end{array}$

$4 \quad$ (Constant)

3.305

.078

42.137

$.000 \quad 3.151$

3.459

Autism

$$
.075
$$

.063

$\begin{array}{llll}.045 & 1.188 & .235 & -.049\end{array}$

.199

MMD

.028

.038

.026

.720

$.472 \quad-.048$

.103

FMD

$.142 \quad .116$

.054

1.226

$.221 \quad-.086$

.370

Alternative

.129

.096

.058

1.341

$.180-.060$

.318

Diploma

Drop/Age Out

$$
-.020
$$

.107

$-.007$

$-.183$

.855

$-.229$

Employment

$-.395$

.040

$-.353$

$-9.853$

.000

$-.474-.317$

Job Interest

$.078 \quad .019$

.146

$4.179 \quad .000 \quad .041$

.114

a. Dependent Variable: Job Satisfaction

\section{Summary}

In conclusion, there was not a statistically significant difference between disability category or type of high school exit in job satisfaction for IWD when controlling for job interest. However, there was a difference in between competitive and 
non-competitive employment. The following chapter will include a discussion of the study findings. 


\section{CHAPTER V: DISCUSSION}

The purpose of this chapter is to discuss the findings of this study within the parameters of generalization, useability, study limitations, ending with a discussion of implications for future research. Limitations of the investigation are presented, followed by implications. The chapter concludes with recommendations for additional research.

\section{Discussion}

\section{Research Questions One}

Research question one sought to answer the question "Are there different levels of job satisfaction based on disability categories (OHI, Autism, MMD, and FMD) among IWD, when controlling for job interest?" The study found that there were no statistically significant differences in job satisfaction based on disability category. While the hope is that one does not see differences in job satisfaction based on disability, there are questions about students with intellectual disabilities fully comprehending the questions asked and then answering them accordingly. For each of the questions, many students used the "I don't know" response. In the population chosen for this study (i.e., students with OHI, autism, MMD, and FMD), around 20\% reported "I don't know" when asked "as far as you know, do you work with people with and without disabilities." Additionally, 8.7\% reported "I don't know" when asked "as far as you know, do you get similar pay as your coworkers doing the same job." Around 10\% reported "I don't know" to the last two questions "as far as you know, do you get similar benefits as your 
coworkers doing the same job" and, "as far as you know, do you get similar opportunities for advancement as your coworkers doing the same job.”

There may be several reasons why people choose the "I don't know" response when answering a survey (Beatty et al., 1998). The first consideration one must make when determining if the person knows the answer to the question, their "cognitive state". Second, whether the person's answer meets the criteria of the surveyor, "adequacy judgment." Finally, whether the respondent wants to answer the question, “communicative intent" (Beatty et al., 1998 p. 408). For individuals with intellectual disabilities, all of these can be a factor. The ability to recall information can be difficult for individuals in this population. Additionally, they may struggle to understand what the surveyor is asking and what answer they would like to receive. According to Nadeau and Niemi (1995), motivation also plays a role in one's ability to answer a question correctly. The higher one's motivation to complete the survey can predict how likely they are to give a correct substantive answer (Nadeau \& Niemi, 1995).

For individuals with intellectual disabilities, their cognitive functioning is part of their disability (IDEA, 2004; Kentucky Administrative Regulations, 2008). Considering Beatty et al.'s (1998) framework for cognitive ability when answering survey questions, when a person answers a survey question, the answer must be available, accessible, known, and the person must be able to generate the answer. For individuals with intellectual disabilities, each of these could pose a problem. Furthermore, many individuals with intellectual disabilities and autism may lack a functional communication system or minimal language for requesting needs and wants and struggle with intraverbal communication or conversational turn-taking (Ingvarsson \& Hollobaugh, 2010). 
It should be noted that within this data set, $38 \%$ of surveys were completed by a parent, guardian, or another person on behalf of the IWD, and these individuals may not have direct knowledge of the employment circumstances. While parents are typically a good source of information about their child (Eapen \& Revesz, 1999), research often shows that individuals and parents do not respond to surveys in the same manner. The parent and guardian answers could be due to a disagreement about the information, differences in perception, or variations in the observation of behavior (Eapen \& Revesz, 1999). For the YOYO survey, parents or guardians were allowed to respond to the survey for the IWD that had exited high school, but the possible differences in responses should be noted.

\section{Research Questions Two}

Research question two sought to answer if job satisfaction differed based on the type of high school exit (i.e., regular diploma, alternate diploma, age out, or drop out) among IWDs, controlling for job interest. The results of this study showed no statistically significant difference in job satisfaction based on type of high school exit. This question has considerations that are similar to research question one as they both are examining the same population of students, those with significant cognitive and functional disabilities. The population of students examined in this study primarily have intellectual disabilities and may have difficulty with answering questions for the survey, as cognitive load and communication could pose a barrier (Beatty et al., 1998). Additionally, parents or guardians may be providing responses to the survey that are from a different perspective than the individual themself may give (Eapen \& Reversz, 1999). These considerations may be especially true with the difference between a general high school 
diploma and an alternative high school diploma (AHSD). By design, the individuals that earn an AHSD have significant disabilities that impact their ability to access the general education curriculum and assessment (KDE, 2008).

The question asked to determine job satisfaction for this study, "As far as you know, do you work with people with and without disabilities?" "As far as you know, do you get similar pay as your coworkers doing the same job?" "As far as you know, do you get similar benefits as your coworkers doing the same job?" and "As far as you know, do you get similar opportunities for advancement as your coworkers doing the same job?," focus on specific items found in the literature that represent higher levels of job satisfaction for all workers. However, for those entering jobs within a year of exiting high school the answers may be very similar. Though there are gaps in the literature, it can be presumed that jobs obtained immediately after exiting high school, either with an AHSD or a general diploma, are often the same type of job. Additionally, people typically do not retain the same employment they obtained shortly after exiting high school. Therefore, it might be concluded that the findings of this study are accurate and there were not significant differences in job satisfaction for individuals based on earning an AHSD or a general diploma, because they are accessing similar jobs. However, those that have earned a general high school diploma have more opportunities for obtaining higher paying jobs in the future (McDermott et al., 2019).

\section{Research Question Three}

Finally, research question three asked "Are there different levels of job satisfaction based on employment status (i.e., competitive and non-competitive employment) among IWDs, when controlling for job interest?" Non-competitive 
employment for the YOYO survey referred to any employment in which a student does not receive competitive wages, including for example sheltered employment, or family businesses and farms (KyPSO, 2020). Sheltered employment is considered a job-training service; therefore, workers typically do not earn minimum wage, and working conditions and benefits may vary significantly. Competitive employment takes place in the community with nondisabled peers and follows the general labor market. Since sheltered employment is used for job training for IWD, primarily those in taking part in the programming have intellectual disabilities (Miglior et al., 2007). Based on the questions used to ascertain job satisfaction for this study, "As far as you know, do you work with people with and without disabilities?" "As far as you know, do you get similar pay as your coworkers doing the same job?" "As far as you know, do you get similar benefits as your coworkers doing the same job?" and "As far as you know, do you get similar opportunities for advancement as your coworkers doing the same job?" it would be expected that those in non-competitive employment would report lower levels of job satisfaction.

Sheltered workshops are considered training programs for IWD, specifically those with intellectual disabilities, but workers rarely transition into competitive employment (Miglior et al., 2007). When considering the question of job satisfaction, it is important to note that many individuals in sheltered employment have less flexibility for movement out of their work conditions. Therefore, it can be determined that lower levels of job satisfaction have a larger impact on this population, because they have less agency for changing their job. 
There was not a statistically significant difference between disability category or type of high school exit in job satisfaction for IWD when controlling for job interest, however there was a difference between competitive and non-competitive employment. Individuals with intellectual disabilities struggle with cognitive functioning. Cognitive ability is a concern when answering survey questions, a person must have information available, accessible, generatable, and known. Furthermore, many individuals with intellectual disabilities and autism struggle with communication skills. It is important to note that many of the surveys were answered by parents/guardians that may not have firsthand knowledge of the IWD's work experience. Lastly, this study analyzed jobs obtained just one year after exiting high school and may not represent the individuals desired job outcome.

\section{Generalization}

Tracking and analyzing postsecondary transitions for individuals with disabilities (IWD) as they exit high school into adult life, is required by IDEA Indicator 14. The data captured in this dataset also gives insight into how transition-education programs are working (20 USC 1416(a)(3)(B); Oertle \& O'Leary, 2017). As previously noted, each state is required to collect this data; however, it is essential to note that there is no mechanism for analyzing the data across states, and it is not analyzed on a national level. The National Longitudinal Transition Study- 2 (NLTS-2; 2011) analyzed data from a nationwide study of IDW five years after graduation. However, the NLTS-2 findings differ from this study because they looked at IWD in a much different time frame (Sanford et al., 2011). Most people, both those with and without disabilities, do not keep the same job they obtained after graduating from high school for life. In fact, according to 
the US Department of Labor Statistics (2018), the median job tenure of adults ages 19-21 is less than one year. This study's results could be used by states similar to Kentucky, states that have both urban and rural populations, to analyze programming for IWD. Further, it could compare states to see how specific programs, such as the Career Work Experience Certification (CWEC) in Kentucky, might impact post-school outcomes for individuals with intellectual disabilities.

\section{Useability}

The results of this research study could be useful to a variety of professionals who are making decisions about postsecondary education for IWD, including special education teachers, district directors of special education, and policymakers. Around 30\% of IWD that exit high school are not engaged in either postsecondary education or employment (KYPSO, 2020). For individuals that exit with an alternative high school diploma (AHSD), the number of individuals unengaged goes up to 70\% (KYPSO, 2020). Despite these statistics, there is a lot research showing the benefits of IWD having employment. Employment fulfills three basic human needs: survival, social connection, and self-determination/well-being (Bluesten, 2008). Therefore, there is a need to ensure that students are receiving good postsecondary education while they are in high school, in an attempt to improve outcomes.

\section{Special Education Teachers}

Special education teachers could use the results of this study to determine what type of programming needed to ensure proper postsecondary transition education for IWD. Specifically, when considering educational experiences for students with intellectual disabilities, teachers need guidance on what is considered a successful post- 
school outcome and the steps needed in order for students to obtain them. Special education teachers are responsible for writing and implementing the student's Individual Education Program (IEP). Once a student turns 16 years old, the IEP aligns with the students' postsecondary goals. However, many teachers lack the knowledge of what postsecondary outcomes look like in real life and fail to write realistic goals (Murray \& Doren, 2013). Knowledge gained from this study and studies like this may help write better IEPs and provide better transition experiences.

The literature review and the results of this study point to self-advocacy as a vital part of transition education (Assselin, 2014; Shaw, 2009; Van Hees et al., 2018; White et al., 2017). Students transitioning from high school to work or educational settings have very similar needs that require them to advocate for themselves. As students enter college or a work setting, they need to be able to discuss their disability with professors or employers and request the accommodations and modifications they need to be successful (Dutta et al., 2009; Shaw, 2009; White et al., 2017). One way to accomplish this is through engaging students in Pre-Employment Transition Services (Pre-ETS) programming. The five Pre-ETS, (a) job exploration, (b) work-based learning, (c) workplace readiness, (d) postsecondary counseling, and (e) self-advocacy, provide the structure for proper postsecondary education planning (Carlson et al., 2019; WIOA, 2014). Allowing students to engage in Pre-ETS activities could lead to better post-school outcomes. Additionally, for individuals with intellectual disabilities in Kentucky, the Career Work Experience Certification (CWEC), is a course of students for students working towards an alternative high school diploma (AHSD). The CWEC provides 
standards and coursework and requires students to engage in work-based learning opportunities that prepare them for postsecondary outcomes (KDE, 2020).

Another consideration for teachers when looking at this study is the impact of an AHSD on an IWD long term outcomes. While there were no significant differences between a general education diploma and AHSD within this study, not earning a high school degree certainly impacts one's ability to enroll in high education or vocational training programs. This limits their ability to obtain high paying jobs. According to the US Bureau Labor Statistics (2018) individuals without a high school diploma make less money and have higher unemployment rates than those with a high school diploma, and even less when compared to individuals with some college education. Individuals that complete a college degree or higher see increasingly higher wages, and lower unemployment. For this reason, teachers and Admissions and Release Committees (ARC) should consider the long-term effects of a student completing programing to earn AHSD versus a high school degree.

\section{Directors of Special Education (DoSE)}

Administrators can use the results of this study to consider what type of programming offered and required of students in their districts. District leadership can help teachers and students by emphasizing transition planning and programming and providing funding. The Workforce Innovation and Opportunity Act (WIOA; P.L. 113128) requires $15 \%$ of the Office of Vocational Rehabilitation (OVR) funding for Pre-ETS programming. Local school districts can access these services free of charge.

Additionally, the CWEC coursework is provided by teachers and does not require

additional funding (KDE, 2020). However, for each of these programs, there is a need for 
staff professional development, transportation, and community connections. Local districts can help students by providing the necessary training and transportation costs to ensure that students can participate in programs that improve postsecondary outcomes.

\section{Policy Makers}

National, state, regional, and local policymakers have different viewpoints when accessing research like this study. IDEA Indicator 14 is a federal accountability requirement for each state. While there is no current mechanism for analyzing data across states, policymakers working on a national level can access research like this study to examine the outcomes of IWD in their states. The outcomes shared in this research study showed a need to examine non-competitive employment options for IWD. In Kentucky, a bill has been put through the general assembly to close the door on sheltered employment and redefine "employee" to include those workers already in sheltered employment (Senate Bill 76).

Further, Senate Bill 76 seeks to eliminate sheltered employment as a choice for covered services and support. State policymakers could refer to the results of this study that show that workers in sheltered employment do show lower levels of job satisfaction. Regional policy makers could look to the results of this study to decide what kind of services are needed in the area, including those provided by the Office of Vocational Rehabilitation. Finally, local policymakers, such as school board members, can use this study, and studies like this, to examine programs that are already in existence for postsecondary transition for IWD. Further, local school districts could also look to this study to see the benefits of the Youth One Year Out survey and encourage better systems for collecting responses. More responses to this survey could help local school districts 
analyze their programming for students with disabilities and ensure those programs lead to better outcomes for IWD.

\section{Study Limitations}

This investigation had several limitations that might have affected its outcome. These limitations should be taken into account when reviewing the conclusions of the investigation. Furthermore, the limitations should be considered when planning training initiatives in the Commonwealth. Each limitation addressed below had a consistent impact across all of the research questions.

The results of this study are based on a limited body of data that comprises one snapshot of recent high school exits and their immediate outcomes and should be interpreted as such. The scope of this research does not extend to outcomes that may arise long-term; for example, any newly employed recent graduate may ultimately choose to seek employment elsewhere. This is a significant limitation, but there is a clear potential for conducting future research. Whether a change or loss of one's employment may affect the conclusions presented thus far is a question that would be best addressed by longitudinal studies, tracking discrete cohorts of high school graduates, and documenting their employment status and satisfaction over time.

Another limitation of this study was that there was a relatively low response rate. According to the Kentucky Post School Outcomes (KyPSO) website only around 55\% of the participants contacted responded to the survey. The U.S. Office of Management and Budget $(\mathrm{OMB})$ recommends an $80 \%$ response rate on federally funded public policy research (Hendra \& Hill, 2019). Given that Kentucky has both a rural and urban population, more responses on the survey would allow for better sampling distribution 
and make the overall study more powerful (Shavelson, 1996). However, while this is a limitation, one must consider that the students are contacted one year post high school exit. School districts use contact information they have from the time of exit, this can pose significant difficulties in finding and surveying former students.

Another limitation of this study was that the survey could be answered by either the individual themself, or a parent/guardian or other member of their family. While family members can be a good source of information about individuals living in their households, research shows each person has the potential to answer questions differently (Eapen \& Revesz, 1999). It is reasonable to assume that answering questions about one's job satisfaction is preferable, as the individual has first-hand knowledge of their job setting.

Finally, while the data collected for this study is mandated by IDEA Indicator 14 compliance, the Youth One Year Out survey may not be the best measure for individuals with intellectual disabilities. Many students with intellectual disabilities struggle with answering questions and may not fully understand what is asked of them. Additionally, the ability to answer the question "I don't know" could be problematic when collecting data for this survey. Individuals may use the "I don't know" response when they are unable to answer the question due to cognitive functioning or ability to generate the information (Beatty et al., 1998). This limitation was consistent across all of our research questions, the levels of "I don't know" responses did contribute to the significance of each question. Furthermore, the "I don't know" response also gives insight into the individual's ability to advocate for the necessary information that people typically learn about their job. 


\section{Implications for Future Research}

This study aimed to add to the research on what constitutes job satisfaction for individuals with intellectual disabilities, using an existing measure the Youth One Year Out (YOYO) survey. As outlined in the study limitations, surveys may yield limited results when used with a population of individuals with cognitive disabilities and limited communication skills. Future research on this topic could include using other methods such as Photovoice to allow alternative means of communicating job satisfaction. According to Wang and Burris (1994), Photovoice uses a photographic technique to allow participants to represent and describe their community. Participants can take pictures to document various aspects of their lives, then use the photographs to help them during the interview process. For an IWD the use of these visual supports could help them provide more explicit details about their work environment, and more fully describe the aspects of their job that they enjoy, and those that they do not enjoy.

While the YOYO gives a snapshot of where IWD are one year after exiting high school, it does not give us information past that year. A study conducted using similar questions five, ten, or even 15 years after high school exit could provide more information about post-school outcomes for IWD. One assumes that as individuals get older, they are less likely to live with their parents. They have had an opportunity to complete training or postsecondary education programs and are more established in their jobs. The last study of this kind is the National Longitudinal Transition Study 2 (NLTS2) in 2011 and examined postsecondary outcomes of IWD 5 years post-high school exit. Certainly, a study investigation of this kind would contribute to the literature on this topic. 
Within the YOYO data set are a few areas for future research. The first is analyzing various outcomes of the "I don't know" responses. While "I don't know" could mean that the IWD does not recall information asked of them, it could also be speculated that the response shows a lack of self-advocacy skills. Analyzing the "I don't know" response could take different forms. A researcher could examine the relationship between the disability category and "I don't know" responses. For this study the "I don't know" responses were eliminated from the data set, given the perspective of self-advocacy, a researcher could run the same analysis of the data, but coding "I don't know" as a "no" response.

The Career Work Experience Certification (CWEC) is a new program in Kentucky (KDE, 2020) for students working towards an alternative high school diploma (AHSD). This program was fully implemented for the 2018-2019 school year. A researcher could use the YOYO data set to compare outcomes of students with AHSD after this program is in full implementation. This would be of particular interest to policy makers, directors of special education, and teachers, to analyze the programming provided through the CWEC coursework.

Finally, using the YOYO data researchers could look at longitudinal studies of outcomes for IWD over time. This would give insight into programming and other trends to improve postsecondary outcomes. A longitudinal study would also give insight into the nature of postsecondary transitions in Kentucky, the questions within the YOYO survey, and post school outcomes over time. 


\section{Summary}

The purpose of this study was to identify the relationship between disability category, manner of exiting high school, and employment type on job satisfaction for students with intellectual disabilities. In order to examine postsecondary transitions for IWD. The conclusions are based on a limited body of data that comprises one snapshot of recent high school exits and their immediate outcomes and should be interpreted as such. The research in this study could be useful to a variety of professionals who are making decisions about postsecondary education for IWD, including special education teachers, district directors of special education, and policymakers. Around 30\% of IWD that exit high school are not engaged in either postsecondary education or employment. This number is much higher for individuals with intellectual disabilities, as many as $70 \%$ are unengaged after exiting high school. When considering educational experiences for students with intellectual disabilities, teachers need guidance on what is considered a successful post-school outcome and the steps needed in order for students to obtain them. While there are many limitations to this study, including its ability to measure the outcomes of individuals with intellectual disabilities accurately, it does provide a snapshot of where students are immediately after leaving high school. Using the YOYO dataset and other means for analyzing job satisfaction for IWD contributes to the literature and provides insight into programming that may help students have more successful post school outcomes. 


\section{REFERENCES}

Akkerman, A., Janssen, C. G. C., Kef, S., \& Meininger, H. P. (2014) Perspectives of employees with intellectual disabilities on themes relevant to their job satisfaction. An explorative study using Photovoice. Journal of Applied Research in Intellectual Disabilities, 27, 542-554.

Alper, S., \& Raharinirina, S. (2006). Assistive technology for individuals with disabilities: A review and synthesis of the literature. Journal of Special Education Technology, 21(2), 47-64.

Alsaman, M. A., \& Lee, C. L. (2017). Employment outcomes of youth with disabilities in vocational rehabilitation: A multilevel analysis of RSA-911 data. Rehabilitation Counseling Bulletin, 60(2), 98-107.

Americans with Disabilities Act of 1990, 42 U.S.C. $§ 12101$ et seq.

Asselin, S. B. (2014). Learning and assistive technologies for college transition. Journal of Vocational Rehabilitation, 40(3), 223-230.

Beatty, D., Herrmann, C., Puskar, J. Kerwin, P. (1998). 'Don't now' responses in surveys: Is what I know what you want to know and do I want you to know it? Memory, 6(4), 407-426.

Betz, N. E. (2007). Career self-efficacy: Exemplary recent research and emerging directions. Journal of Career Assessment, 15, 403-422.

Biggs, E., \& Carter, E. (2016). Quality of life for transition-age youth with autism or 
intellectual disability. Journal of Autism \& Developmental Disorders, 46(1), 190 204.

Blustein, D. L. (2008). The role of work in psychological health and well-being. American Psychologist, 63, 228-240.

Bonham, G. S., Basehart, S., Schalock, R. L., Marchand, C. B., Kirchner, N., \& Rumenap, J. M. (2004). Consumer-based quality of life assessment: The Maryland ask me! Project. Mental Retardation, 42(5), 338-355.

Bureau of Labor Statistics. (2011). Persons with a disability: Labor force characteristics summary. Retrieved from http://www.bls.gov/news.release/disabl.nr0.htm

Bureau of Labor Statistics, U.S. Department of Labor. (2016). Persons with a disability: Labor force characteristics - 2015. (USDL-16-1248). Retrieved from http://www.bls.gov/news.release/disabl.htm

Career Readiness Partner Council. (2013). Building blocks for change: What it means to be career ready. Retrieved from http://careerreadynow.org/ docs/CRPC_4pagerB.pdf

Carl D. Perkins Vocational and Applied Technology Education Act. (1990). Pub. L. No. 101-392, 104 Stat. 756.

Carl D. Perkins Vocational Education Act. (1984). Pub. L. No. 98-524, 98 Stat. 2435.

Carlson, S. R., Thompson, J. R., \& Monahan, J. (2020). An analysis of state PreEmployment Transition Services policies. Journal of Vocational Rehabilitation, $52(1), 43-59$

Carter, E. W., Austin, D., \& Trainor, A. A. (2012). Predictors of postschool employment 
outcomes for young adults with severe disabilities. Journal of Disability Policy Studies, 23(1), 50-63. https://doi.org/10.1177/1044207311414680

Carter, E. W., Swedeen, B., \& Moss, C. K. (2012). Engaging youth with and without significant disabilities in inclusive service learning. Teaching Exceptional Children, 44(5), 46-54.

Cease-Cook, J., Fowler, C., \& Test, D. W. (2015). Strategies for creating work-based learning experiences in schools for secondary students with disabilities. Teaching Exceptional Children, 47(6), 352-358.

Cimera, R. E., Gonda, J., \& Vaschak, J. (2015). Are high schools referring transition-age youth with intellectual disabilities to vocational rehabilitation? A state-by-state analysis. Journal of Vocational Rehabilitation, 42, 263-270.

Claes, C., Hove, G., Loon, J., Vandevelde, S., \& Schalock, R. (2010). Quality of life measurement in the field of intellectual disabilities: Eight principles for assessing quality of life-related personal outcomes. Social Indicators Research, 98(1), 6172.

Conley, D. T. (2010). College and career ready: Helping all students succeed beyond high school. San Francisco, CA: Jossey-Bass

Cushing, L. S., Parker-Katz, M., Athamanah, L. S., Walte, S. A., \& Pose, K. M. (2019). Transition Trends Associated with Topic Focus Since 1990: A Literature Review. Remedial and Special Education, 0741932519835926.

DeStefano, L., \& Snauwaert, D. (1989). A Value-Critical Approach to Transition Policy Analysis. 
disABLEd, (2020). What Is Considered a Reasonable Accommodation Under the Americans With Disabilities Act in 2020? Retrieved August 25, 2020, from https://www.disabledperson.com/blog/posts/what-is-considered-a-reasonableaccommodation-under-the-americans-with-disabilities-act-in2020?keyword=ada + act

Doren, B., Yan, M. C., \& Tu, W. M. (2013). Key program features to enhance the school-to-career transition for youth with disabilities. The Prevention Researcher, 20(2), 11-14.

Dutta, A., Schiro-Geist, C., \& Kundu, M. M. (2009). Coordination of postsecondary transition services for students with disabilities. Journal of Rehabilitation, 75(1), $10-17$.

Eapen, V., \& Revesz, T. (1999). Self-perception profile in children with cancer: Self vs. parent report. Psychological Reports, 84(2), 427. https://doiorg.echo.louisville.edu/10.2466/pr0.1999.84.2.427

Education Amendments of 1972, 20 U.S.C. $§ 1681$ et seq.

Education Amendments of 1974. Pub. L. No. 93-380, 88 Stat. 580.

Education of All Handicapped Children Act of 1975, 20 U.S.C. $§ 1401$ et seq.

Education of the Handicapped Act of 1970. Pub. L. No. 91-230, § 601-662, 84 Stat. 175.

Education of the Handicapped Amendments of 1986, 20 U.S.C. $§ 1401$ et seq.

Elementary and Secondary Education Act of 1965, 20 U.S.C. $§ 6301$ et seq.

Every Student Succeeds Act (2018). Retrieved November 10, 2019, from https://ncd.gov/sites/default/files/NCD_ESSA-SWD_Accessible.pdf Farrington, C. A., Roderick, M., Allensworth, E., Nagaoka, J., Keyes, T. S., Johnson, D. 
W., \& Beechum, N. O. (2012). Teaching adolescents to become learners. The role of non- cognitive factors in shaping school performance: A critical literature review. Chicago, IL: University of Chicago Consortium on Chicago School Research.

Flexer, R. W., Baer, R. M., Luft, P., \& Simmons, T. J. (2013). Transition planning for secondary students with disabilities, 4th edition. Upper Saddle River, NJ: Prentice Hall.

Grigal, M., Hart, D., \& Weir, C. (2012). A survey of postsecondary education programs for students with intellectual disabilities in the United States. Journal of Policy \& Practice in Intellectual Disabilities, 9(4), 223-233.

Greene, G. (2009). Transition pathways. In C. A. Kochhar-Bryant \& G. Greene (Eds.), Pathways to successful transition for youth with disabilities: A developmental process (2nd ed., pp. 264-293). Upper Saddle River, NJ: Merrill/Prentice Hall

Gold, P. B., Fabian, E. S., \& Luecking, R. G. (2013). Job acquisition by urban youth with disabilities transitioning from school to work. Rehabilitation Counseling Bulletin, 57(1), 31-45.

Grigal, M., Dwyre, A., Emmett, J., \& Emmett, R. (2012). A program evaluation tool for dual enrollment transition programs. Teaching Exceptional Children, 44(5), 3645.

Halpern, A. S. (1985). Transition: A Look at the Foundations. Exceptional Children, $51(6), 479-486$.

Halpern, A. S. (1993). Quality of life as a conceptual framework for evaluating transition outcomes. Exceptional Children, 59, 486-498. 
Halpern, A. S., Nave, G., Close, D. W., \& Nelson, D. (1986). An empirical analysis of the dimensions of community adjustment for adults with mental retardation in semi-independent living programs. Australia and New Zealand Journal of Developmental Disabilities, 12(3), 147-157.

Hart, D., Zimbrich, K., \& Parker, D. R. (2005). Dual enrollment as a postsecondary education option for students with intellectual dis- abilities. In E. E. Getzel \& P. Wehman (Eds.), Going to college (pp. 253-267). Baltimore, MD: Paul H. Brookes.

Hendra, R., \& Hill, A. (2019). Rethinking response rates: New evidence of little relationship between survey response rates and nonresponse bias. Evaluation Review, 43(5), 307-330.

Hofmans, J., De Gieter, S., \& Pepermans, R. (2013). Individual differences in the relationship between satisfaction with job rewards and job satisfaction. Journal of vocational behavior, 82(1), 1-9.

Honeycutt, T., Martin, F., \& Wittenburg, D. (2017). Transitions and vocational rehabilitation success: Tracking outcomes for different types of youth. Journal of Vocational Rehabilitation, 46(2), 137-148.

Honeycutt, T., Thompkins, A., Bardos, M., \& Stern, S. (2015). State differences in the vocational rehabilitation experiences of transition-age youth with disabilities. Journal of Vocational Rehabilitation, 42(1), 17-30.

Individuals with Disabilities Education Act of 1990, 20 U.S.C. $§ 1400$ et seq. Individuals with Disabilities Education Act Amendments. (1997). Pub. L. No. 105-17. Individuals with Disabilities Education Act Regulations. (1997). 34 C.F.R. $§ 300.533$ et 
seq.

Individuals with Disabilities Education Improvement Act of 2004. (2004), 20 U.S.C. $\S$ 1400 et seq.

Ingvarsson, E. T., \& Hollobaugh, T. (2010). Acquisition of intraverbal behavior:

Teaching children with autism to mand for answers to questions. Journal of Applied Behavior Analysis, 43(1), 1-17.

Institute of Education Science: National Center for Special Education Research (2019).

National longitudinal transition study 2. Retrieved from:

https://ies.ed.gov/ncser/projects/nlts2/

Johnson, D. R. (2012) Policy and adolescent transition education. In Wehmeyer, L., M., Webb, W., K. (Eds), Handbook of Adolescent Transition Education for Youth with Disabilities. New York, NY: Routledge

Johnson, D. R., \& Sharpe, M. N. (2000). Results of a national survey on the implementation transition service requirements of IDEA of 1990. Journal of Special Education Leadership, 13(2), 15-26.

Johnson, D. R., Stout K. E., \& Thurlow M. L. (2009). Diploma options and perceived consequences for students with disabilities, Exceptionality, 17, 3, 119-134, DOI: $10.1080 / 09362830903028390$

Kena, G., Hussar, W., McFarland, J., de Brey, C., Musu-Gillette, L., Wang, X., Velez, E. D. (2016). The condition of education 2016 (NCES 2016-144). Washington, DC: NCES, IES, U.S. Department of Education

Kentucky Department of Education (2008). Kentucky Administrative Regulations (Special Education Programs, 707 KAR 1:002 - 707 KAR 1:380) Frankfort, KY. 
Kentucky Department of Education (2019). Guidance for Admissions and Release Committees (ARCs) on Participation Decisions for the Kentucky Alternate Assessment, Frankfort, KY.

Kentucky Department of Education (2020). Kentucky Alternate Assessment Career Work Experience Certification Administration Guide, Frankfort, KY.

Kentucky Post School Outcomes. (2014) 2014 Annual Report.

Kentucky Post School Outcomes. (2020). Youth One Year Out data. Data for public use. Retrieved from: http://www.kypso.org Kohler, P. (1993). Best practices in transition: Substantiated or implied? Career Development for Exceptional Individuals, 16(2), 107-121.

Kohler, P. D., \& Field, S. (2003). Transition-focused education: Foundation for the future. The Journal of Special Education, 37(3), 174-183.

Kohler, P. D., Gothberg, J. E., Fowler, C., and Coyle, J. (2016). Taxonomy for transition programming 2.0: A model for planning, organizing, and evaluating transition education, services, and programs. Western Michigan University. Available at www.transitionta.org.

Lee, A. M. (1975). Learning a living across the nation: Project baseline. Flagstaff, AZ: Northern Arizona University.

Lindstrom, L., Doren, B., \& Miesch, J. (2011). Waging a living: Career development and long-term employment outcomes for young adults with disabilities. Exceptional Children, 77(4), 423-434.

Lombardi, A. R., Kern, L., Flannery, K. B., \& Doren, B. (2017). Is College and Career Readiness Adequately Addressed in Annual and Postsecondary Goals? Journal of 
Disability Policy Studies, 28(3), 150-161.

Malin, J. R., Bragg, D. D., \& Hackmann, D. G. (2017). College and career readiness and the Every Student Succeeds Act. Educational Administration Quarterly, 53(5), 809-838. https://doi-org.echo.louisville.edu/10.1177/0013161X17714845

Mazzotti, V. L., \& Rowe, D. A. (2015). Meeting the transition needs of students with disabilities in the 21 st century. TEACHING Exceptional Children, 47(6), 298300. doi:10.1177/0040059915587695

Metzel D. B., Boeltzig H., Butterworth J., Sulewski J. S. \& Gilmore D. S. (2007) Achieving community membership through community rehabilitation provider services: are we there yet? Intellectual and Developmental Disabilities, 45, 149 160.

Migliore A., Mank D., Grossi T. \& Rogan P. (2007). Integrated employment or sheltered workshops: preferences of adults with intellectual disabilities, their families, and staff. Journal of Vocational Rehabilitation 26, 5-19.

McConnell, A. E., Martin, J. E., \& Hennessey, M. N. (2015). Indicators of postsecondary employment and education for youth with disabilities in relation to GPA and general education. Remedial and Special Education, 36(6), 327-336.

McDermott, E. R., Donlan, A. E., \& Zaff, J. F. (2019). Self-control and persistence in the transition to adulthood: employment outcomes among individuals with no credential, a GED, and a high school diploma. Compare: A Journal of Comparative \& International Education, 49(5), 742-758. https://doiorg.echo.louisville.edu/10.1080/03057925.2018.1453350

Morningstar, M. E., Lombardi, A., Fowler, C. H., \& Test, D. W. (2017). A college and 
career readiness framework for secondary students with disabilities. Career Development and Transition for Exceptional Individuals, 40(2), 79-91.

Murray, C., \& Doren, B. (2013). The effects of working at gaining employment skills on the social and vocational skills of adolescents with disabilities: A school-based intervention. Rehabilitation Counseling Bulletin, 56(2), 96-107.

Nadeau, R., \& Niemi, R. G. (1995). Educated guesses: The process of answering Factual knowledge questions in surveys. Public Opinion Quarterly, 59(3), 323346. https://doi-org.echo.louisville.edu/10.1086/269480

Newman, L., Wagner, M., Cameto, R., Knokey, A. M., \& Shaver, D. (2010).

Comparisons across time of the outcomes of youth with disabilities up to 4 years after high school: A report of findings from the National Longitudinal 177 Transition Study (NLTS) and the National Longitudinal Transition Study-2 (NLTS2) (NCSER 2010-3008). Menlo Park, CA: SRI International.

Newman, L., Wagner, M., Knokey, A. M., Marder, C., Nagle, K., Shaver, D., Wei, X., (with Cameto, R., Contreras, E., Ferguson, K., Greene, S., and Schwarting, M.) (2011). The post-high school outcomes of young adults with disabilities up to 8 years after high school: A report from the National Longitudinal Transition Study-2 (NLTS2) (NCSER 2011-3005). Washington, DC: NCSER, IES, U.S. Department of Education

No Child Left Behind Act of 2001, 20 U.S.C. 7801

Norman, M. E., \& Bourexis, P. S. (1995). Including students with disabilities in schoolto-work opportunities. Council of Chief State School Officers.

Olympus Research Corporation. (1974). An assessment of vocational education programs 
for the handicapped under Part B of the 1968 Amendments to the Vocational Education Act. Salt Lake City, UT: Olympus Research Corporation.

Oertle, K. M., \& O’Leary, S. (2017). The importance of career development in constructing vocational rehabilitation transition policies and practices. Journal of Vocational Rehabilitation, 46(3), 407-423.

Osborne, J. W. (2016). Regression \& linear modeling: Best practices and modern methods. Sage Publications.

Raue, K., \& Lewis, L. (2011). Students with disabilities at degree-granting postsecondary institutions (NCES 2011-018). U.S. Department of Education, National Center for Education Statistics. Washington, DC: U.S. Government Printing Office.

Rehabilitation Act of 1973, Section 504, 29 U.S.C. § 794.

Rehabilitation Act Amendments. (1992). 29 U.S.C. § 794 et seq.

Rehabilitation, Comprehensive Services, and Developmental Disabilities Act. (1978). Pub. L. No. 95-062.

Riza, D. S., Ganzach, Y., \& Liu, Y. (2018). Time and job satisfaction: A longitudinal study of the differential roles of age and tenure. Journal of Management, 44(7), $2558-2579$.

Sanford, C., Newman, L., Wagner, M., Cameto, R., Knokey, A.-M., \& Shaver, D. (2011). The post-high school outcomes of young adults with disabilities up to 6 years after high school. Key findings from the National Longitudinal Transition Study-2 (NLTS2) (NCSER 2011-3004). Menlo Park, CA: SRI International. Retrieved from http://ies.ed.gov/ncser/pubs/20113004/pdf/20113004.pdf 
Sattler, J. M. (2018). Assessment of children: Cognitive foundations and applications and Resource guide to accompany assessment of children: Cognitive foundations and applications. La Mesa, CA: Jerome M. Sattler, Publisher, Inc.

Schalock, R. L., Verdugo, M. A., Bonham, G. S., Fantova, F., \& Van Loon, J. (2008a). Enhancing personal outcomes: Organizational strategies, guidelines, and examples. Journal of Policy and Practice in Intellectual Disabilities, 5(4), 276285.

Schalock, R. L., Bonham, G. S., \& Verdugo, M. A. (2008b). The conceptualization and measurement of quality of life: Implications for program planning and evaluation in the field of intellectual disabilities. Evaluation and Program Planning, 31(2), 181-190.

Shavelson, R. J. (1996). Statistical reasoning for the behavioral sciences. Boston, Mass: Allyn and Bacon.

Section 504 of the Rehabilitation Act of 1973, 29 U.S.C. $§ 794$.

Siegel, S. (1998). Foundations for a school-to-work system that serves all students. Beyond high school: Transition from school to work, 146-178.

Simonsen, M. L., \& Neubert, D. A. (2013). Transitioning youth with intellectual and other developmental disabilities: Predicting community employment outcomes. Career Development and Transition for Exceptional Individuals, 36(3), 188-198.

Shaw, S. F. (2009). Transition to postsecondary education. Focus on Exceptional Children, 42(2), 1-16.

Shogren, K. A., \& Shaw, L. A. (2016). The Role of Autonomy, Self-Realization, and Psychological Empowerment in Predicting Outcomes for Youth With 
Disabilities. Remedial \& Special Education, 37(1), 55-62.

Statistics Solutions. (2013). Data analysis plan: Linear Regression [WWW Document]. Retrieved from http:/www.statisticssolutions.com/academic-solutions/ member-resources/member-profile/data-analysis-plan-templates/data-analysisplan-linear-regression/

Stetser, M. C., \& Stillwell, R. (2014). Public high school four-year on-time graduation rates and event dropout rates: School years 2010-2011 and 2011-12: First look (NCES 2014-391). Washington, DC: NCES, IES, U.S. Department of Education

Technology-Related Assistance for Individuals with Disabilities Act of 1988, 29 U.S.C. $\S$ 2201 et seq.

Test, D. W., Aspel, N. P. \& Everson, J. M. (2006) Transition Methods for Youth with Disabilities. Upper Saddle River, New Jersey: Pearson

Thurlow, M., Ysseldyke, J., \& Anderson, A. (1995). High school graduation requirements: What's happening for students with disabilities? Minneapolis, MN: University of Minnesota, National Center on Educational Outcomes.

Turnbull, A. P., \& Turnbull, H. R. (1990). Families, professionals, and exceptionality: A special partnership (2nd ed.). Upper Saddle River, NJ: Merrill/Prentice Hall.

U.S. Census Bureau. (2002, November). Demographic trends in the 20th century: Census 2000 special reports. Washington, DC: U.S. Department of Commerce, U.S. Census Bureau.

U.S. Census Bureau. (n.d.). 2010 census data. Washington, DC: Author. Available at: http://2010.census.gov/2010census/data/

U.S. Department of Education. (1995). Seventeenth annual report to Congress on the 
implementation of the Individuals with Disabilities Education Act. Washington, DC: Author.

U.S. Department of Education. (1997). Nineteenth annual report to Congress on the implementation of the Individuals with Disabilities Education Act. Washington, DC: Author.

U.S. Department of Education. (2004). Twenty-sixth annual report to Congress on the implementation of the Individuals with Disabilities Education Act. Washington, DC: Author.

U.S. Department of Education. (2007). Twenty-ninth annual report to Congress on the implementation of the Individuals with Disabilities Education Act. Washington, DC: Author.

U.S. Department of Education. (2008). Special education and rehabilitative services: OSERS OSEP Part B and C state monitoring and formula grants. Washington, DC: Author. Retrieved from: http://www.ed.gov/policy/speced/guid/ idea/monitor/index.html

U.S. Department of Education, Office for Civil Rights. (1987). 1986 elementary and secondary school civil rights survey: National summaries. Arlington, VA: DBS Corporation (subcontract from Opportunity Systems, Inc.).

U.S. Department of Education, Office for Civil Rights. (1994). 1992 elementary and secondary school civil rights compliance report (Draft). Washington, DC: Author.

U.S. Department of Education. Office of Special Education Programs. (2016). Part B state performance plan/annual performance report 2016 indicator analyses. Retrieved from https://osep.grads360.org/\#communities/pdc/documents/12827 
U.S. Department of Health and Human Services. (2000). The Developmental Disabilities Assistance and Bill of Rights Act of 2000.

U.S. Department of Labor. (1991). The revised handbook for analyzing jobs. Washington, DC: Employment and Training Administration.

U.S. Department of Labor. (1991b). What Work Requires of Schools: A SCANS Report for America 2000. The Secretary’s Commission on Achieving Necessary Skills.

U.S. Department of Labor. (1993). Learning a living: A blueprint for high performance (SCANS report). Washington, DC: U.S. Government Printing Office.

US Department of Labor, Bureau of Labor Statistics. (2018). Employee tenure summary. U.S. Department of Labor, Bureau of Labor Statistics (2018). Employment status of the civilian noninstitutional population by disability status and selected characteristics, 2014 annual averages [Economic News Release]. Available from http://www.bls.gov/news.release/disabl.t01.html

U.S. Department of Labor, Bureau of Labor Statistics (2019). Persons with a disability: Labor force characteristics- 2019, https://www.bls.gov/news.release /pdf/disabl.pdf

United States Bureau of Labor Statistics (2018). Measure the value of education. Retrieved from https://www.bls.gov

Van Hees, V., Roeyers, H., \& De Mol, J. (2018). Students with autism spectrum disorder and their parents in the transition into higher education: Impact on dynamics in the parent-child relationship. Journal of Autism \& Developmental Disorders, 48(10), 3296-3310.

Wang C. C. \& Burris M. (1994) Empowerment through photonovella: Portraits of 
participation. Health Education Quarterly 21, 171-186.

Webb, K., Repetto, J., Seabrooks-Blackmore, J., Patterson, K. B., \& Alderfer, K. (2014). Career development: Preparation, integration, and collaboration. Journal of Vocational Rehabilitation, 40(3), 231-238.

Wehmeyer, M. L., Abery, B., Mithaug, D. E., \& Stancliffe, R. (2003). Theory in self-determination: Foundations for educational practice. Springfield, IL: Charles C. Thomas.

Wehmeyer, L., M., \& Webb, W., K. (2011) Handbook of Adolescent Transition Education for Youth with Disabilities. [VitalSource Bookshelf]. Retrieved from https://bookshelf.vitalsource.com/\#/books/9781136869754/

Wei, X., Wagner, M., Hudson, L., Yu, J. W., \& Javitz, H. (2016) The effect of transition planning participation and goal-setting on college enrollment among youth with autism spectrum disorders. Remedial \& Special Education, 37(1), 3-14.

Will, M. (1983). OSERS programming for the transition of youth with disabilities: Bridges from school to working life. Washington, DC: U.S. Department of Education, Office of Special Education and Rehabilitative Services. Available from ERIC database. (ED256 132)

Wilson, M. G., Hoffman, A. V., \& McLaughlin, M. J. (2009). Preparing youth with disabilities for college: How research can inform transition policy. Focus on Exceptional Children 41(7), 1-10.

White, S., Elias, R., Capriola-Hall, N., Smith, I., Conner, C., Asselin, S., Howlin, P., 
Getzel, E., \& Mazefsky, C. (2017). Development of a college transition and support program for students with autism spectrum disorder. Journal of Autism \& Developmental Disorders, 47(10), 3072-3078.

Workforce Innovation and Opportunity Act, Pub. L. 113-128. 29 USC §3101. 128 Stat. 1425-1722 (2014, July 22). Retrieved from https://www.congress.gov/ 113/plaws/publ128/PLAW- 113pub1128.pdf 
APPENDICES 


\section{Appendix A: Youth One Year Out Survey}

Return to User Home Hide All

Interviewer Note (Record your attempts to contact the former student: make a note of dates and times of day):

\section{INTERVIEWER INSTRUCTIONS}

All questions are phrased as though the interviewer were talking directly to the former student(s). However, if the interviewer must ask questions about the former student to a parent/ guardian, rephrase the question as appropriate. "Stress that the parent/guardian's response should reflect what the parent / guardian thinks the former student's response would be.

Please don't read the answer choices out loud. Ask the question and use your judgment to pick the best category for the answer. You can ask for clarification if you don't have enough information.

If you, as the Interviewer, reach someone, introduce yourself and read and/or paraphrase the following script:

"Hello my name is_ and I'm a _title)_ at _ (school)_. We're calling to find out how our students that left school last year are doing now. We want to find out what helps our students be successful after high school. The interview will take around 15 minutes, and all of the information is confidential and private. We do not share your personal information. You can skip any question that you don't want to answer. Doing this interview will not affect any of your benefits, including SSI."

1. Would you (or your son/daughter) be willing to give us your thoughts about how things are going for you now?

- Yes (agreed to be interviewed)

No (contacted, but declined interview)

Could not contact (please try at least three times, at different times/days)

$\begin{array}{lll}\text { Page Title: Respondent } & \end{array}$

Potential Resources: None

2. Respondent (PERSON INTERVIEWED) was

- Former Student

Parent/Guardian

Other

3. If respondent (person interviewed) was NOT the Former Student, why was it necessary to interview someone else?

Page Title: $\quad$ Residence

Potential Resources For Community Living (http://resources.hdiuk.org/directory/directory_category/community-livingL); also see "Residence / Housing"

Resources: section in "Supplemental YOYO Resources"

4. Where did you live for most of last year?

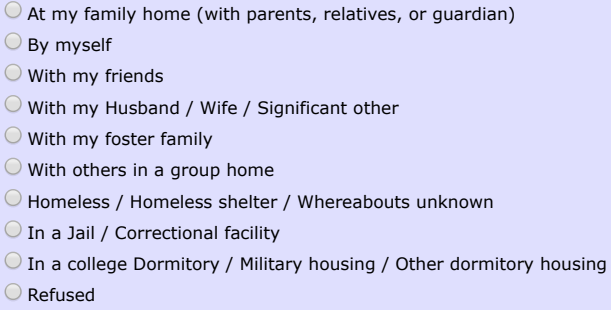


Page Title: Drop Out Probe

Potential Resources: Refer directly to Transition Consultant

5. What are the reasons you left high school without graduating?

DO NOT READ CATEGORIES, CODE ALL THAT APPLY

$\square$ I was failing my classes

$\square$ Bullying/Harassment

$\square$ I had a baby

$\square$ I did not like school

$\square$ I had to work

$\square$ Health Reasons

$\square$ Other

6. What might have helped you stay in school?

DO NOT READ CATEGORIES. CODE ALL THAT APPLY.

$\square$ More flexible hours

$\square$ Classes that would have helped me in real life.

$\square$ Teachers/ Counselors who encouraged me

$\square$ other

Page Title: Employment

Potential Resources: Employment Support Resources (http://resources.hdiuk.org/directory/directory category/employment/

7. From the time you left high school until now, have you ever had a paying job?
Yes
No
Refused

Page Title: Employment Probe

Potential Resources: Employment Support Resources (http://resources.hdiuk.org/directory/directory category/employment/

8. Since leaving high school, have you worked for a total of 3 months (90 days)?

Yes

No

Refused

9. How many hours per week do you usually work?
Less than 20
More than 20 but less than 37.5
More than 37.5 (full-time)

10. Were you paid at least legal minimum wage for your community?
Yes
No
Refused

11. Which, if any, of the following supports / accommodations did you receive at your job?

$\square$ Job coach /employment specialist (someone who offers advice to improve performance)

$\square$ Personal aide or assistant (for personal care needs, not specifically work related)

$\square$ Special equipment like computer, braille, furniture, etc.

12. Are you still working? 


$$
\begin{aligned}
& \text { Yes I am } \\
& \text { No I am not } \\
& \text { Refused }
\end{aligned}
$$

13. On a 5-point scale from "Very Interesting" to "Not interesting at all," how interesting do you think your job is?

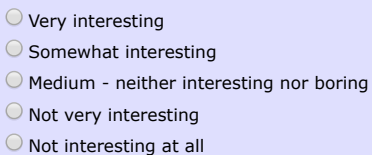

14. As far as you know, do you work with people with and without disabilities?
Definitely yes
Probably yes
Probably not
Definitely not

Don't know

15. As far as you know, do you get similar pay as your coworkers doing the same job?

$$
\begin{aligned}
& \text { Definitely yes } \\
& \text { Probably yes } \\
& \text { Probably not } \\
& \text { Definitely not } \\
& \text { Don't know }
\end{aligned}
$$

16. As far as you know, do you get similar benefits as your coworkers doing the same job?

Definitely yes

Probably yes

Probably not

Definitely not

Don't know

17. As far as you know, do you get similar opportunities for advancement as your coworkers doing the same job?

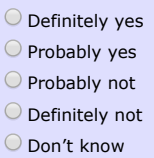

Potential Employment Support Resources (http://resources.hdiuk.org/directory/directory category/employment/ also see "Finance" section of Resources: "Supplemental YOYO Resources"

18. What is the main reason that you are not working, or not working more hours?

$\begin{array}{ll}\text { Page Title: } & \text { Education } \\ \text { Potential } & \text { Vocational Rehabilitation (https://www.hdi.uky.edu/setp/Materials/OVRDirectory212.pdf Also consider local Community College } \\ \text { Resources: } & \text { (http://www.kctcs.edu/ }\end{array}$

19. From the time you left high school until now, have you been in any type of school or training program?
Yes
No
Refused

https://data.kypso.org/yoyo/yoyolnstrument/YOYOInterview.aspx 
Page Title: Education Probe

Potential Resources: Vocational Rehabilitation (https://www.hdi.uky.edu/setp/Materials/OVRDirectory212.pdf Also consider local Community College

Potential Resources: (http://www.kctcs.edu/

20. Please describe the kind of school or training program:

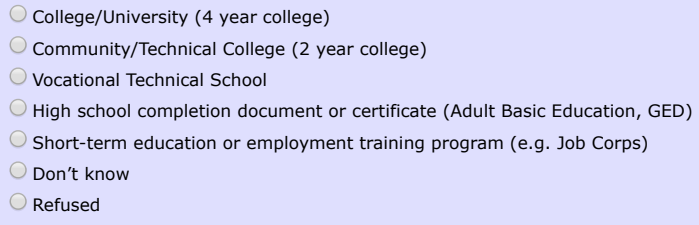

21. Did you complete an entire term / semester?

Yes

No

Don't Know

22. What degree do you expect to get when you are finished with school?

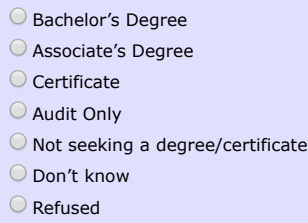

23. Have you ever contacted the Disability Service Coordinator at your post-secondary school or training program?
Yes
No
Refused

24. Do you live with your family while you go to school?
Yes
No
Refused

25. If you faced any problems in your post-secondary school / training program, please let us know what they were.

\begin{tabular}{|ll} 
Page Title: & No Education Probe \\
Potential & Vocational Rehabilitation (https://www.hdi.uky.edu/setp/Materials/OVRDirectory212.pdf Also consider local Community College \\
Resources: & (http://www.kctcs.edu/
\end{tabular}

26. What would you say is the main reason you did not go on to post-secondary education?

\begin{tabular}{|l|l|l}
\hline & \\
\hline Page Title: & No Education Probe \\
Potential & Vocational Rehabilitation (https://www.hdi.uky.edu/setp/Materials/OVRDirectory212.pdf Also consider local Community College \\
Resources: & (http://www.kctcs.edu/
\end{tabular}


27. How do you spend your time?

DO NOT READ CATEGORIES. CODE ALL THAT APPLY.

$\square$ Hobbies/Community Groups/Religious Activities

$\square$ Spend time at home with or without others

$\square$ Go to appointments related to disability services \& supports

$\square$ Unpaid work outside the home (including family business)

$\square$ Unpaid work within the home (chores, care for family)

\section{Page Title: Community}

Potential Additional Resources (http://resources.hdiuk.org/directory/directory category/additional-resources/ also "Recreation," "Transportation," and

Resources: "Voting" sections in "Supplemental YOYO Resources"

28. Do you have a driver's license?
Yes
No
Refused

29. Are you registered to vote?

Yes

No

Refused

30. Please name the most important thing during high school that helped you in your life right now (For e.g. high school programs, classes,

agencies).

31. Since leaving high school, have you had any contact (phone, letter, or face-to-face) with a counselor from the Office of Vocational

Rehabilitation?
Yes
No
Don't Know
Refused

32. If "yes," please describe the type of help you are getting:

33. That was the last question of the interview. Is there anything else you would like to add about how things have been going for you since you left school?

Thank Former Student for Doing Interview

"Thank you so much for talking with us. We have talked about a number of services that young people with disabilities use. If you would like more

information about these services I can give you the name and phone number for your regional transition consultant. Would you like that

information?"

If so: 
34. INTERVIEWERS COMMENTS: (If you as the interviewer have any additional notes or thoughts that you gathered during this interview regarding this former students' transition from high school to adult life, please add them here):

35. What information was shared with the respondent?

$\square$ Transition consultant

$\square$ Vocational Rehabilitation

$\square$ Medicare / Medicaid

$\square$ Michelle P. Waiver

$\square$ Information related to employment (including supported employment)

$\square$ Information related to higher education

$\square$ Interviewer's personal information

Prev Next

Proceed 


\section{Appendix B: Completed IRB Application}

\section{IRB Study Application (Version 1.2)}

\subsection{General Information}

*Please enter the full title of your study:

Job Satisfaction for Individuals with Disabilities

*Please enter the Short Study Title you would like to use to reference the study:

Job Satisfaction for IWD

* This field allows you to enter an abbreviated version of the Study Title to quickly identify this study.

\subsection{Add Department(s)}

2.1 List the departments associated with this study. Add the Principal Investigator's department as the PRIMARY DEPARTMENT. For research conducted at a Norton facility add: Norton Healthcare. For research conducted at a Jewish Hospital/KyOne facility (e.g. Frazier, St Mary' s, etc) add: Ky One Health. For research conducted at University Hospital/James Graham Brown Cancer Center add: University Hospital:

\subsection{Assign key study personnel (KSP) access to the project}

3.1 * Please add a Principal Investigator for the study:

Cooper, Katherine $\mathrm{M}$

3.2 In this section, please add any project personnel that needs to have access to the submission or will need to approve the submission. In the case of the Undergraduate Research Symposium, your mentor and co-authors would be included in this section.

A) Additional Investigators

Immekus, Jason C, Ph.D.

Co-Investigator

B) Research Support Staff

3.3 *Please add a Study Contact. The Study Contact(s) will receive all important system notifications along with the Principal Investigator. If applicable, please add Kentucky One Health, Norton Healthcare or UMC Research as a study Contact. Adding someone here does not add them as study personnel. 
Cooper, Katherine $\mathrm{M}$

Immekus, Jason C, Ph.D.

The Study Contact(s) will receive all important system notifications along with the Principal Investigator. If applicable, please add Kentucky One Health, Norton Healthcare or UMC Research as a study Contact.

3.4 Please select the Designated Approvers:

Courtade, Ginevra R

Department Chair

4.0 RESEARCH NATURE

4.1 Please select the primary nature of your research. NOTE: If you are a MEDICAL department please ONLY select biomedical.

Biomedical

C Social Behavioral Educational

\title{
5.0
}

\section{APPLICATION TYPES}

\subsection{Which of the following project types bests describes your submission?}

\author{
(c) IRB Application \\ C Case Report \\ Emergency Use (EU) \\ IRB Authorization Agreement (IAA) - Another IRB is IRB of Record \\ Non Human Subjects Research (NHSR)
}

\section{STUDY INFORMATION}

6.14 Give a brief non-technical explanation of the purpose of your study:

The purpose of this study is to analyze the Kentucky Youth One Year Out survey to determine if the disability category, type of high school exit, and job type (competitive vs. non-competitive) employment, is a predictor for job satisfaction for youth one year after high school exit.

6.15 Give a brief non-technical explanation of research methods. For example:

- Study design

- Statistical analysis methods

- Sample size and power analysis

In this study, we will use a Linear Multiple Regression to create a composite score from questions in the Youth One Year Out survey that relate to job satisfaction predictors. The Kentucky Youth One Year Out survey is collected annually by the state to comply with IDEA Compliance Indicator 14 . This will be a secondary data analysis of the data collected in the summer of 2019 . The overall sample size is 2,480 respondents, for this study we will be investigating students with specific disabilities, Other Health Impairment (OHI), Autism, Mild Mental Disability (MMD), and Functional Mental Disability (FMD), for a total of 1,444 respondents.

6.16 
Give a brief non-technical explanation of the procedures that will be performed on or with subjects. For example:

- Surveys

- Assessments or questions that will be administered to subjects

- Interview questions that may be asked

- Data collection tools that will be used

This is a secondary data analysis of existing data from the Kentucky Youth One Year Out survey, which is administered by phone with either the student or the parent/guardian.

6.17 Please select the description which best describes your study:

$\square$ Questionnaire/Survey

$\square$ Interview/Focus Groups

$\sqrt{\checkmark}$ Existing Data Review-Retrospective

$\square$ Data Review-Prospective

$\square$ Other

If you selected other, please explain:

SPONSOR

7.1 What is your funding source? Please check all that apply (at least one selection is required)

$\sqrt{\square}$ Not Funded

I Industry

$\square$ Government

$\square$ Cooperative Group

Toundation

I Internally supported by UofL/JHHS/NHI or UofL Hospital

$\square$ Other

If you selected other, please explain:

\section{STUDY SITES}

8.1 Study Sites (locations where you will be running your study), please select all that apply:

$\square$ UOFL FACILITIES (including Belknap, Shelby, and HSC campuses, Ambulatory Care Building/ACB, Other UofL owned/leased space, UofL Clinics, Cardinal Research Cluster/CRC)

$\square$ UNIVERSITY HOSPITAL/JAMES GRAHAM BROWN CANCER CENTER (including ULH services in UofL Healthcare Outpatient Center/HCOC, CENTER for WOMEN and INFANTS)

$\square$ NORTON HEALTHCARE FACILITIES (including Norton Hospital, Norton Children's Hospital, Norton Audubon Hospital, Norton Brownsboro Hospital, Norton Women's \& Children's St. Matthews, Norton Children's Brownsboro, Norton Brownsboro, Space leased by UofL in NHC facility, Norton Physician Practices)

$\square$ JEWISH HOSPITAL \& ST. MARY'S HEALTHCARE (including Frazier Rehab Institute, Jewish Hospital, Jewish Hosp Med Ctr East, Jewish Hosp Med Ctr NE, Jewish Hosp Med Ctr South, Jewish Hosp Med Ctr SW, Jewish Hosp Outpatient Ctr, Jewish Hosp Rudd Heart Lung, Jewish Hosp Shelbyville, Our Lady of Peace, Sts Mary \& Elizabeth, St Mary Surgery Ctr, Health Resource Ctr, Southern Ind Rehab, Taylor Regional Hosp, VNA Nazareth Home, Jewish Hosp Meade, Jewish Hosp Hand Care)

$\square$ UNIVERSITY OF LOUISVILLE PHYSICIANS GROUP

$\square$ OTHER PRIVATE PRACTICE/PSC

$\square$ VA MEDICAL CENTER (Requires separate submission to VA) 
$\square$ FAMILY AND GERIATRIC MEDICINE sites

$\square$ CLINICAL TRIALS UNIT - HEALTHCARE OUTPATIENT CENTER (HCOC)

$\square$ OWENSBORO MEDICAL HEALTH SYSTEM

$\square$ INTERNATIONAL SITES - with contact information and address

$\square$ SITES OUTSIDE OF KENTUCKY - with contact information and address

$\square$ OTHER SITES - with contact information, address

If you selected other above, please explain. (Include the name and address of all sites you will be utilizing):

Off-Site (Home)

Katherine Cooper

714 E. Maple St.

Jeffersonville, IN 47130

\section{IMPORTANT!! YOU MUST OBTAIN APPROVAL FROM THE STUDY SITE(S) BEFORE YOU BEGIN YOUR STUDY}

REVIEW TYPE

9.1 Which of the following review types do you believe your study meets the regulatory requirements for?
Exempt
(c) Expedited
Full Board

9.2 REQUEST FOR EXPEDITED REVIEW The IRB may find that submitted research meets one of the categories eligible under the regulations for Expedited Review. Carefully read the descriptions of research eligible for expedited review and indicate under which category your research falls.

- Category 1: Clinical studies of drugs and medical devices only when condition (a) or (b) is met: (1)(a) Research on drugs for which an investigational new drug application (21 CFR Part 312) is not required (1)(b) Research on medical devices for which: (1)(b)(i) an investigational device exemption application ( 21 CFR Part 812) is not required; or: (1)(b)(ii) the medical device is cleared/approved for marketing and the medical device is being used in accordance with its cleared/approved labeling.

- Category 2: Collection of blood samples by finger stick, heel stick, ear stick, or venipuncture as follows (2)(a) from healthy, nonpregnant adults who weigh at least 110 pounds. For these subjects, the amounts drawn may not exceed $550 \mathrm{ml}$ in an 8 week period and collection may not occur more frequently than 2 times per week; or (2)(b) from other adults and children, considering the age, weight, and health of the subjects, the collection procedure, the amount of blood to be collected, and the frequency with which it will be collected. For these subjects, the amount drawn may not exceed the lesser of $50 \mathrm{ml}$ or $3 \mathrm{ml}$ per $\mathbf{k g}$ in an 8 week period and collection may not occur more frequently than 2 times per week.

- Category 3: Prospective collection of biological specimens for research purposes by noninvasive means.

- Category 4: Collection of data through noninvasive procedures (not involving general anesthesia or sedation) routinely employed in clinical practice, excluding procedures involving $\mathbf{x}$-rays or microwaves. Where medical devices are employed, they must be cleared/approved for marketing.

- Category 5: Research involving materials (data, documents, records, or specimens) that have been collected, or will be collected solely for non-research purposes (such as medical treatment or diagnosis). 


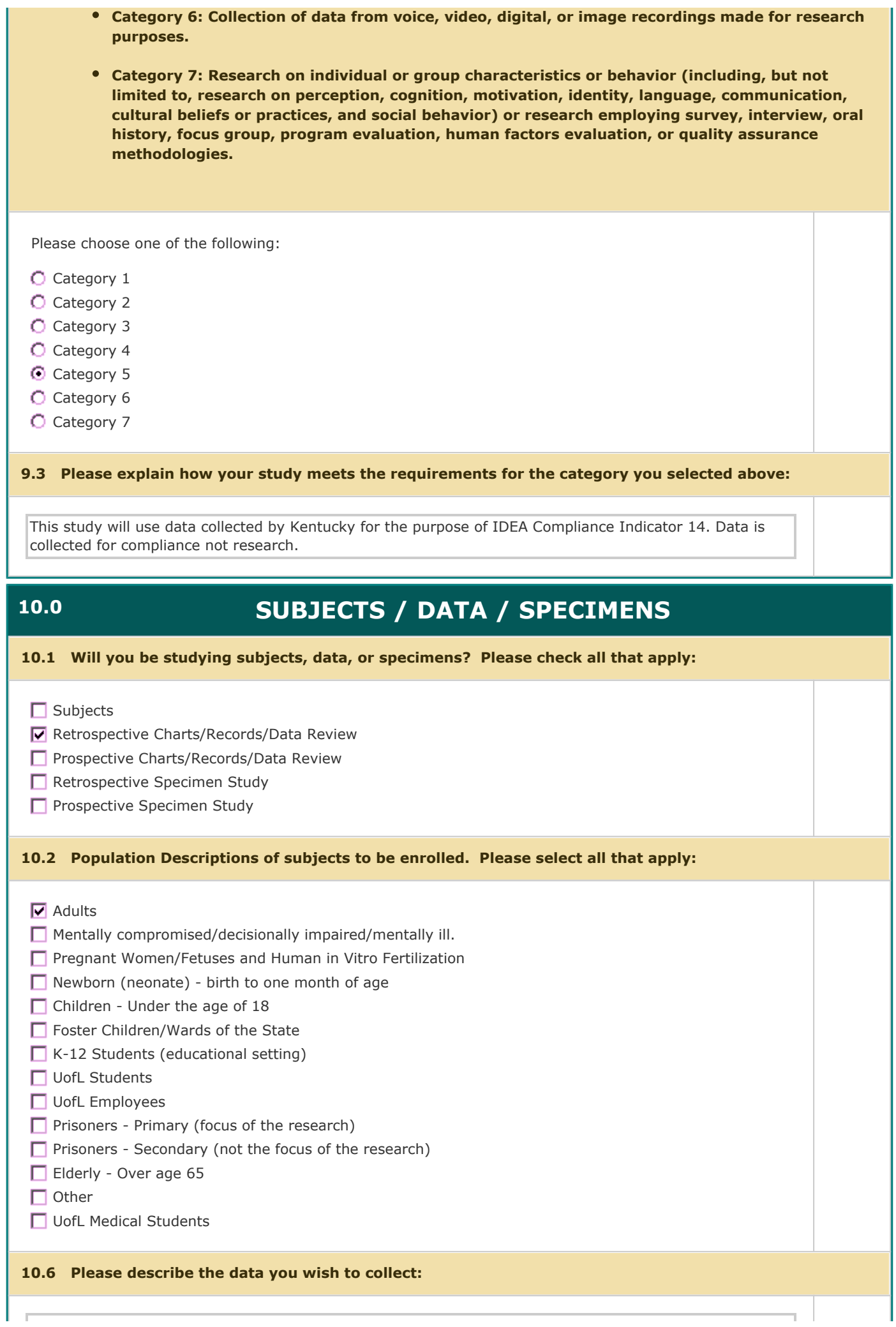


Using the Kentucky Youth One Year Out Survey we want to collect data on predictors of job satisfaction.

10.7 How many charts/records/pieces of data will you review?

We will review one data set, taken from the Youth One Year Out survey.

10.8 If you have a data collection form, please attach it below. You will not need to add this document again in the Initial Review Submission Packet. Please Note: For data collection studies, the data collection form is required and must be attached.

\begin{tabular}{|l|l|l|l|l|l|l|}
\hline Version & Title & Category & $\begin{array}{l}\text { Expiration } \\
\text { Date }\end{array}$ & $\begin{array}{l}\text { Document } \\
\text { Outcome }\end{array}$ & $\begin{array}{l}\text { Checked Out } \\
\text { View } \\
\text { Document }\end{array}$ \\
\hline 1.0 & IRB Protocol & Protocol & & & $34.27 \mathrm{~KB}$ \\
\hline \multirow{2}{*}{$\begin{array}{l}\text { YOYO Interview } \\
\text { Questions 2019 }\end{array}$} & Questionnaire & & & 375.65 \\
\hline
\end{tabular}

11.0

RISK / BENEFIT

11.1 As the investigator, what is your analysis of the potential risk versus potential benefit of participating in this study? Justify the risk in terms of the potential scientific yield in relation to the anticipated benefits to the subjects.

This is a secondary data analysis and poses no potential risk to the participants in the study.

11.2 What direct and societal benefits do you expect the subjects you enroll to get from this study? If there is no direct benefit to the subjects, simply state that there will be no benefit to the subjects enrolled.

The societal benefits we hope to gain from this study are better practices for transition planning for students with disabilities. There are not benefits to the subjects in the study.

11.3 Does this research involve any of the following that might add additional risk? Please check all that apply:

$\square$ Use of private records including educational records or medical charts?

$\square$ Manipulation of physical, psychological or social variables, such as sensory deprivation, physical stimuli, social isolation, or psychological stresses?

$\square$ Any probing for or presentation of any materials which subjects might consider sensitive, offensive, threatening or degrading?

$\square$ Collect information that would be reportable to authorities or collection of information that might render the subject prosecutable under the law (e.g. child abuse, elder abuse, danger to self or others)?

$\square$ Major changes in diet, exercise or sleep?

$\square$ Use of a deceptive technique? (If deception is part of the experimental design, the protocol must include a debriefing procedure which will be followed upon completion of the study or upon withdrawal of a subject.)

$\square$ None of the above

Describe the nature and degree of risk or harm from all of the items checked above. (The described risks /harms must be disclosed in the consent form.)

11.4 What are the specific physical, psychological, social, economic, and legal risks of participating in this study? 
Using the Kentucky Youth One Year Out Survey we want to collect data on predictors of job satisfaction.

10.7 How many charts/records/pieces of data will you review?

We will review one data set, taken from the Youth One Year Out survey.

10.8 If you have a data collection form, please attach it below. You will not need to add this document again in the Initial Review Submission Packet. Please Note: For data collection studies, the data collection form is required and must be attached.

\begin{tabular}{|l|l|l|l|l|l|l|}
\hline Version & Title & Category & $\begin{array}{l}\text { Expiration } \\
\text { Date }\end{array}$ & $\begin{array}{l}\text { Document } \\
\text { Outcome }\end{array}$ & $\begin{array}{l}\text { Checked Out } \\
\text { View } \\
\text { Document }\end{array}$ \\
\hline 1.0 & IRB Protocol & Protocol & & & $34.27 \mathrm{~KB}$ \\
\hline \multirow{2}{*}{$\begin{array}{l}\text { YOYO Interview } \\
\text { Questions 2019 }\end{array}$} & Questionnaire & & & 375.65 \\
\hline
\end{tabular}

11.0

RISK / BENEFIT

11.1 As the investigator, what is your analysis of the potential risk versus potential benefit of participating in this study? Justify the risk in terms of the potential scientific yield in relation to the anticipated benefits to the subjects.

This is a secondary data analysis and poses no potential risk to the participants in the study.

11.2 What direct and societal benefits do you expect the subjects you enroll to get from this study? If there is no direct benefit to the subjects, simply state that there will be no benefit to the subjects enrolled.

The societal benefits we hope to gain from this study are better practices for transition planning for students with disabilities. There are not benefits to the subjects in the study.

11.3 Does this research involve any of the following that might add additional risk? Please check all that apply:

$\square$ Use of private records including educational records or medical charts?

$\square$ Manipulation of physical, psychological or social variables, such as sensory deprivation, physical stimuli, social isolation, or psychological stresses?

$\square$ Any probing for or presentation of any materials which subjects might consider sensitive, offensive, threatening or degrading?

$\square$ Collect information that would be reportable to authorities or collection of information that might render the subject prosecutable under the law (e.g. child abuse, elder abuse, danger to self or others)?

$\square$ Major changes in diet, exercise or sleep?

$\square$ Use of a deceptive technique? (If deception is part of the experimental design, the protocol must include a debriefing procedure which will be followed upon completion of the study or upon withdrawal of a subject.)

$\square$ None of the above

Describe the nature and degree of risk or harm from all of the items checked above. (The described risks /harms must be disclosed in the consent form.)

11.4 What are the specific physical, psychological, social, economic, and legal risks of participating in this study? 
12.1 Will subjects be compensated for their participation in the research study?

Yes $\bullet$ No

\section{0} CONFIDENTIALITY AND PRIVACY

13.1 Will you or any member of your research team have access to or view any of the identifiers listed below?

- Names

- Geographic subdivisions smaller than a state, including street address, city, county, precinct, ZIP codes, and their equivalent geographical codes

- Elements of dates (except year) for dates directly related to an individual, including birth date, admission date, discharge date, date of death; and all ages over 89 and all elements of dates (including year) indicative of such age, except that such ages and elements may be aggregated into a single category of age 90 or older

- Telephone numbers

- Facsimile numbers

- Electronic mail addresses

- Social security numbers

- Medical record numbers

- Health plan beneficiary numbers

- Account Numbers

- Certificate/license numbers

- Vehicle identifiers and serial numbers, including license plate numbers

- Device identifiers and serial numbers

- Web universal resource locators (URLs)

- Internet protocol (IP) address numbers

- Biometric identifiers, including fingerprints and voiceprints

- Full-face photographic images and any comparable images

- Any unique identifiers not mentioned above that may identify a subject

- Yes $\mathrm{O}$ No

You identifed above that you will be accessing or viewing identifiable data. Will you also be collecting data that can identify a human subject?

( Yes $\mathrm{O}$ No

\subsection{Will you be collecting health information?}

Yes $\bullet$ No

13.5 Who will keep the link between the information identfiying a subject and the data?

The link between the information identifying the subject and the data will be kept by the state Youth One Year Out survey data analyst. The information we will have on file will be kept in a password-protected file.

13.6 Will you share any data identifying subjects with anyone other than the research team, e.g. researchers at other instutions, study sponsor,etc.? 
13.7 Describe procedures you will utilize to protect study data. For example: data stored in a locked file cabinet or a password protected computer in a secure room with access limited to the investigator and key personnel)? For information on data security and the University's requirements for data security please contact the Information Security office, isopol@louisville.edu.

Data is stored in a password-protected file, in a password-protected computer.

\section{0 \\ INFORMED CONSENT}

14.1 Please describe the process you will use to obtain informed consent. Describe what will be said to subjects so that they can make an informed decision about whether to participate.

This is a secondary data analysis.

14.2 Please answer the following questions in lay language. Do not write "see consent form".

1. Who will obtain informed consent (PI, sub-PI, coordinator, etc. Use title not given names)?

2. Who will explain the consent to the subject?

3. Approximately how long the subject will have to review the consent?

4. Approximately how much time will the person explaining the consent spend with the subject?

\section{Not applicable}

14.3 What questions will be asked to assess the subject's understanding of the informed consent? Questions should be open-ended and go beyond requiring only a Yes/No response. At least one question should assess whether there is an understanding of the potential conflicts of interest when the subject cannot understand the difference between research and treatment.

\section{Not applicable}

14.4 Please indicate whether you believe your study qualifies for one of the following waivers to the informed consent process. Additional information can be found at: http://louisville. edu/research/humansubjects/policies/020InformedConsentWaiverofConsent.pdf

An unsigned consent form (e.g. preamble) or other unsigned consent procedure (e.g. audio taped verbal consent) will be used as described in 45 CFR 46.117 (Waiver of written documentation of consent)

c A waiver of consent or alteration of required consent elements will be utilized as described in 45 CFR $46.116(d)$

No form of consent will be obtained for this because this is emergency research as described in 21 CFR 50.24 (Waiver of informed consent for emergency research)

A signed consent form WILL be used. This study does not qualify for a waiver of written documentation of consent.

The IRB, in some specific instances, may waive the requirement for informed consent or approve consent procedures that alters some or all elements of the informed consent in accordance with 45 CFR 46.116 (d). The IRB must be able to determine and document that the study meets the five criteria for waiver of informed consent. The investigator must provide protocol specific written justification for the following criteria:

1. The research involves no more than minimal risk to the subjects;

2. A waiver will not adversely affect the rights and welfare of the subjects; 
3. The research could not be practicably carried out without waiver or alteration;

4. Where appropriate, the subjects will be provided with additional pertinent information after participation; and

5. If the research involves using identifiable private information or biospecimens, the research could not practicably be carried out without using such information in an identifiable format.

The research invovles no more than minimal risk to the subjects because:

It is a secondary data analysis.

A waiver will not adversely affect the rights and welfare of the subjects because:

It is a secondary data analysis.

The research could not be practicably carried out without waiver or alteration because:

Not applicable

Where appropriate, the subjects will be provided with additional pertinent information after participation when:

Not applicable

If the research involves using identifiable private information or biospecimens, the research could not practicably be carried out without using such information in an identifiable format because:

Not applicable

\section{0 \\ IRB AUTHORIZATION AGREEMENT (IAA)}

15.1 Will the University of Louisville IRB be the IRB with oversight responsibility for another institution?

Yes

(6) No

16.1 DO NOT START ANY STUDY RELATED ACTIVITIES BEFORE RECEIVING IRB APPROVAL This includes: data collection, chart review, distributing surveys and other study materials, posting study advertisements, soliciting potential subjects, screening potential subjects, etc.

( I acknowledge that I have reviewed the following information above in relation to this submission

16.2 JOURNAL PUBLISHING Journals that follow the International Committee of Medical Journal Editors (ICMJE) Trial Registration Policy require clinical trials to be publicly registered at or prior to first subject enrollment. ICMJE broadly defines interventional clinical trials. Intervention types can include, for example, behavioral treatments and educational programs. Member journals are enforcing this policy and delayed registration risks the inadmissaibility of your article. For more information or questions, please email trialgov@louisville.edu.

16.3 TRAINING BLOCK iRIS will automatically "stop" IRB Initial Submissions that have study personnel who are not showing current Human Subjects \& HIPAA Research Training in the iRIS system. If your submission is stopped, proof of training for the personnel in question must be submitted to the iRIS Service Desk at: https://iris.support.louisville.edu/jira/servicedesk/customer /portal/6. Submissions will not be routed to the IRB until the training has been updated in the iRIS system. Additional information on how to check study personnel training prior to submission and how to submit tickets to the service desk can be found on pages 27-32 in the IRIS Submission 
manual: http://louisville.edu/research/humansubjects/iRISSubmissionManual.pdf Information on how to complete the required Human Subjects and HIPAA Research training can be found at: http://louisville.edu/research/humansubjects/lifecycle/before-you-begin *Block effective as of April, 1, 2017

I acknowledge that I reviewed the information above related to training blocks in iRIS.

( Yes $\mathrm{O}$ No

16.4 CV REQUIRED FOR ALL STUDY PERSONNEL All study personnel must have a valid CV on file in the iRIS system. Approval will not be granted by the IRB for any submission until this action has been completed. Information on how to upload a CV into iRIS can be found at: http://louisville.edu/research/humansubjects/lifecycle/before-you-begin

( I acknowledge that I have reviewed the following information above in relation to this submission

16.5 ADF REQUIRED FOR ALL STUDY PERSONNEL It is University policy that all study personnel must have a current Attestation and Disclosure Form on file in the iRIS system. A study /submission will not be granted approval from the IRB until each member of the study have completed this action. For additional information on this requirement or instructions for how to complete this in iRIS please follow this link: http://louisville.edu/conflictofinterest

- I acknowledge that I have reviewed the following information above in relation to this submission 


\section{Appendix C: IRB Approval Letter}

\section{UNIIERSSIT Of LOUISVILLE}

Human Subjects Protection Program Office

MedCenter One - Suite 200

501 E. Broadway

Louisville, KY 40202-1798

\begin{tabular}{ll}
\hline DATE: & June 24,2020 \\
TO: & Katherine M Cooper, M.Ed \\
FROM: & The University of Louisville Institutional Review Board \\
IRB NUMBER: & 20.0515 \\
STUDY TITLE: & Job Satisfaction for Individuals with Disabilities \\
REFERENCE \#: & 710115 \\
IRB STAFF CONTACT: & Jackie Powell, CIP 852-4101 jspowe01@louisville.edu
\end{tabular}

This study was reviewed and approved with changes on $06 / 23 / 2020$ by the Chair of the Institutional Review Board. The resubmitted changes were approved administratively on $06 / 24 / 2020$. This study was approved through Expedited Review Procedure, according to 45 CFR 46.110(b), since this study falls under Category 5: Research involving materials (data, documents, records, or specimens) that have been collected, or will be collected solely for nonresearch purposes (such as medical treatment or diagnosis)

Category 7: Research on individual or group characteristics or behavior (including, but not limited to, research on perception, cognition, motivation, identity, language, communication, cultural beliefs or practices, and social behavior) or research employing survey, interview, oral history, focus group, program evaluation, human factors evaluation, or quality assurance methodologies

This study now has final IRB approval from 06/24/2020 through 06/23/2023.

This study was also approved through 45 CFR 46.116 (D), which means that it has been granted a waiver of informed consent.

The following items have been approved:

\begin{tabular}{|c|c|c|c|c|}
\hline \multicolumn{5}{|l|}{ Submission Components } \\
\hline Form Name & \multicolumn{2}{|l|}{ Version } & \multicolumn{2}{|l|}{ Outcome } \\
\hline Submit for Initial Review & \multicolumn{2}{|c|}{ Version 1.0} & \multicolumn{2}{|c|}{ Approved as Submitted } \\
\hline $\begin{array}{l}\text { Review Response Submission } \\
\text { Form }\end{array}$ & \multicolumn{2}{|l|}{ Version 2.0} & \multicolumn{2}{|c|}{ Approved as Submitted } \\
\hline $\begin{array}{l}\text { Review Response Submission } \\
\text { Form }\end{array}$ & \multicolumn{2}{|c|}{ Version 1.0} & \multicolumn{2}{|c|}{ Approved as Submitted } \\
\hline IRB Study Application & \multicolumn{2}{|c|}{ Version 1.2} & \multicolumn{2}{|c|}{ Approved as Submitted } \\
\hline \multicolumn{5}{|l|}{ Study Document } \\
\hline \multicolumn{2}{|l|}{ Title } & Version \# & Version Date & Outcome \\
\hline \multicolumn{2}{|l|}{ IRB Protocol } & Version 1.0 & $06 / 15 / 2020$ & Approved \\
\hline \multicolumn{2}{|l|}{ YOYO Interview Questions 2019} & Version 1.0 & $06 / 05 / 2020$ & Approved \\
\hline
\end{tabular}


Your study does not require annual continuing review. Your study has been set with a three year expiration date. If your study is still ongoing you will receive iRIS automated reminders to submit a request to continue your study prior to the expiration date above.

All other IRB requirements are still applicable. You are still required to submit amendments, personnel changes, deviations, etc... to the IRB for review. Please submit a closure amendment to close out your study with the IRB if it ends prior to the three year expiration date.

Human Subjects \& HIPAA Research training are required for all study personnel. It is the responsibility of the investigator to ensure that all study personnel maintain current Human Subjects \& HIPAA Research training while the study is ongoing.

\section{Site Approval}

Permission from the institution or organization where this research will be conducted must be obtained before the research can begin. For example, site approval is required for research conducted in UofL Hospital/UofL Health, Norton Healthcare, and Jefferson County Public Schools, etc...

\section{Privacy \& Encryption Statement}

The University of Louisville's Privacy and Encryption Policy requires identifiable medical and health records; credit card, bank account and other personal financial information; social security numbers; proprietary research data; and dates of birth (when combined with name, address and/or phone numbers) to be encrypted. For additional information: http://louisville.edu/security/policies.

\section{Implementation of Changes to Previously Approved Research}

Prior to the implementation of any changes in the approved research, the investigator must submit modifications to the IRB and await approval before implementing the changes, unless the change is being made to ensure the safety and welfare of the subjects enrolled in the research. If such occurs, a Protocol Deviation/Violation should be submitted within five days of the occurrence indicating what safety measures were taken, along with an amendment to revise the protocol.

\section{Unanticipated Problems Involving Risks to Subjects or Others (UPIRTSOs)}

A UPIRTSO is any incident, experience, or outcome, which has been associated with an unexpected event(s), related or possibly related to participation in the research, and suggests that the research places subjects or others at a greater risk of harm than was previously known or suspected. The investigator is responsible for reporting UPIRTSOs to the IRB within 5 working days. Use the UPIRTSO form located within the iRIS system. Event reporting requirements can be found at: http://louisville.edu/research/humansubjects/lifecycle/event-reporting.

The committee will be advised of this action at a regularly scheduled meeting.

If you have any questions, please contact: Jackie Powell 852-4101 jspowe01@louisville.edu

Full Accreditation since June 2005 by the Association for the Accreditation of Human Research Protection Programs, Inc.

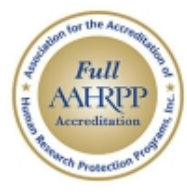




\section{Pete $m$ Lusach}

Peter M. Quesada, Ph.D., Chair

Social/Behavioral/Educational Institutional Review Board

$\mathrm{PMO} / \mathrm{jsp}$

We value your feedback; let us know how we are doing: https://www.surveymonkey.com/r/CCLHXRP

Full Accreditation since June 2005 by the Association for the Accreditation of Human Research Protection Programs, Inc.

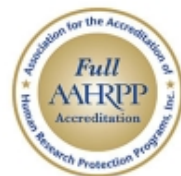




\title{
CURRICULUM VITAE
}

\author{
Katherine Cooper \\ Greater Louisville Education \\ Cooperative Louisville, KY 40218 \\ (502)550-3863 \\ katiecoop@icloud.com
}

\section{Education and Professional Credentials}

\section{Degrees}

$\begin{array}{llll}\text { PhD } & 2020^{*} & \text { University of Louisville } & \begin{array}{l}\text { Curriculum and } \\ \text { Instruction }\end{array} \\ \text { MEd } & 2007 & \text { University of Louisville } & \text { Special Education } \\ \text { BA } & 2002 & \text { Indiana University- Southeast } & \text { Communications }\end{array}$

*Anticipated Graduation Date: December 2020

\section{Licenses Held}

Rank 1 KMS- Professional Certificate for Teaching Exceptional Children--Moderate and Severe Disabilities, Grades Primary Through 12

L11- Approval for Teaching Consultant in Program for Exceptional Children

\section{Professional Experiences}

2018-present Greater Louisville Education Cooperative

Cooperative Consultant- Low Incidence, Assistive Technology and

Transition

2007-2018 Jefferson County Public Schools

Churchill Park School- Goal Clarity Coach

Low Incidence Resource Teacher

MSD Teacher

2013-present Georgetown College

Department of Education, Special Education 
Adjunct Professor

2015-present University of Louisville

Special

College of Education and Human Development, Department of Education

Adjunct Faculty

\section{Publication}

Bauder, D.K., Cooper K., \& Simmons, T. (2020). SAMR strategies for the integration of technology through UDL. In E. Dalton \& S. Gronseth (Eds.), Universal Access Through Inclusive Instructional Design: International Perspectives on UDL. New York, NY: Routledge

Cooper, K., Bauder, D. \& Simmons, T. (2019). Augmented Reality: Changing the reality of your classroom. In K. Graziano (Ed.), Proceedings of Society for Information Technology \& Teacher Education International Conference (pp. 2294-2296). Las Vegas, NV, United States: Association for the Advancement of Computing in Education (AACE). Retrieved March 25, 2019 from https://www.learntechlib.org/primary/p/208022/.

Bauder, D., Cooper, K. \& Simmons, T. (2019). The UDL/SAMR model: Online courses in higher education. In K. Graziano (Ed.), Proceedings of Society for Information Technology \& Teacher Education International Conference (pp. 2241-2245). Las Vegas, NV, United States: Association for the Advancement of Computing in Education (AACE). Retrieved March 25, 2019 from https://www.learntechlib.org/primary/p/208011/

Gronseth, S., Dalton, E., Alvarez, B., Iglesias, I., Vergara, P., Ingle, J.C., PachecoGuffrey, H., Bauder, D., Cooper, K., Anderson, C., Anderson, K., Intatano, V., Semingson, P., Pole, K., Armstrong, K., Boreham, B., Mack, T., Harris, L., Edyburn, D., Arndt, J., Ferguson, B.T., Luo, N. \& Yearta, L. (2019). Using UDLrelated methods in education, teacher training, and job-development for young women with developmental disabilities in India. In K. Graziano (Ed.), Proceedings of Society for Information Technology \& Teacher Education International Conference (pp. 245-249). Las Vegas, NV, United States: Association for the Advancement of Computing in Education (AACE).

\section{Courses Taught}

\section{University of Louisville}

EDSP 520 Assessment of Exceptional Learners: MSD

EDSP 594 Foundational Concepts in Intellectual and Physical Disabilities 
EDSP 664 (Co-taught) Computer Access

EDSP 218 Technology for Students with Disabilities

\section{Georgetown College}

ECE $542 \quad$ Using Technology to Remove Barriers for Students with Disabilities

ECE 565 Typical and Atypical Human Development

ECE 600 Introduction to Teaching Students with Moderate/Severe Disabilities

ECE 602 Curriculum and Instruction for Students with Moderate/Severe Disabilities

ECE 604 Teaching Individuals with Physical and Multiple Disabilities

ECE 606 Transition Services for Students with Disabilities

ECE 608 Field Component in MSD

ECE 612 Language Development and Literacy Instruction

ECE 623/624 Social Skills Development and Community Access

EDU 570 Topics in Universal Design for Learning and Assistive Technology

\section{National Presentations}

Cooper, K., Bauder, D. \& Simmons, T. (2019). Augmented Reality: Changing the Reality of Your Classroom. In K. Graziano (Ed.), Society for Information Technology \& Teacher Education International Conference. Las Vegas, NV, United States: Association for the Advancement of Computing in Education (AACE).

Bauder, D., Cooper, K. \& Simmons, T. (2019). The UDL/SAMR Model: Online Courses in Higher Education. In K. Graziano (Ed.), Society for Information Technology \& Teacher Education International Conference. Las Vegas, NV, United States: Association for the Advancement of Computing in Education (AACE).

\section{Regional Presentations}

\section{Jefferson County Public Schools}

Autism Updates

Transdisciplinary Approach to Instruction

Using Smartboards in the MSD Classroom

Collaborative Teaming

Classroom Management and Organization in the MSD Classroom

Instructional Technology for the Low Incidence Classroom

A Unique Curriculum for the Low Incidence Classroom

Understanding Family Dynamics: Fly Away

Including Samuel: A Look at Inclusive Education

Unique Learning Training

Educational Apps for iPad

Creating Supportive Classroom Climates

Equals Math Curriculum Workshop

Creating a Functional Curriculum

Summer Institute Coordinator Churchill Park School

Team Building
Year

(2012)

(2012)

(2016)

(2016) 
Summer Institute Coordinator Churchill Park School

Working with Instructional Assistants

Book Study: Ghost Boy

Summer Institute Coordinator Churchill Park School

New Instructional Assistant Training

Strategies for Effective Collaboration

Deeper Learning for the MSD Classroom

MSD Curriculum Overview

\section{Greater Louisville Education Cooperative}

IEP Development is a Process not an Event

Next Level Leaders: Reading

Next Level Leaders: Math

Next Level Leaders: Writing

IEP Coaching Sessions

UDL/SAMR Model- Deeper Learning Symposium

Neurodiversity- Deeper Learning Symposium

IEP Training

FBA/BIP Training

ARC Training

Transition Cohort

Utilizing Principals of UDL to Prepare for the Start of School

Specially Designed Instruction for MSD

Meaningful Progress Monitoring

Alternate Assessment Training

Transition 101: Beyond Compliance

Co-Teaching for NTI

Ohio Valley Education Cooperative

Universal Design for Learning/Peer Support Networks

\section{Grants}

Cooper, K. Sensory Room Flooring Churchill Park School. Lowe's Toolbox for Education. Funded for $\$ 10,000$. (January 2015)

Cooper, K. Adapted ELA Curriculum. Dollar General Literacy Foundation Youth Literacy Grant. Funded for $\$ 2,000$ (September 2016)

\section{Professional Memberships}

Society for Information Technology and Teacher Education (SITE)

Co-Chair, Assistive Technology SIG (2019-21) 